\title{
Ueber den Einfluss von Giften auf den Bewegungsapparat der Augen.
}

\author{
Von
}

Dr. Gmillery, Oberstabsarzt in Köln.

Bei den acuten wie chronischen Vergiftungen, namentlich den durch pflanzliche Stoffe hervorgerufenen, pflegt man gewissen, am Sehorgan auftretenden Erscheinungen eine besondere Beachtung zu schenken. Es sind dies diejenigen Veränderungen, welche der Zustand der Pupillen und unter Umständen auch der Accomodation aufweist, und können dieselben mit Recht unsere Aufmerksamkeit beanspruchen, da sie für viele Vergiftungen geradezu charakteristisch und ein wesentliches Hülfsmittel für die Diagnose sind. Auch bei der beabsichtigten Einwirkung von Giften zu medicamentösen Zwecken gewinnen wir aus der Beobachtung der Pupille werthvolle Anhaltspunkte für den Grad der Finwirkung und die Dosirung des Mittels. Diese Dinge sind jedem Arzte so geläufig, dass zu der genauen Untersuchung eines Falles von Vergiftung fast immer eine Feststellung der Weite der Pupille und ihrer Reflexerregbarkeit gehört. Viel weniger hat man bisher dem Verhalten der äusseren Augenmuskeln Beachtung geschenkt, ja eigentlich nur dam, wenn deutliche Lähmungserscheinungen an denselben hervortreten. So kennen wir schon längst beim Botulismus die Ptosis mit oder obne Betheiligung anderer vom Oculomotorius innervirter Muskeln, ferner das Vielen wohl aus persönlicher Erfahrung bekannte Doppelsehen bei der acuten Alkoholvergiftung u. A. m. Fs liegt in der Natur der Sache, dass die Störungen an den äusseren Muskeln viel weniger erforscht sind, als die der inneren, weil die letzteren der Untersuchung weitaus leichter, ohne Aufwand von Zeit und besondere Vorrichtungen zugänglich sind. Dazu kommt, dass das Pupillenspiel ein ausserordentlich feines Reagens ist, an welchem sich auch leichte Veränderungen nachweisen lassen, während solche bei den äusseren Muskeln sich den üblichen Untersuchungsmethoden viel eher entziehen.

Wir pflegen eine Affektion des Bewegungsapparates der Augen erst dinn zu diagnosticiren, wern das Auftreten von Doppelbildern, 
oder eine objelitiv feststellbare Beschränkung der Beweglichkeit nach der einen oder anderen Richtung uns dieselbe bemerklich macht. Im Vergleiche hierzu sind die diagnostischen Hülfsmittel, deren wir uns an anderen Muskeln des Körpers bedienen, um eine Beeinträchtigung ihrer Thätigkeit aufzudecken, viel besser entwickelt, insofern dieselben nicht nur die vollständige oder theilweise Lähmung, sondern auch geringfügige Herabsetzungen der Muskelenergie, ja sogar gewisse physiologische Schwankungen erkennen lassen. So besitzen wir in den Dynamometern verschiedener Construction und in dem Ergographen die Möglichkeit, eine Abschwächung der Muskelleistung festzustellen, auch ohne dass es dabei bis zu einem mehr oder weniger vollständigen Ausfalle einer Bewegung, also einer wirklichen Lähmung oder wenigstens Parese gekommen ist. Nur dieser Grad von Störung war aber am Auge bisher diagnosticirbar, sei es durch die unmittelbare Beobachtung des untersuchenden Arztes, sei es durch die den Kranken belästigenden Doppelbilder. Eine vollkommenere, den dynamometrischen Messungen analoge Methode, welche uns in den Stand setzte, auch eine geringe Herabsetzung der Contractionsenergie des einen oder anderen Augenmuskels zu erkennen, bedurfte erst der Entwiekelung. Die übliche Untersuchungsweise auf Augenmuskelstörungen würde dieser Anforderung nur genügen können, wenn der Bewegungsapparat des Auges ein so feiner wäre, dass schon minimale Abschwächungen nach der einen oder anderen Richtung sich durch Störungen des binoculären Sehactes zu erkennen gäben. Dies ist indessen thatsächlich nicht der Fall, vielmehr lehrt uns die Erfahrung, dass gerade der binoculäre Sehact selbst ein mächtiges Mittel zum Verdecken kleinerer Störungen ist, indem er eine stärkere Innervation zur Ueberwindung von Hindernissen in der einen oder anderen Richtung im Interesse des Einfachsehens veranlasst. Pflegen wir doch diese Erfahrung in der Weise auszunutzen, dass wir in besonderen Fällen das Verfahren zu verfeinern suchen durch eine Aufhebung des binoculären Sehactes, um die Augenbewegungen dem ausgleichenden Einflusse desselben zu entziehen. Aber selbst wenn dies geschehen, kann man nicht annehmen, dass jede, auch geringe Schwäche des einen oder andern Augenmuskels sich durch einen Bewegungsansfall kundgeben wird. Es wäre dies nur dann zu erwarten, wenn jede Bewegung nur bei Vorhandensein der vollen Muskelenergie in regelmässiger Weise ablaufen könnte. Dies ist bei den Augenmuskeln aber ebensowenig der Fall, wie bei den übrigen 
Körpermuskeln. So gut wie bei diesen ein Theil der Energie in Reserve bleibt, und nur aufgewendet wịrd, wenn zur Ueberwindung besonderer Hindernisse eine ungewöhnliche Kraftanstrengung erforderlich ist, so wissen wir, das auch die Augenmuskeln sich unter Umständen stärker contrahiren können, als es bei der grossen Beweglichkeit des Bulbus unter normalen Verhältnissen gefordert wird. Dynamometer wie Ergograph beruhen nun auf dem Grundsatz, die Leistungsfähigkeit des zu untersuchenden Muskels anf das Höchste anzuspannen, da nur unter diesen Umständen ein geringer Schwächezustand herantreten kann. Der gleiche Grundsatz hat bisher zur Untersuchung der Augenmuskeln nur in so weit Anwendung gefunden, als man bei Prüfung gewisser Verhältnisse die Fähigkeit zur Ueberwindung von Prismen feststellte; doch kommen bei den Leistungen der Fusion auch centrale Vorgänge. in Betracht, welche beeinträchtigt sein können, ohne dass die Kraft des Muskels selbst gelitten hat.

Es kann somit keinem Zweifel unterliegen, dass eine geringe Herabsetzung der Kraftleistung, wie wir sie an den Extremitäten dynamometrisch nachweisen können, sich an den Augenmuskeln unseren bisherigen Untersuchungs-Methoden entzieht. Speciell für das Studium der Einwirkung von toxischen Substanzen auf die Augenbewegungen fällt dies um so mehr ins Gewicht, als gerade die schwereren Störungen, wie sịe durch grosse Dosen entstehen, der Untersuchung weniger zugänglich sind, weil sie denjenigen Stadien der Vergiftung entsprechen, in welchen durch die Begleiterscheinungen und die Einwirkung auf das Allgemeinbefinden eine genaue Untersuchung kaum möglich ist. Wir können hier aus der Stellung der Doppelbilder die Art der Lähmung zuweilen mehr oder weniger genau diagnosticiren, müssen aber in der Regel mit Rücksicht auf den Allgemeinzustand des Patienten auf eingehendere Feststellungen verzichten. Es fehlt uns somit für die Diagnose leichterer Affectionen, welche noch nicht zu Lähmungen geführt haben, ein geeignetes Instrument, und bei den schweren, welche an sich den üblichen Methoden wohl zugänglich wären, treten andere Hindernisse entgegen. Während diese letzteren unüberwindlich erscheinen, würde der Versuch, die erstere Schwierigkeit zu beseitigen, einen Erfolg versprechen, wenn man den zu untersuchenden Augenmuskeln äbniliche dufgaben stellte, wie bei der dynamometrischen Messung anderer Muskeln, also solche, bei denen ibre Leistungsfähigkeit bis an die Grenze des 
Möglichen angespannt würde. In analoger Weise sehen wir ja, dass auch auf anderen Gebieten das Studium der Intoxicationen neue Ergehnisse förderte, als durch eine Verfeinerung der Untersuchungsmittel die ersten Stadien der Forschung zugänglich wurden, indem die äusserste physiologische Leistungsfähigkeit des zu untersuchenden Apparates so genau festgestellt war, dass auch geringe Abweichungen sofort in die Erscheinung traten. Ich meine hier, soweit ein Vergleich überhaupt zulässig ist, die verschiedenen Einwirkungen von Giften auf die Psyche, wie sie von Kraepelin und seinen Schülern studiert sind. Während z. B. die Prüfung der schädlichen Einwirkungen des Alkohols auf die Geistesthätigkeit ein wenig ausgiebiges Resultat haben würde, wenn man sie an einem schwer Betrunkenen vornehmen wollte, sehen wir, dass die verfeinerten psychophysischen Methoden, wie sie von den genannten Autoren angewendet sind, uns einen Einblick gestatten in die auch durch kleinere Dosen dieses, sowie anderer Mittel hervorgerufenen Störungen der psychischen Functionen. Nach gleichem Grundsatze verspricht anch das Studium der Augenmuskelstörungen eine neue Ausbente, sobald wir ein Verfahren besitzen, welches uns ermöglicht, auch geringe Veränderungen in der Thätigkeit der Augenmuskeln nachzuweisen, bevor es zu ausgesprochenen Lähmungserscheinungen gekommen ist. Der Hinweis auf die schon ziemlich umfangreiche Literatur der ergographischen Untersuchungen bietet sich von selbst.

Die Ausführung derjenigen Bewegungen, welche für den normalen binoculären Sehact erforderlich sind, beansprucht, wie gesagt, nur einen Theil der den Muskeln zur Verfügung stehenden Energie. Eine Verminderung der letzteren kann also auch nicht ohne Weiteres als eine Störung der gemeinschaftlichen Bewegungen zum Ausdrucke kommen, sondern wird dies erst dann der Fall sein, wenn die Schwächung einen gewissen Grad erreicht hat. Betrachten wir die Möglichkeit, die Anfangsstadien zu erforschen, etwas näher, so ist die Untersuchung mit Prismen für gewisse Zwecke nicht von der Hand zu weisen, wenn wir berücksichtigen, dass die Ergebnisse nicht lediglich von der Kraft der betheiligten Muskeln abhängen. Auch eine verminderte Leistungsfähigkeit derjenigen Centren, welche die Fusionsbewegungen auslösen, muss die Ueberwindung von Prismen erschweren, und dass jene vorkommen kann, ohne dass die Energie der in Betracht kommenden Muskeln für andere Functionen geschwächt wäre, wird sich aus dieser Arbeit mehrfach ergeben. Wie 
Ueber den Einfluss von Giften auf den Bewegungsapparat der Augen. 325

bekannt, beruht die Untersuchung mit Prismen darauf, dass durch Vorlegen eines solchen eine Schielstellung verursacht werden kann, welche den Zweck hat, ein durch das Prisma verschobenes Netzhautbild wieder auf das Netzhautcentrum zu bringen. Das stärkste Prisma, dessen Wirkung durch eine entsprechende Schielstellung überwunden wird, gibt uns den Maassstab für die Leistungsfähigkeit der Fusion. Da nun die Fähigkeit, Prismen zu überwinden, bei verschiedenen Mensehen eine sehr verschiedene ist, so müsste immer die Leistungsfähigkeit der Augenmuskeln desjenigen Individuums, an dem etwaige Veränderungen der Fusion festgestellt werden sollen, vorher genau bekannt sein, und würde sich auf dieser Grundlage die Einwirkung verschiedener Mittel auf die Fusion studiren lassen. Desgleichen hätte jede andere Methode, welche eine geringe Abschwächung der Kraftleistung nachweisen will, auszugehen von einer Festlegung der für den zu Untersuchenden geltenden Normalwerthe.

Eine solche andere Methode bietet sich dar durch die von mir angegebene Schnelligkeitsmessung der Augenbewegungen, welche ich in diesem Archiv Band 71 und 73 beschrieben habe. Es wird hierbei die grösste Schnelligkeit festgestellt, welche das Auge bei möglichst energischer Ausführung einer Bewegung erreichen kann. An einer Versuchsperson, deren diesbezügliche physiologische Werthe in einer ausreichenden Versuchsreihe festgestellt sind, muss sich jede pathologische Verminderung der Leistung bemerkbar machen, und kann daher der für die Messung von mir angegebene Apparat in gewissem Sinne als Dynamometer für die Augenmuskeln gelten. Mit Hülfe desselben habe ich die Einwirkung verschiedener Substanzen auf die Augenbewegungen studirt, und die Versuche ergänzt durch Feststellung der äussersten Divergenz und Convergenz, oder des Fusionsfern- und -Nahepunktes ( $\mathrm{Nagel}$ ), welche letzteren Leistungen zum Theil eine grosse Unabhängigkeit von den ersteren zeigten. Für Diejenigen, welche die erwähnten Arbeiten über den Gegenstand nicht zur Hand haben, sei die Methode der Schnelligkeitsmessung hier kurz beschrieben.

Lässt man eine Linie von einer gewissen Länge während eines kurzen Zeitintervalles von einem Ende zum anderen aufleuchten, so wird sie bei rubig bleibendem Auge ein Nachbild entwerfen, welches in seiner Richtung der Richtung der Linie entspricht. Stand die Linie senkrecht, so wird auch das Nachbild senkrecht erscheinen, war sie geneigt, so wird auch das Nachbild die gleiche Neigung 
zeigen u. s. w. Führt dagegen das Auge eine Bewegung aus während der Zeit des Aufleuchtens, so wird die Lage des Nachbildes nur dann unverändert bleiben, wenn die Bewegung des Auges der Richtung der Linie parallel ist ${ }^{1}$ ); in jedem anderen Falle muss im Nachbilde eine Verschiebung des oberen Endes der Linie gegen das untere zu Stande kommen, und zwar am meisten, wenn die Richtung der Bewegung zu der Richtung der Linie senkrecht steht. Der Grund hierfür ist leicht ersichtlich. Erfolgt z. B. die Aufhellung einer senkrechten Linie in der Richtung von oben nach unten, und bewegt sich das Auge während dieser Zeit in wagerechter Linie, so wird derjenige Punkt der Netzhaut, welcher durch den Lichtreiz am oberen Ende der Linie erregt wird, nicht mehr senkrecht stehen unter demjenigen, welcher dem Lichtreize am unteren Ende entspricht, sondern die beiden werden gegen einander verschoben sein um eine Grösse, welche abbängt von der Ausgiebigkeit der während des Aufleuchtens ausgeführten Bewegung und dem Zeitraume, welcher zwischen dem Aufleuchten des oberen und des unteren Endes der Linie liegt. Mit dem Anwachsen dieser beiden Werthe wird auch die Seitenverschiebung des oberen Endes gegen das untere grösser werden und umgekehrt. Das Nachbild der senkrechten Linie erscheint daher bei Seitenwendungen nicht mehr senkrecht, sondern geneigt, und können wir aus der Grösse des Neigungswinkels die Schnelligkeit berechnen, wenn sich diese Winkelgrösse messen lässt, und wenn die Zeit bekannt jst, welche die Aufhellung der Linie vom oberen bis zum unteren Ende erfordert. In Bezug auf die Ausfübrung dieser Berechnung muss ich auf die bezeichneten Arbeiten verweisen.

Die Messung des Winkels lässt sich leichter bewerkstelligen, wenn das Nachbild gerade erscheint, als wenn dasselbe schief steht, und kann man auch bei bewegtem Auge sehr einfach ein gerade stehendes Nachbild erzielen, wenn die Linie selbst bei Ausfübrung der Bewegung, so weit erforderlich, geneigt wird. Fs empfieblt sich daher, bei Ausführung des Versuches die Linie schräg zu stellen, und zwar der Richtung der auszuführenden Bewegung entgegen geneigt. Das Nachbild wird alsdann durch die Bewegung aufgerichtet, und der Grad der Neigung so lange verändert, bis dasselbe genau senkrecht erscheint, was durch den Vergleich mit einem senkrecht aus-

1) Von den Drehungen des Bulbus nach dem Donders'schen Gesetze können wir hierbei absehen. 
gespannten Faden leicht festgestellt wird. Dass die Linie mit ihrem oberen Ende der Richtung der Bewegung entgegen geneigt sein muss, um im Nachbilde gerade zu erscheinen, gilt übrigens nur für. den hier angenommenen Fall, dass die Aufhellung derselben von oben nach unten erfolgt. Im anderen Falle wäre es umgekehrt (siehe 1. c.).

Die einzelnen Contractionen, auch desselben Muskels, erfolgen nun nicht immer mit ganz gleicher Energie, und kann man daher nicht schon bei der ersten Bewegung die Gewissheit haben, dass sie mit der äusserst möglichen Schnelligkeit ausgeführt ist. Um diese zu finden, ist daher der Versuch zu wiederholen, und gilt der höchste Werth unter mehreren Contractionen für maassgebend, $d . h$. also der stärkste Grad von Neigung, welcher durch die Bewegung in der Weise überwunden wird, dass das Nachbild gerade erscheint. Lässt man nur ein derartiges Bild auftauchen, so wird der Versuch unsicher wegen der kurzen Daner des Eindruckes, und weil es schwierig ist, ein einzelnes Nachbild gerade so dicht an dem Faden erscheinen zu lassen, dass seine Stellung verglichen werden kann. Aus diesem Grunde lasse ich immer eine ganze Reihe solcher Bilder neben einander zum Vorschein kommen, von denen dann immer mindestens eines so nahe bei dem Faden liegt, dass die Richtung leicht zu erkennen ist. Diese Vermehrung der Bilderzahl wird dadurch erreicht, dass die Linie während Ausführung der Bewegung mehrfach abwechselnd hell und dunkel wird, und entspricht jedem Aufleuchten ein neues Nachbild, deren nunmehr, je nach der Schnelligkeit und Ausgiebigkeit der Bewegung, sowie nach der Häufigkeit des Wechsels von Hell und Dunkel eine mehr oder weniger grosse Zahl erseheint. Wird z. B. die Bewegung ron rechts nach links auf die leuchtende Linie zu ausgeführt, so sieht man eine von der entgegengesetzten Seite, also von links her anscheinend auf das Object zueilende Reihe von Nachbildern, von denen die letzten, in nächster Nähe der Linie befindlichen am deutlichsten sind, weil sie am nächsten dem Centrum der Netzhaut entstehen. Hängt man demnach neben der Linie an der entsprechenden Seite den Faden auf, so kann man die zuletzt erscheinenden Bilder bequem mit diesem vergleichen. Je nach derjenigen Strecke, welche für die Untersuchung gewählt wird, lässt sich in dieser Weise die Bewegungsgeschwindigkeit an jeder beliebigen Stelle der Bahn bestimmen. Ich habe den Versuch jetzt immer so eingerichtet, dass die Lage der leuchtenden Linie dem 
Nullpunkte eines Perimeters entsprach, vor welches ich mich mit den nothwendigen Stützvorrichtungen für den Kopf bei geradeaus gerichtetem Blicke hinsetzte. Wurde das Auge von links oder rechts auf die leuchtende Linie zu bewegt, so durchlief es also beiläufig die Hälfte der im Ganzen möglichen Excursion, und die Geschwindigkeit, welche durch die Richtung der zuletzt und in nächster Nähe der Linie auftauchenden Nachbilder gemessen wird, ist somit ungefähr diejenige der Mitte der im Ganzen möglichen Bewegungsbahn. Die mit Unterbrechung auftauchende Linie kann man sich leicht herstellen durch einen feinen Spalt, hinter welchem eine Scheibe mit abwechselnd bellen und dunklen Sectoren rotirt. Ich nahm hierzu einen sogenannten Episkotister, d. h. eine schwarze Scheibe, an welcher vier kreuzweise einander gegenüberstehende, schmale Sectoren ausgeschnitten waren, durch welche das Licht einer mit einer Milchglasglocke bedeckten Petroleumflamme fiel. Von der Breite dieser Sectoren und von der Umdrehungsgeschwindigkeit der Scheibe hängt es $a b$, wie lange die Zeit des Aufleuchtens dauert. Diese ist für den Ausfall des Versuches nicht gleichgültig, denn je länger die Aufhellung andauert, um so breiter muss das Nachbild des Spaltes werden, da jeder lenehtende Punkt in der Richtung der Augenbewegung $\mathrm{zu}$ einer Linie ausgezogen wird. Man erhält hierdurch unter Umständen ganz breite Figuren, an welchen die Beobachtung viel schwieriger ist, als an feinen strichförmigen Bildern. Bei meiner Scheibe, welche sich $18 \mathrm{Mal}$ in der Secunde drehte, fand ich eine Breite des Sectoren von etwa $3^{\circ}$ am zweckmässigsten.

Die Anordnung war im Einzelnen folgende. Vor dem Beobachter war ein schwarzer Schirm aufgestellt, welcher das Licht der Lampe, soweit es nicht durch den Spalt fiel, abblenden solite. Der Spalt war in einer, um eine sagittale Aclse drehbaren Platte in der Mitte des Schirmes angebracht, und zwar in einer Entfernung vom Beobachter, welche demselben ermöglichte, selbst die Einstellung vorzunehmen. Ich wählte eine solche von $45 \mathrm{~cm}$ und blieb dieselbe natürlich für alle Versuche die gleiche. Hinter dem Spalte befand sich die rotirende Scheibe. Weil die Aufhellung von oben nach unten erfolgen sollte, und die Scheibe sich in der Richtung des Uhrzeigers drehte, so musste der Spalt vor der (vom Beobachter aus gesehen) rechten Hälfte der Scheibe stehen. Die Drehungsgeschwindigkeit in der Nähe des Centrums ist eine andere als in der Peripherie, und war desshalb bei der Aufstellung darauf zu achten, dass die 
Ueber den Einfluss von Giften auf den Bewegungsapparat der Augen. 329

Projection des Spaltes immer auf dieselbe Stelle der Scheibe fiel. Die Höhe war so gewählt, dass eine durch die Mitte der Scheibe gelegte Horizontale der Mitte des Spaltes entsprach, so dass, da das Auge des Beobachters sich in derselben Höhe befand, gleich grosse Stücke des Spaltes auf die obere und untere Hälfte der Scheibe fielen. Da bei Schrägstellung des Spaltes das eine Ende desselben immer näher dem Centrum der Scheibe liegt, als das andere, so ist eine gleichmässige Schnelligkeit in allen Theilen der Linie nicht zu erreichen. Bei starker Neigung treten hierdurch Veränderungen des Nachbildes ein, welche ich früher (l. c.) näher beschrieben und erklärt habe. Bei dem grössten der für unsere Versuche erforderlichen Neigungswinkel fingen diese Veränderungen an sich bemerkbar zu machen, doch wurde die Einstellung hierdurch nicht erschwert. Hinter der Scheibe folgte alsdann die Petroleumlampe. Die Kopfstellung war durch Stütze für Kinn und unteren Orbitalrand gesichert. An der Seite des Spaltes, und zwar an derjenigen, wo, der Bewegungsrichtung entsprechend, das Auftauchen der Nachbilder zu erwarten war, hing ein weisser, unten beschwerter Faden. Die Helligkeit des Raumes reichte nicht aus, um während der Einstellung an der Gradeintheilung ablesen zu können, sondern geschah dies erst nach Beendigung des Versuches durch Zuhülfenahme eines besonderen Lichtes. Das Auge wurde jedes Mal von äusserster Seitenwendung (andere Blickbewegungen habe ich hier nicht untersucht) möglichst schnell auf den Spalt zu gedreht, welch' letzterer in seiner Neigung so lange verändert wurde, bis auch bei den stärksten Contractionen eine Schiefstellung des Nachbildes nicht mehr zu Stande kam. Mehr wie sechs Contractionen hinter einander wurden, um eine zu schnelle Ermüdung zu vermeiden, in der Regel nicht vorgenommen. Ich bemerkte bei diesen Versuchen, dass, wenn man eine Bewegung möglichst energisch ausführen will, stets die Neigung vorhanden ist, unmittelbar vorher die entgegengesetzte $\mathrm{zu}$ machen. Soll z. B. das Auge schnell von links nach rechts gewendet werden, so gelingt das rascher, wenn man es unmittelbar vorher von rechts nach links gewandt hat, als wenn es vorher eine Weile ruhig am Anfange der Bahn verharrte. Eine gewisse Analogie hat dies bei anderen Muskelwirkungen. Will man z. B. möglichst kräftig einen Stein schleudern, so wird Niemand den Arm zuerst ruhig nach hinten halten und dann schnell nach vorne bewegen, sondern man schleudert ihn im Gegentheil zuerst rück- und dann vorwärts. Es 
kostet sogar eine gewisse Ueberwindung, die erstere Bewegung zu unterdrücken, und fällt die zweite dann entschieden weniger kräftig aus. Man kann sich mit Hülfe unseres Apparates leicht davon überzeugen, dass dies für die Augenbewegungen ebenfalls gilt, denn die kräftigsten sind immer diejenigen, welche in unmittelbarem Anschlusse an die entgegengesetzte ausgeführt werden. Es ist also darauf zu achten, dass auch in dieser Hinsicht das Verfahren ein gleichmässiges ist.

Die aus je zehn Einstellungen gefundenen Mittelwerthe für die Bewegungen nach beiden Seiten (sowie auch nach oben und unten) sind in der erwähnten Arbeit angegeben, und die Geschwindigkeit aus ihnen berechnet, d. h. die Strecke, welche das Auge in der Zeiteinheit zurücklegen würde, wenn es sich mit der grössten, ibm nach den betreffenden Richtungen zu Gebote stehenden Geschwindigkeit bewegte. Diese Werthe habe ich bei den unten folgenden Versuchen nicht mehr ausgerechnet, sondern nur den Grad der Winkelneigung des Spaltes angegeben, was genügt, um die $\mathrm{Zu}$ - oder $\mathrm{Ab}$ nahme der Schnelligkeit zu erkennen, wenn man das normale Verhalten damit vergleicht. Die Versuche haben (abgesehen von den früberen) mebrere Monate in Anspruch genommen, und sind die normalen Werthe täglich zu verschiedenen. Zeiten festgestellt, wobei sich gewisse, wenn auch nicht erhebliche Schwankungen ergaben. Da ich die Einwirkung der verschiedenen geprüften Mittel nur Abends von etwa 10 Uhr an studiren konnte, als der einzigen Zeit, zu der ich mit einiger Sicherheit über mich verfügen durfte, so liessen sich auch nur die normalen Abendwerthe, welche, wie wir noch sehen werden, den morgendlichen nicht immer entsprechen, zum Vergleiche heranziehen. Die bei den früheren Versuchen (und zwar auch Abends) gefundenen Grössen für die Neigung waren für linken Internus 27,4, linken Externus 21,5, rechten Internus 25,8 und rechten Externus 23,6, d. h. also: bewegte sich das linke Auge nach innen, so musste der Spalt durchschnittlich $27,4^{\circ}$ nach links (der Bewegungsrichtung entgegen) gedreht werden, wenn das Nachbild senkrecht erscheinen sollte, bei Bewegung desselben Auges nach links musste die Neigung $21,5^{\circ}$ nach rechts sein. In analoger Weise sind die Zahlen für das rechte Auge zu verstehen. Auf die muthmaassliche Bedeutung der ungleichen Geschwindigkeit von Internus und Externus derselben Seite, sowie beider Interni und beider Externi. unter sich, bin ich früher ausführlich eingegangen. 
Ueber den Einfluss von Giften auf den Bewegungsapparat der Augen. 331

Die Versuche wurden, wie gesagt, Monate lang fortgesetzt, während welcher Zeit ich den Genuss von allen Mitteln, welche einen Einfluss auf die Energie der Muskel- und Nerventhätigkeit haben konnten, darunter auch den Alkohol, vollständig vermied, soweit nicht die Versuchszwecke eine Ausnahme erforderten. Nach Einwirkung eines solchen Mittels wurde jedes Mal eine Pause von mehreren Tagen gemacht, so dass alle Nachwirkungen geschwunden waren, jedenfalls nicht eher zu einem neuen Versuche übergegangen, bis die Augenbewegungen in jeder Hinsicht wieder ein normales Verbalten zeigten. Der Durchschnitt von 30 Normalbestimmungen, welche Abends gegen $10 \mathrm{Uhr}$ vorgenommen und nach der Reihenfolge der Versuchsprotokolle ausgewählt sind, ist folgender: linker Internus 27,2, linker Externus 20,7, rechter Internus 25,76 und rechter Externus 23,7. Im Vergleiche zu den früheren Ergebnisseu sehen wir also für das rechte Auge fast genau dieselben Werthe, die für das linke um einige Zehntel geringer.

Wenn nun auch das Verhalten der Convergens- und Divergenzfähigkeit in den Bereich der Untersuchung gezogen werden sollte, so waren auch hier vorerst die normalen Werthe zu ermitteln. Der für die erstere lässt sich am einfachsten und schnellsten durch Fixiren eines sich dem Auge nähernden schwarzen Punktes auf weissem Papier feststellen. Ich fand als Durchschnittswerth von 25 beliebig herausgegriffenen Versuchen $5,25 \mathrm{~cm}$, welche Zahl dadurch gefunden wurde, dass die Entfernung des punctum proximum vom Nasenrücken bestimmt und die Höhe des letzteren in senkrechtem Abstande von einer die inneren Augenwinkel verbindenden Linie hinzuaddirt wurde. Die Lage dieses punctum proximum scheint bei verschiedenen Personen innerhalb weiter Grenzen zu schwanken. Nach den Versuchen von Schuurmann, v. Graefe und Donders soll dasselbe in einer Entfernung von 8,12 $\mathrm{cm}$ liegen ${ }^{1}$ ). Graefe $\mathrm{e}^{2}$ ) fand den Punkt früher durchschnittlich etwa $3-5 \mathrm{~cm}$ von der Angesichtsfläche, nach seiner neuesten Mittheilung ${ }^{3}$ ) bezeichnet er die Stelle als $2-4 \mathrm{~cm}$ vor dem Nasenrücken liegend. Ebenso sagt $\mathrm{Nagel}^{4}$ ), dass der ConvergenzNahepunkt „wenige Centimeter vor dem Nasenrücken" liege, hält

1) Graefe-Saemisch, Handbuch der Augenheilkunde Bd. 3 S. 295.

2) Ibid. Bd. 6 S. 12.

3) Ibid. 2. Aufl. 1. Lieferung S. 15.

4) Ibid. 1. Aufl. Bd. 6 s. 484. 
denselben im Uebrigen aber für so inconstant, dass sich genauere Angaben nicht machen liessen. Mein punctum proximum würde etwa in der Mitte liegen von den von Graefe zuletzt angegebenen Distanzen. Die Fähigkeit, Adductionsprismen zu überwinden, scheint, wie nach den obigen Angaben nicht anders zu erwarten, bei verschiedenen Personen ebenfalls sehr verschieden zu sein, wenigstens findet man bei den Autoren Angaben hierüber, die unter einander ganz erheblich abweichen. Entsprechend der grossen Nälı meines Convergenznahepunktes ist die Fähigkeit zur Ueberwindung adducirender Prismen bei mir gleichfalls sehr gross. Durch äusserste Anstrengung der Convergenz kann ich noch ein Prisma vou $60^{\circ}$, bei einer Entfernung des Objectes von $5 \mathrm{~m}$, überwinden, wobei mir allerdings in Folge der damit verbundenen Accommodationsanstrengung das Bild undeutlich wird.

Das Divergenzvermögen meiner Augen ist grösser, als es die meisten Beobachter finden. Prisma $10^{\circ}$ mit der Basis nach Innen kann ich bei einer Entfernung des Prüfungsobjectes (Wachsstockflamme) von $5 \mathrm{~m}$ fast immer mit Leichtigkeit überwinden, ausnahmsweise sogar $12^{\circ}$, wenn auch nur vorübergehend für wenige Secunden. Die gewöhnliche Angabe ist bekanntlich $4-6^{\circ}$.

Die Fusionsfähigkeit steht nun, wie ich im Laufe dieser Untersuchungen fand, keineswegs immer in Parallele zu der Leistungsfähigkeit der einzelnen Augenmuskeln, wie sie sich in der Schnelligkeit der von ihnen ausgeführten Bewegungen zu erkennen gibt. Es können sogar beide Arten von Leistungen sich unter der Einwirkung desselben Mittels entgegengesetzt gestalten. Nachdem ich dies bemerkt, habe ich selbstverständlich dieser Beobachtung eine besondere Aufmerksamkeit zugewendet, da, wie wir unten noch näher erörtern werden, die Unabhängigkeit der verschiedenen in Betracht kommenden Theile für die Physiologie der Augenbewegungen von Bedeutung ist.

Ausserdem ist bei diesen Versuchen auch noch jedes Mal das Verhalten von Accommodation und Pupille beobachtet. Ersteres unter Zuhülfenahme von feinen Figuren, wie ich sie als "Sehproben für die Nähe" angegeben habe, welche so lange angenäbert wurden, bis sie anfingen undeutlich zu werden. Man würde hierzu ebenso gut feine Schriftproben benutzen können, an welchen ein Undeutlichwerden ebenfalls bald zu erkennen ist, und konnte ich wiederholt nach beiden Methoden feststellen, dass mein Accommodationsnahepunkt in $20 \mathrm{~cm}$ Entfernung liegt. Ich kann hier gleich vorausschicken, dass ich 
niemals bei den folgenden Versuchen eine Veränderung dieses Nahepunktes bemerkt habe und dass derselbe immer in der genannten Entfernung in jedem Stadium der verschiedenen Versuche blieb. Aus diesem Grunde soll die Accommodation in den folgenden Versuchsprotokollen nicht noch ausdrücklich erwähnt werden. Einige Male glaubte ich allerdings eine Annäherung des Nahepunktes der Accommodation $\mathrm{zu}$ finden, doch überzeugte ich mich, dass dies nur der Fall war, wenn gleichzeitig die Pupille sich verengte (z. B. beim Morphium). Da jene Anuäherung eine sehr geringe war, so dürfte sie wohl durch die Verminderung der Zerstreuungskreise genügend erklärt sein, ohne dass man eine Einwirkung auf den Accommodationsapparat anzunehmen braucht. Ein Accommodationskrampf liess sich durch die Fernprüfung jedes Mal ausschliessen.

Die Pupillenmessung wurde in der Weise vorgenommen, dass vor einem kleinen Spiegel ein Maassstab, welcher eine Ablesung bis zu $1 / 2 \mathrm{~mm}$ gestattete, vor ein Auge, entsprechend dem Pupillendurchmesser, bei verschlossenem anderen gehalten wurde. Der Blick war dabei stets gegen die Milchglasglocke derselben Petroleumlampe gerichtet, so dass das Auge inmer der gleichen Helligkeit ausgesetzt war.

Die sämmtlichen unten angeführten Versuchsprotokolle sind durch Selbstbeobachtung entstanden, da ich keine Gelegenheit hatte, die Untersuchung an anderen Personen vorzunehmen. Die Benutzung des Apparates erfordert immerhin eine gewisse Uebung und Gewandtheit im Beobachten, wodurch seine Verwendbarkeit beschränkt ist. Bei intelligenten Laien bin ich allerdings bisher anch immer zum Ziele gekommen, insofern ich nach einigen Vorübungen Ergebnisse von genügender Constanz, abgesehen von unvermeidlichen kleinen Schwankungen, erhielt. Leider fand ich aber Niemanden, der die erforderliche Geduld und Neigung gehabt hätte, um eine längere Zeit hindurch die Energie seiner Augenmuskeln theils mit, theils ohne Einfluss von Medicamenten zu controliren. Es ist aber schon zur Vorbereitung der Versuche eine längere Beobachtungsreihe unbedingt erforderlich, da man nur auf diese Weise ein sicheres Urtheil über die physiologische Leistungsfähigkeit der Augenmuskeln gewinnt, um über die Grenze, wo die Schwankungen anfangen, pathologiseh zu werden. Ich selbst glaube es durch die lange Uebung dahin gebracht zu haben, dass ich jede Störung schon fast bei der ersten Bewegung merke. Selbstverständlich habe ich mich indessen niemals auf den 
ersten Eindruck verlassen, sondern bin immer streng methodisch in der oben angegebenen Weise vorgegangen. Den Einfluss irgend welcher Suggestion halte ich für ausgeschlossen, weil die Einstellung erst nach Beendigung des Versuches abgelesen werden konnte, und weil bei den angewandten Medicamenten niemals mit Sicherheit die Wirkung vorauszusehen war, ja zuweilen ganz anders ausfiel, als sich erwarten liess. Die vielen negativen Versuche dürften auch dafür sprechen, dass die Beobachtung eine durchaus objective war.

Da auch unter physiologischen Verhältnissen die einzelnen Einstellungen nicht genau übereinstimmen, sondern, wie bei jeder Feststellung von Grenzwerthen, Schwankungen unvermeidlich sind, so war zu bestimmen, von welchem Grade an die Veränderungen als patbologische gelten mussten. Unter normalen Verhältnissen betragen die Schwankungen bei mir in jeder einzelnen Sitzung nicht mehr als $3^{0}$, und zwar nicht in Bezug auf den Durchschnitt, sondern beim Vergleiche der äussersten Grenzwerthe. Es wäre also berechtigt, eine Herabsetzung des vor dem Versuche gefundenen böchsten Werthes um meh̆ als $3^{0}$ als Ausdruck einer pathologischen Veränderung anzusehen. Um aber ganz sicher zu sein, habe ich nur ein Hinabsinken unter den kleinsten von allen jemals gefundenen physiologischen Werthen als pathologisch angesehen. Es ist dies für linken Internus 25, linken Externus 18, rechten Internus 24 und rechten Externus 23. Die obere Grenze kommt, wie wir sehen werden, für unsere Versuche nicht in Betracht.

An den einzelnen Versuchsabenden musste die Messung der Schnelligkeit fortlaufend in regelmässigen Zwischenräumen wiederholt werden, damit der Beginn der Wirkung des eingenommenen Giftes und der weitere Verlauf derselben controlirt werden konnte. Vor Beginn des Versuches überzeugte ich mich immer von der normalen Leistung jedes Seitenwendens durch je eine Einstellung (sc. die stärkste unter sechs Contractionen). Sobald eine Veränderung sich bemerkbar machte, wurden in derselben Weise je drei Einstellungen für jeden Muskel gemacht und aus diesen das Mittel genommen. Im Ganzen waren es also zwölf endgültige Bestimmungen, und da ausserdem noch das Verhalten der Fusionsfähigkeit, sowie der Pupille und Accommodation zu beobachten war, so musste eine Zeit von etwa 10 Minuten aufgewendet werden. Alsdann erfolgte eine Ruhepause von 10 Minuten, worauf alle Bestimmungen wiederholt wurden, und so fort, oft Stunden lang, bis weitere Veränderungen nicht mehr 
Ueber den Einfluss von Giften anf den Bewegungsapparat der Augen. 335

zu erwarten waren. Der Fusionsnahepunkt ist stets durch Convergenz auf einen schwarzen Punkt und zwar auch als Mittel aus je drei Bestimmungen festgestellt, rer Fusionsfermpunkt durch abriucirende Prismen, von denen zunächst immer das der letzten Feststellung entsprechende gewählt und rasch in der erforderlichen Weise verstärkt oder abgeschwächt wurde. Auf diese Weise wurde den Augenmuskeln eine nicht gewöhnliche Anstrengung zugemuthet, und es war daher die Möglichlieit zu berücksichtigen, ob nicht hierdurch allein Veränderungen, insbesondere eine Abnahme der Schnelligkeit bedingt werden konnte. Zutreffenden Falles musste die etwa durch eine Einwirkung des Giftes auftretende Abschwächung der Leistung stärker erscheinen, als sie wirklich war, oder es konnte sogar eine Abschwächung vorgetäuscht werden, die von der Giftwirkung ganz unabhängig und lediglich auf die normale Ermüdung zurückzuführen war. Um in dieser Hinsicht Gewissheit zu erlangen, wurden Controlversuche angestellt, bei welchen ohne Einnahme irgend eines Mittels in den gleichen Zeitabschnitten, zuweilen sogar mit abgekürzten Pansen, die nämlichen Versuche vorgenommen wurden. Hierbei stellte sich heraus, wie wir gleich sehen werden, dass die angegebene Ruhepause vollständig zur Erholung genügte, so dass eine merkliche Lirmüdung nicht eintrat. Eine weitere Controle ergaben ausserdem die zahlreichen Versuche, bei denen ich auch nach Einnahme eines Mittels Veränderungen nicht fand, und würde herdurch schon der Beweis erbracht sein, dass etwaige Veränderungen nur als pathologische angesehen werden können. Da die Controlversuche gleichsam ein Paradigma für den Gang sämmtlicher Untersuchungen geben, so seien einzelne derselben hier angeführt. Es sind dabei nur die äusseren Muskteln berücksichtigt, da für die Accommodation, welche hier aliein von den inneren Muskelwirkungen in Betracht kommen kann, die Versuche nicht besonders anstrengend waren, wie dies auch aus dem stets unveränderten Zustande derselben hervorgeht.

\section{Controlversuch I.}

Beginn $10^{\mathrm{b}} 20^{\prime}$ Abends. $10^{\mathrm{h} 20^{\prime}}$ bis $30^{\prime}$ linker Internus 28 , linker Externus 20, rechter Internus 25, rechter Externus 24, F.-N.-P. ${ }^{1}$ ) 5,4, F.-F.-P. ${ }^{1}$ ) (entspricht) $10^{\circ} \mathrm{Pr}$.

$10^{\mathrm{h}} 40^{\prime}$ bis $50^{\prime}$ 1. Int. 27,6 , 1. Ext. 19 ; r. Int. 25,6 , r. Ext. 24,3 . F.-N.-P. 5,4, F.-F.-P. $10^{\circ}$.

1) Abkürzung für Fusionsnahepunkt bezw. Fusionsfernpunkt. 
$11^{\mathrm{h}} 0^{\prime}$ bis $10^{\prime}$ 1. Int. 27,3, 1. Ext. 19,3; r. Int. 25,6, r. Ext. 23,6. F.-N.-P. 5,3, F.-F.-P. $10^{\circ}$.

$11^{\mathrm{h} 20^{\prime}}$ bis $30^{\prime}$ l. Int. 27,6, 1. Ext. 20; r. Int. 25,6, r. Ext. 23,3. F.-N.-P. 5,3, F.-F.-P. $10^{\circ}$.

\section{Controlversuch II.}

In diesem wurden die Pausen stellenweise absichtlich etwas verkürzt. Beginn $10^{\mathrm{h}} 15^{\prime}$ Abends.

$10^{\mathrm{h}} 15^{\prime}$ bis $25^{\prime}$ I. Int. 27, 1. Ext. 21 ; r. Int. 25, r. Ext. 24,6. F.-N.-P. 5,2, F.-F.P. $10^{\circ}$.

$10^{\text {h }} 95^{\prime}$ bis $45^{\prime}$ I. Int. 27,3 , I. Ext. 20 ; r. Int. 26, r. Ext. 24 . F.-N.-P. 5,4, F.-F.-P. $10^{\circ}$.

$10^{\mathrm{h}} 50^{\prime}$ bis $60^{\prime}$ 1. Int. 27,6, l. Ext. 21; r. Int. 26,3, r. Ext. 24,3. F.-N.P. 5,5, F.-F.P. $10^{\circ}$.

$11^{\text {h }} 5^{\prime}$ bis $15^{\prime}$ 1. Int. 27,6, 1. Ext. 21,6; r. Int. 25,6, r. Ext. 23,3 . F.-N.-P. 5,3, F.-F.-P. $10^{\circ}$.

Also trotz kürzerer Pausen keine anderen Schwankungen, als sie von vornherein zu erwarten waren.

Wie die späteren Versuchsprotokolle zeigen, findet man, was ja eigentlich selbstverständlich, an verschiedenen Tagen nicht immer dieselben Anfangswerthe, sondern es kommen hier Schwankungen von $2-3^{0}$ vor. An ein und demselben Abende bleiben die Zahlen aber sehr gleichmässig, wenn die Durchschnittswerthe in der obigen Weise bestimmt werden und halten sich stets innerhalb der Grenzen von höchstens $1,5^{\circ}$. Es würde zwecklos sein, noch mehr solcher Controlversuche anzuführen und dürften die obigen Protokolle das Gesagte zur Genüge erläutern.

Wir gehen nunmehr über zu den Versuchen, welche sich auf die Giftwirkungen beziehen, wobei ich bemerke, dass dieselben nicht etwa in der Reihenfolge vorgenommen wurden, wie sie hier anfgeführt sind. Es hat vielmehr, um jede Gewöhnung zu vermeiden, ein fortwährender Wechsel stattgefunden, so dass jede erneute Anwendung eines Mittels von der vorhergehenden durch eine längere Pause getrennt war, während welcher theils eine vollständige Unterbrechung war, theils Controlversuche gemacht, oder mit einem anderen Gifte experimentirt wurde, dessen Wirkungen natürlich gänzlich beseitigt sein mussten, bevor zu neuen Versuchen geschritten wurde. 
Ueber den Einfluss von Giften auf den Bewegungsapparat der Augen. 337

\section{A) Alkohol}

Bei Gelegenheit seiner grundlegenden Versuche über die Einwirkung des Alkohols auf physische Vorgänge hat $\mathrm{Kraepeli}{ }^{1}$ ) auch den Einfluss desselben auf die Intensität der Muskelinnervation geprüft, um auf diese Weise das durch den Alkohol hervorgerufene subjective Gefühl der erhöhten Kraftleistung und seine angeblich "stärkende" Wirkung zu controliren. Er verfuhr in der Weise, dass er in Intervallen von etwas weniger als $1 / 2$ Minute die Arme eines Dynamometers mit der rechten Hand so kräftig wie möglich zusammendrückte, und zwar unmittelbar nach Einnahme von $20 \mathrm{~g}$ Alkohol. Vorher waren an verschiedenen Tagen die normalen Durchschnittswerthe festgestellt. Diese letzteren zeigten im Allgemeinen von 10 zu 10 Minuten eine Steigerung während der ersten halben Stunde (Uebung), worauf ein geringer Nachlass, offenbar in Folge der physiologischen Ermüdung folgte. In den Alkoholversuchen liegen die Anfangswerthe (i. e. die Durchschnittswerthe der ersten 10 bis 12 Minuten) höher als normal und zeigen darauf, mit einer Ausnahme, ein rasches Sinken. Diese Ausnahme gestaltet sich so, dass die Durchschnittszahl der zweiten 10 Minuten das Maximum ist und von da an erst die Abnahme erfolgt. Der Gesammteindruck ist aber der, dass im Anfange eine rasch vorübergehende Steigerung der Muskelleistung durch den Alkohol bewirkt wird. Eine zweite Versuchsreihe, welche einen anderen Forscher (Dehio) betrifft und ebenfalls von Kraepelin mitgetheilt wird, beweist, dass hier nicht unerhebliche individuelle Verschiedenheiten vorkommen. Sowohl die Normal- wie die Alkoholversuche zeigen ein abweichendes Verhalten. Bei ersteren fehlt die regelmässige Steigerung, wie auch die nachfolgende Ermüdung, so dass in einer Reihe sogar nach einer Stunde ein höherer Dynamometerausschlag erzielt wurde, als am Anfange. In den drei Alkoholreihen sind die Anfangswerthe dagegen nicht nur nicht gegen die Norm erhöht, sondern es zeigt sich schon in den ersten zehn Minuten eine Herabsetzung, welche in zwei Versuchen während des Verlaufes einer Stunde noch erheblich zunimmt, in dem dritten von einer Steigerung gefolgt ist, so dass nach 40 Minuten der Normalwerth wieder erreicht ist. Wenn man also nach Kraepelin's Versuchen zwei Stadien der Alkobolwirkung auf die

1) Ueber die Beeinflussung einfacher physischer Vorgänge durch einige Arzneimittel. Jena 1892.

v. Pflũger, Archiv für Physiologie. Bd. 77. 
Muskelinnervation annehmen darf, eine anfängliche Steigerung mit nachfolgender lähmender Wirkung, so sehen wir bei Debi o schon innerhalb der ersten 10 Minuten einen lähmenden Einfluss, so dass also das erste Stadium entweder gar nicht vorhanden, oder so kurz war, dass es in den über 10 Minuten sich erstreckenden Durchschnittswerthen nicht mehr zum Ausdrucke kam. Kraepelin ist der Ansicht, dass dieses Verbalten nicht nur durch die etwas grössere Dosis, welche Dehio nahm (nämlich $30 \mathrm{~g}$ ), sondern vielmehr dadurch zu erklären sei, dass Dehio wie sich auch in anderen Versuchen zeigte, den lähmenden Wirkungen des Alkohols mehr ausgesetzt war. Solche Verschiedenheiten können gewiss nicht befremden, da ja auch die Einwirkungen auf die Psyche bekanntlich durchaus nicht bei allen Menschen die gleichen sind. Eine erhöhte motorische Innervation dürtte aber wohl bei den Meisten der anfänglichen Wirkung des Alkohols entsprechen, worauf das gesteigerte Kraftgefübl, dem so manche Excesse entspringen, sehr deutlich binweist. Die Versuche von De Sarlo, Bernardini, Warren u. A. bestätigen ebenfalls diese anfängliche Steigerung, abgesehen davon, dass auch die Beobachtungen Kraepelin's über die Einwirkung auf die psychische Reaction Momente ergeben, welche für eine solche sprechen. Er fand nämlich, dass, während die sensorischen und intellectuellen Vorgänge durch den Alkohol erschwert werden, diejenigen leichter ablaufen, bei welchen die Innervation der Sprechmuskeln in den Vordergrund tritt. Die Geschwindigkeit, mit welcher diese Impulse ausgelöst werden, steigert sich durch den Alkohol, und zwar noch viel deutlicher, als die Kraftleistung am Dynamometer. Kraepelin ist daher der Ansicbt, dass diese beiden Seiten des motorischen Actes nicht in gleichem Maasse durch den Alkohol beeinflusst werden. Während die Schnelligkeit, mit welcher der gesammte Bewegungsvorgang sich abspielt, deutlich gesteigert sei, erfahre die Kraftleistung nur ganz vorübergehend bei kleineren Gaben und bei geringer Empfindlichkeit gegen das Mittel eine Zunahme, die sehr bald einer erheblichen Herabsetzung Platz mache. Jene Beschleunigung der motorisehen Acte könnte vielleicht darauí zurückgeführt werden, dass der Ablauf der Muskelbewegung selbst durch den Alkohol erleichtert würde. So nehme z. B. beim schnellen Lesen die Sprechzeit der einzelnen Silben ab unter gleichzeitigem Anwachsen der Geschwindigkeit ihrer Aufeinanderfolge, und Kraepelin hält es für möglich, dass bei einem Studium des Ablaufes der Muskelzuckung unter der 
Ueber den Einfluss von Giften auf den Bewegungsapparat der Augen. 339

Einwirkung des Alkohols sich eine Beschleunigung finden würde. Diesen experimentellen Feststellungen entspräche auch das durch die tägliche Erfahrung wohlbekannte Bild der Alkoholvergiftung: das Sinken der intellectnellen Leistung einerseits, das erhöhte Kraftgefühl anderseits, als dessen Quelle die Erleichterung der motorischen Reactionen anzusehen sei, und welches in seinen Folgen zu den vielen unüberlegten, impulsiven Handlungen der Berausehten führe.

In neuerer Zeit ist die Alkoholwirkung auf die Muskeln auch mit Hülfe rles Ergographen (Mosso) studirt worden. Rossi ${ }^{1}$ ) fand, dass $25 \mathrm{~g}$ Rum die Ermüdung aufhielten, während $80 \mathrm{~g}$ die Leistung anfangs steigerten, aber bald eine Lähmung folgen liessen durch centrale Wirkung. Sehr eingehend hat auch Frey ${ }^{2}$ ) diese Angelegenheit nach derselben Methode studiert. Seine Háuptergebnisse sind folgende: 1. Der Genuss mässiger Quantitäten von Alkohol hat einen verschiedenen Einfluss auf den ermüdeten und nicht ermüdeten Muskel. 2. Bei dem nicht ermüdeten entsteht eine Verminderung der maximalen Einzelleistung in Folge von Herabsetzung der peripherischen Erregbarkeit des Centralnervensystems. 3. Beim ermüdeten Muskel stejgt die Arbeitsleistung ganz bedeutend durch Zufuhr neuer Spannkräfte, doch kann die Arbeitsleistung des ermüdeten Muskels durch den Alkohol niemals zu der des nicht ermüdeten gesteigert werden, weil auch hier die peripherische Erregbarkeit des Nervensystems herabgesetzt ist. Die Wirkung tritt schon 1 bis 2 Minuten nach dem Genusse auf und dauert längere Zeit an. Das Mudigkeitsgefühl wird mehr oder weniger beseitigt, so dass die Arbeit leichter erscheint. Bei mässigen Dosen war eine nachfolgende Lähmung, wie sie Kraepelin fand, nicht zu bemerken, indem die Lähmungserscheinungen erst bei stärkereu Gaben hervortraten.

Was nun die Veränderungen in der Thätigkeit der Augenmuskeln betrifft, so finden wir als acute Alkoholwirkung Lähmungserscheinungen häufig erwähnt, doch sind auch Krämpfe beobachtet. Naturgemäss zeigen sich dieselben erst in den späteren Stadien des Rausches, wenn auch an den übrigen Körpermuskeln eine deutliche Beeinträchtigung der Leistungsfähigkeit bemerkbar wird. Da auch an der Papille erst in den schwersten Stadien des Rausches eine Verminderung oder gänzliche Aufhebung der Reflexerreglbarkeit be-

1) Rossi, Arch. ital. de Biol. t. 23.1 u. 2.

2) Mittheilungen aus klin. und medicin. Instituten dex Schweiz. R. 4 H. 1. 
merkbar wird, so treten die Augensymptome bei der acuten Akoholvergiftung gegenüber den anderen Rauschwirkungen in den Hintergrund und werden solche in manchen Lehrbüchern der Toxicologie überhaupt nicht erwähnt. Nichts destoweniger ist es eine bekannte Erfahrung, dass Doppelsehen nach reichlichem Alkobolgenusse sehr häufig ist, und wird dieses Symptom von dem Berauschten oft viel lästiger und störender empfunden, als manche andere. Jedenfalls sind im Vergleiche zu den Lähmungen die Krämpfe viel seltener und sollen auch hauptsächlich nur als Theilerscheinungen anderweitiger Muskelkrämpfe beobachtet sein ( $\mathrm{Kni}$ es).

Es kann nicht Wunder nehmen, dass die Wirkungen eines Giftes, welches so ausgesprochene Störungen der nervösen Centralorgane und der Muskelthätigkeit hervorruft, sich mehr oder weniger auch an den Augenmuskeln zeigen. Die auf der Basis des chronischen Alkoholmissbrauches sich entwickelnden Muskellähmungen lehren, dass die verschiedenen Körpermuskeln und Nerven nicht in gleichem Maasse der Giftwirkung zugänglich sind, sondern dass dieselbe sich an gewissen Stellen mit besonderer Vorliebe entwickelt.. Es sind dies bekanntlich in erster Linie die Extensoren der Unterarme und Unterschenkel, denen gegenüber Lähmungen anderer Muskelgruppen seltener sind. Unter den von cerebralen Nerven versorgten sind am häufigsten die Augenmuskeln befallen. Eine hierher gehörige, aber wenig beachtete Bemerkung findet sich bereits bei v. Gräfe ${ }^{1}$ ), welcher sagt: "Chloroforminhalationen und die Trunkenheit haben einen allerdings rasch vorübergehenden Einfluss auf die Spannkraft der inneren Augenmuskeln. Potatoren sah ich zuweilen mit muskulärer Asthenopie behaftet, doch blieb die Causalität zweifelhaft." Genauere Untersuchungen in dieser Richtung liegen nicht vor, und hat man später die Aufmerksamkeit mehr auf die eigentlichen Lähmungen gerichtet. Uhtho $\mathrm{ff}^{2}$ ) erwähnt in seiner eingehenden Monographie über den Gegenstand den Alkoholismus als Ursache muskulärer Asthenopie überhaupt nicht, Lähmungserscheinungen beobachtete er dagegen mehrfach. Unter 1000 Fällen wurde vier Mal über vorübergehendes Doppelsehen geklagt, ohne dass sich eine typische Augenmuskellähmung mit Sicherheit feststellen liess; drei Mal waren aber ausgesprochene Lähmungen vorhanden, und mussten diese auf

1) Archiv f. Ophthalmol. Bंd. 8 H. 2 S. 343.

2) Ibid. Bd. 32 H. 4 S. 181. 
Ueber den Finfluss von Giften auf den Bewegungsapparat der Augen. 341

den Alkoholmissbrauch zurückgeführt werden. Es handelte sich dabei jedes Mal um doppelseitige Abducensparese, in einem Falle verbunden mit einer leichten Bewegungsbeschränkung im Sinne der beiden Interni. In allen diesen Fällen waren Erscheinungen von Seiten der peripheren Nerven vorhanden, welche auf multiple Neuritis hindeuteten. Bei 13 Patienten fand Uhthoff nystagmusartige Zuckungen in verschiedenen Augenmuskeln, besonders in den rect. intern. et extern., welche sich bemerkbar machten, sobald die Kranken versuchten, ihre Augen in die seitlichen Endstellungen zu bringen. Ebenso fand sich bei zweien der drei Lähmungsfälle Nystagmus und zwar einmal nicht nur in den Endstellungen, sondern auch bei ruhigem Blicke geradeaus. Doppelseitige Abducenslähmung wird ebenfalls erwähnt bei zwei älteren Beobachtungen von Lilienfeld ${ }^{1}$ ) und von Schulz ${ }^{2}$ ).

Wenn ich oben sagte, dals eine Wirkung des Alkohols auf einzelne Muskelgruppen angenommen werden müsse, so sollte damit nicht speciell der Muskel als Sitz der Läsion bezeichnet sein. Wir wissen vielmehr, dass gerade an den Nerven sich sehr deutliche Veränderungen zeigen, welche hauptsächlich in Schwund der Markscheiden, Vermehrung der Kerne und Verdickungen des Neurilemms bestehen. Wenn diese die intermuskulären Stämmchen betreffen, so können die benachbarten Muskelfasern von den neugebildeten Bindegewebsringen eingeschnürt und secundär zur Atrophie gebracht werden (neuritis fascians). Aufserdem sind auch in den Muskeln selbst Zunahme des interstitiellen Bindegewebes und Atrophie der Muskelfasern, daneben stellenweise Hypertrophie (Siemerling), Vermehrung der Kerne in den Fasern und Verdickung der Blutgefässe (Oppenheim) beschrieben. Siemerling fand die Muskeln stärker erkrankt als die Nerven, so dass er glaubte, der Alkohol könne zuerst und vorwiegend gerade auf die Muskelsubstanz wirken.

Ein der multiplen Neuritis analoger Befund zeigt sich bekanntlich auch am Sehnerven in Form einer neurit. axial, welche klinisch das Bild der sog. Intoxicationsamblyopie hervorruft. Für die den Augenmuskelstörungen entsprechenden Erkrankungen sind einzelne Autoren geneigt, centralen Sitz anzunehmen. So glaubt Thomson

1) Neurolog. Centralbl. 1885 S. 352.

2) Ibid. 1885 Nr. 19. 
dieselben seien nucleären Ursprunges und durch kleine Blutungen im Gebiete der Augenmuskelkerne hervorgerufen. Dem entspricht z. B. der anatomische Befund von $S \operatorname{chül} \mathrm{e}^{1}$ ), welcher nach akuter centraler Augenmuskellähmung bei einem Alkoholiker hämorrhagisch entzündliche Herde in sämmtlichen Kernen fand. Die Affection kann auch klinisch unter dem Bilde rer Poliencephalitis super. acut. auftreten und führt alsdann meist in wenigen Tagen zum Tode. Dass aber solche tiefgreifende Zerstörungen nicht immer die Ursache der Lähmungen sein können, beweist der zweite Fall von Uhthoff, in welchem innerhalb 8 Tagen schon eine deutliche Rückbildung der vorher completen doppelseitigen Abducenslähmung sich zeigte und dieselbe nach vier Wochen fast vollständig gehoben war. Knies hält in den Fällen von Uhthoff einen Convergenzkrampf nicht für ausgescblossen. Letzterer Autor selbst glaubt mit Rücksicht auf die an anderen peripheren Nerven nachgewiesenen Degenerationserscheinungen annehmen zu sollen, dass auch degenerative Veränderungen in den nn. abduc. die Ursachen für die Augenmuskelläbmungen seien.

Welche anatomischen Veränderungen den bei der akuten tödtlichen Alkoholvergiftung auftretenden Lähınungserscheinungen entsprechen, entzieht sich bisher unserer näheren Kenntniss, da die Hyperämie des Gehirnes und einzelne apoplektische Herde, welche man findet, das klinische Bild nicht genügend erklären. Noch weniger kennen wir die anatomische Grundlage des gewöhnlichen Rausches. Da die Wirkung desselben nur eine vorübergehende ist, so ist auch sehr fraglich, ob die Veränderungen, welche er hervorruft, unseren anatomischen Untersuchungsmethoden überhaupt zugänglich sein würden. Vielleicht sind sie der gleichen Art, wie diejenigen, welche die Beeinträchtigung der physischen Functionen bewirken, über welche sich bisher ebenfalls nur Vermuthungen aufstellen lassen. Sehr wahrscheinlich ist es ja überhaupt nicht, dafs vereinzelte Alkoholwirkungen dauernde Spuren hinterlassen. Vermuthlich werden die Folgen mehr oder weniger rasch sich wieder ausgleichen und erst bei häufiger Wiederholung bleibende Veränderungen setzen, namentlich wenn die Zwischenzeit für einen vollständigen Ausgleich zu kurz ist.

Sehen wir nun zu, welche Störungen im Gebiete der Augen-

1) Münch. med. Wochensehr. 1894 S. 605. 
Ueber den Einfluss von Giften auf den Bewegungsapparat der Augen. 343 muskeln in Folge der akuten Alkoholwirkung sich mit Hülfe der von uns angewandten Methoden nachweisen lassen. Nachdem ich etwa acht Tage lang gar keinen Alkohol zu mir genommen, sondern nur regelmässig jeden Abend die Beobachtungen über Schnelligkeit, Fusion u. s. w. angestellt hatte, machte ich einen Vorversuch in der Weise, dass ich während des Abendessens eine nicht genau dosirte Menge Alkohol zu mir nahm in Gestalt von $1 / 2$ Liter leichten Bieres und ebensoviel Moselwein, also ein Quantum, welches wohl noch nicht als ein unmässiges bezeichnet werden kann. Diese Flüssigkeiten dürften im Ganzen etwa $70 \mathrm{~g}$ Alkohol enthalten haben und verteilten sich dieselben auf einen Zeitraum von fast $1^{1 / 2}$ Stunde. Unmittelbar vor dem Abendessen war festgestellt, dass alle in Betracht kommenden Muskelleistungen die normalen Werthe zeigten. Subjectiv bemerkte ich als nächste Folge die bekannte erregende Wirkung, welcher später eine geringe Schläfrigkeit folgte. Unmittelbar nachdem der letzte Rest getrunken, wurde folgendes Versuchsprotokoll aufgenommen.

I.

10h. L. Int. 22,6, 1. Ext. 15; r. Int. 19, r. Ext. 20,3. Convergenznahepunkt ist abgerïckt und liegt zwischen 7,0 und 7,5. Die Prüfung des F.-F.-P. ergab, dass Prisma $4^{0}$ das stärkste war, welches überwunden werden konnte; alle höheren Nummern ergaben Doppelbilder. Bei $10^{\circ}$, welches vorber mit Leichtigkeit überwunden wurde, standen sie um etwa $8 \mathrm{~cm}$ auseinander (in einer Entfernung von $5 \mathrm{~m}$ ). Pupillen 4,5 (wie vorher).

Diese Störungen waren noch ohne wesentliche Veränderungen bis $12 \mathrm{Uhr}$ nachweisbar, zu welcher Zeit der Versuch abgebrochen wurde. Nach einer Pause von fünf Tagen wurde derselbe mit genauer Dosirung erneuert und in regelmässigen Zwischenräumen, wie oben angegeben, untersucht.

II.

$10^{\mathrm{h}} 0^{\prime}$ bis $10^{\prime}$. L. Int. 26, 1. Ext. 20; r. Int. 25, r. Ext. 23. F.-N.-P. 5,3, F.-F.P. $10^{\circ}$ (leicht), Pupille 4,5 . $10^{\mathrm{h}} 25^{\prime} .20 \mathrm{ccm}$ Alkohol in ebensoviel Zucker-

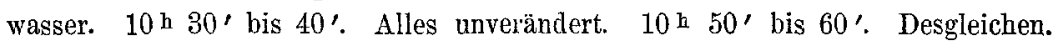
$11 \mathrm{~h} 10^{\prime}$ bis $20^{\prime}$. Desgleichen.

Bei den Versuchen von Kraepelin hatte um diese Zeit die lähmende Wirkung ihren Höhepunkt erreicht. Es war indessen hinsichtlich der Function der Augenmuskeln noch absolut keine Wirkung zu bemerken. Keine Allgemeinwirkung ausser angenehmem Wärmegefühl. Der Versuch wurde abgebrochen.

Nach drei Tagen 3. Versuch.

III.

$10^{\text {h }} 0^{\prime}$ bis $10^{\prime}$. L. Int. 26, I. Ext. 20; r. Int. 25, r. Ext. 22. F.-N.-P. 5,5, F.-F.-P. $10^{\circ}$ (leicht, vorübergehend $12^{\circ}$ ). 
$10^{\mathrm{h}} 15^{\prime} 40 \mathrm{ccm}$ Alkohol wie bei II.

$10 \mathrm{~h} 20^{\prime}$ bis $30^{\prime}$. Alles normal.

$10^{\mathrm{h}} 40^{\prime}$ bis $50^{\prime}$. L. Int. 22,6, 1. Ext. 20; r. Int. 22,6, r. Ext. 19,6. F.-N.-P. 6,3, F.-F.-P. $8^{\circ}\left(10^{\circ}\right.$ entschieden zu stark).

$11^{\mathrm{h}} 0^{\prime}$ bis $10^{\prime}$. L. Int. 28,3, I. Ext. 20; r. Int. 24,6, r. Ext. 20,6 . F.-N.-P. 6,4, F.-F.-P. $8^{\circ}$.

11 ${ }^{\mathrm{h}} 20^{\prime}$ bis $30^{\prime}$. F.-N.-P. 5,5-6,0. F.-F.-P. $8^{\circ}$. Bis auf den rechten Externus, welcher keine Veränderung zeigt, gibt jetzt die Schnelligkeitsmessung wieder normale Werthe. Die Pupille blieb unverändert $(4,5)$.

Das Ergebniss ist also, dass nach 25' sich eine Verminderung der Schnelligkeit der Contraction am rechten Externus und den beiden Interni zumal dem linken bemerkbar macht, welche beim rechten nach $45^{\prime}$, beim linken nach $65^{\prime}$ wieder verschwunden ist. Ebenso zeigt sich die Fusion gestört, und zwar hauptsächlich die Wirkung der Interni. Der Nahepunkt ist nach $25^{\prime}$ hinausgerückt, der (negative) Fernpunkt ebenso. Nach $65^{\prime}$ ist ersterer fast wieder normal, letzterer noch unverändert.

Allgemeinbefinden: In der ersten halben Stunde starkes Hitzegefühl und geringe aber deutliche Rauschwirkung.

\section{IV.}

Um die Entwicklung der Störung und ihren allmäligen Ausgleich noch besser hervortreten zu lassen, wurde ein 4 . Versuch mit einem noch grösseren Quantum gemacht.

$10^{\mathrm{h}} 30^{\prime}$. L. Int. 28, 1. Fixt. 19; r. Int. 25, r. Ext. 24. F.-N.-P. 5,4, F.-F.-P. $10^{\circ}$ (leicht). Pupille 4,5 .

$10 \mathrm{~h} 40^{\prime} .60 \mathrm{ccm}$ Alkohol (w. o.).

10 h $45^{\prime}$. Einige Stichproben ergeben keine Veränderung. F.-N.P. und F.-F.-P. w. o.

$10^{\mathrm{h}} 50^{\prime}$ bis 55'. Stichproben am 1. Int. und r. Ext. zeigen keine Veränderung. F.-N.-P. w. 0., F.-F.-P. $8^{\circ}$ (10 $0^{\circ}$ macht ca. $3 \mathrm{~cm}$ Abstand). Der daraufhin gleichfalls untersuchte 1 . Ext. ergibt $18^{\circ}$, also noch keinen wesentlichen Unterschied, da so kleine Schwankungen ja auch unter normalen Verhältnissen gefunden werden. $11^{\mathrm{h}} 0^{\prime}$. Pupille 4,5-5,0.

$11^{\text {h }} 5^{\prime}$ bis $15^{\prime}$. L. Int. 21,6, l. Ext. 16,3; r. Int. 20, r. Ext. 20. F.-N.-P. 6,1, F.-F.-P. $6^{\circ}$ (bei $8^{\circ} 3-4 \mathrm{~cm}$ Abstand). Subjectiv deutliches Rauschgefühl. Hitze im Gesicht.

$11^{\text {h }} 25^{\prime}$ bis $35^{\prime}$. L. Int. 19,6 , 1. Ext. 16 ; r. Int. 20 , r. Ext. 21,3. F.-N.-P. 6,6, F.-F.-P. $6^{\circ}$. Pupille 4,5-5,0. Allgemeiner leichter Schweissausbruch und Hitzegefühl.

$11^{\mathrm{h}} 45^{\prime}$ bis $55^{\prime}$. L. Int. 24,6 , 1. Ext. 18 ; r. Int. 20 , r. Ext. 20,6. Hitze und Rauschgefühl nehmen ab.

$12^{\mathrm{h}} 5^{\prime}$ bis $15^{\prime}$. I. Int. 26,3, I. Ext. 15,6; r. Int. 17,6, r. Ext. 22,6. F.-N.-P. 6,8, F.-F.-P. $6^{\circ}$. Pupille 4,5-5,0.

12h $30^{\prime}$ bis $40^{\prime}$. L. Int. 27, l. Ext. 18; r. Int. 20, r. Ext. 23,3. F.-N.-P. 6,6, F.-F.-P. $6^{0}$ ( $8^{\circ}$ vorübergehend). Pupille $4,5-5,0$. 
Die Schnelligkeitsmessung ergibt also bis auf rechten Internus wieder normale Zahlen, wohingegen die Fusionsstörung sich viel langsamer ausgleicht.

Bevor wir noch weitere Versuchsprotokolle anführen, wollen wir erst sehen, was die bisherigen lehren. Zunächst ist in allen positiv ausgefallenen Versuchen von einer erregenden Wirkung nichts zu bemerken, vielmehr deuten alle Abweichungen, welche hervortreten, immer auf eine Herabsetzung der Leistungsfähigkeit. Wenn man bei der Verschiedenheit der Methode und der untersuchten Functionen einen Vergleich ziehen darf, so würden meine Zahlen eine Analogie mit den für Dehio festgestellten Dynamometerversuchen zeigen, nur mit dem Unterschiede, dafs die Lähmungserscheinungen selten schon innerhalb der ersten 10 Minuter, sondern meist später auftreten, selbst bei viel grösseren Dosen. $30 \mathrm{~g}$, welche bei Dehio schon deutlich die Muskelleistung beeinflussten, verursachten bei mir keine Veränderungen (Dynamometerversuche anzustellen hatte ich selbst keine Gelegenheit). Nach $40 \mathrm{ccm}$ zeigte sich in der ersten Viertelstunde alles normal, erst nach 25' die ersten Erscheinungen von Abschwächung der Leistung. Leider lässt sich eine fortgesetzte Beobachtung mit so kurzen Pausen, wie sie Kraepelin anwendete, für die Augenmuskeln nicht ausführen. Das Intervall zwischen zwei Dynamometerversuchen betrug bei Dehio eine halbe Minute, bei $\mathrm{Kr}$ a epelin noch etwas weniger. In so kurzen Zwischenräumen sind angestrengte Bewegungen der. Augenmuskeln nicht möglich, da sehr rasche Ermüdung die Folge sein würde. Ich muss es also dahingestellt sein lassen, ob vielleicht doch ein vorübergehendes Erregungsstadium vorhanden war. Um so deutlicher sind die Lähmungserscheinungen, wie daraus hervorgeht, dass unter normalen Verhältnissen der linke Internus bei mir niemals einen geringeren Werth als 25, des rechten Internus als 24 zeigt. Die Zeit des Eintrittes dieses Lähmungsstadiums stimmt mit den Angaben Kraepelin's gut überein; ebenso wie der Umstand, dass dasselbe sich um so früher zeigte, je stärker die Dosis war (nach $60 \mathrm{ccm}$ schon nach 10 Minuten). Bei den Versuchen Frey's am Ergographen (s. o.) fand sich eine Zunahme der Leistungsfähigkeit am ermüdeten Muskel, während beim nicht ermüdeten (was unserem Falle entspricht) auch nur eine lähmende Wirkung des Alkohols beobachtet wurde, welche nach Ansicht des Autors einer Herabsetzung 
der peripherischen Erregbarkeit des Centralnervensystems zuzuschreiben wäre.

Sehen wir die Ergebnisse unserer Versuche noch etwas näher an, so bemerken wir bei III als erste Wirkung eine Störung der Fusion, sowohl für Fernpunkt wie Nahpunkt, gleichzeitig mit einer Verminderung der Schnelligkeit der Interni und eines Externus. Bei Versuch IV geht dieser Verminderung der Schnelligkeit eine Störung der Fusion voraus, und zwar zunächst in Bezug auf die Abduction. Sie zeigt sich schon nach 10', und dürfte ihr Auftreten zu einer Zeit, wo bei III noch richts zu bemerken war, wohl auf die höhere Dosis zurückzuführen sein. Erst nach weiteren $10^{\prime}$ zeigt sich auch hier die Abschwächung der Contractionsenergie, welche ebenso wie bei III 25' nach Einnahme des Mittels und zwar ziemlich rasch sich entwickelt, ohne grosse Schwankungen eine Zeit lang auf der gleichen Höhe bleibt, um sich allmälig wieder auszugleichen. Sämmtliche Störungen, auch die der Fusion sind, entsprechend der Dosis bei IV, stärker als bei III und betreffen auch beide Externi. Im weiteren Verlaufe treten unregelmässige Schwankungen ein, so dass die einzelnen Werthe theils $\mathrm{Zu}$ - theils Abnahme zeigen. Hierdurch wird auch deren sonst ganz festes gegenseitiges Verhältniss gestört, so dass z. B. der rechte Externus eine grössere Contractionsgeschwindigkeit erlangt, als der Internus derselben Seite, ein Verhalten, welches ich in der Norm niemals beobachtet habe. Der Ausgleich findet ebenfalls nicht gleichmässig statt, sondern an einzelnen Muskeln schneller als an anderen, indem z. B. (Versuch IV) der linke Internus und rechte Externus wieder normal waren, während die beiden anderen noch sehr niedrige Werthe zeigten, so dass also die Rechtsdrehung beiderseits schon mit normaler Geschwindigkeit erfo]gte, die Linksdrehung noch nicht.

Das Verhalten der Fusion erwies sich sowohl bei der Entwicklung der Störung, wie bei ihrem Ausgleiche ziemlich unabhängigvon der Energie der in Betracht kommenden Muskeln. Die Abduction findet sich (Versuch IV) zuerst herabgesetzt ohne jede nachweisbare Schwäche der Seitenwendung, und ebenso kann die Fusionsstörung zuletzt bestehen bleiben, während sonst fast Alles wieder in Ordnung ist. Es spricht dies für die Ansicht, dass die Centren für die gemeinschaftliche Innervation der Seitenwendung einer- und der Fusion andererseits von einander bis zı einem gewissen Grade unabhängige Einrichtungen sind, und wir werden unten andere Versuche finden, 
Ueber den Einfluss von Giften auf den Bewegungsapparat der Augen. 347

bei denen dies in noch stärkerem Maasse hervortritt. Jedenfalls deutet dies darauf hin, dass nicht etwa die Muskeln selbst, oder wenigstens nicht ausschliesslich, Sitz der Störung sind, sondern dass die letztere auch als Ausdruck der Einwirkung auf die Centralorgane anzusehen ist, auf welche ja ausserdem die psychischen Erscheinungen hindeuten.

Es würde keinen Zweck haben, das Gesagte noch durch eine grössere Reihe von Versuchsprotokollen zu erläutern, da aus denselben keine neuen Gesichtspunkte abzuleiten sind. Ich will nur noch eines anführen, wobei die Dosis die Mitte hält zwischen derjenigen von III und IV und unmittelbar nach Einnabme des Mittels auf ein etwaiges Erregungsstadium besonders geachtet wurde.

V.

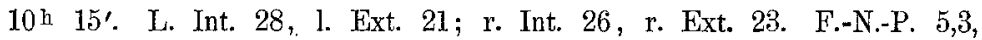
F.F.P. $10^{\circ}$. Pupille 4,5 .

10 h $30^{\prime}$. $50 \mathrm{ccm}$ Alkohol w. 0.

Es wurden unmittelbar nach Einnahme dieses Quantums 10 Minuten lang in Pausen von je 1/2-1 Min. abwechselnd Stichproben an ein bis zwei Muskeln genommen. Dieselben blieben während dieser Zeit immer innerhalb der physiologischen Grenzen. Ausserdem wurde in dem genannten Zeitraume vier bis fün Mal die Fusionsbreite festgestellt. Dieselhe zeigte sich während der ersten 7 Minuten den obigen Werthen entsprechend, insbesondere wurde auch hier nichts bemerkt, was auf eine Erhöhung der Leistung hingedeutet hätte. Nach 7 Minuten war aber eine deutliche Abnahme der Fusionsbreite zu constatiren.

10h 37'. F.-F.-P. Bei $10^{\circ}$ bleibt ein Abstand von $1-2 \mathrm{~cm}$; erst $8^{\circ}$ wird vollständig überwunden. F.-N.-P. 6,3. Trotz grösster Anstrengung gelingt es nicht, ihn näher zu bringen.

10 $40^{\prime}$. Stichproben am 1. Ext. und r. Int. normal. Subjectiv angenebmes Wärmegefühl.

$10^{\text {h }} 45^{\prime}$. F.-N.-P. 6,3 , F.-F.-P. $8^{\circ}$ (bei $10^{\circ} 3-4 \mathrm{~cm}$ Abstand). Stichproben an einzelnen Muskeln normal.

$10^{\mathrm{h}} 50^{\prime}$ bis $60^{\prime}$. $10^{\mathrm{h}} 50^{\prime}$ wird die erste Schnelligkeitsabnahme bemerkbar. Von jetzt ab je drei Einstellungen an allen Muskeln, wie früher. Danach $10^{\prime}$ Pause.

L. Int. 25 , 1. Ext. 18,6 ; r. Int. 24,6, r. Ext. 23 . F.-F.-P. und F.-N.-P. w. o. Pupille 4,5 .

$11^{\text {h }} 10^{\prime}$ bis $20^{\prime}$. L. Int. 23,6 , 1. Ext. 18 ; r. Int. 22,6 , r. Ext. 23 . F.-F.-P. $8^{\circ}$ wird nicht mehr ganz überwunden, $6^{\circ}$ vollständig. F.-N..P. 6,2.

$11^{\text {h }} 30^{\prime}$ bis $40^{\prime}$. L. Int. 23,3, 1. Ext. 19; r. Int. 22,3, r. Ext. 21,6. F.-N.-P. 6,4, F.-F.-P. $8^{\circ}$, noch etwas zu stark, bei $10^{\circ} 4-5 \mathrm{~cm}$ Abstand. $6^{\circ}$ wird überwunden.

$11^{\text {h }} 50^{\prime}$ bis $60^{\prime}$. L. Int. 25,3, 1. Ext. 18,3; r. Int. 22, r. Ext. 22. F.-N.-P. 6,5, F.-F.-P. unverändert. Pupillen gleichfalls. 
$12^{\mathrm{h}} 10^{\prime}$ bis $20^{\prime}$. L. Int. 24,6 , 1. Ext. 20,3 ; r. Int. 22, 1. Ext. 23. F.-N.-P. 6,0, F.-F.-P. $8^{\circ}$ wird wieder überwunden, bei $10^{\circ}$ nach $2 \mathrm{~cm}$ Abstand.

Linker und rechter Externus also normal. Letzterer war auch hier wieder am wenigsten betheiligt.

$12^{\mathrm{h}} 30^{\prime}$ bis $40^{\prime}$. L. Int. 25,3 , 1. Ext. 20,6 ; r. Int. 23, r. Ext. 28,6. Also auch die Interni fast wieder normal. F.-N.-P. 5,6, F.-F.-P. $10^{\circ}$ immer noch etwas zu stark ( $1-2 \mathrm{~cm}$ Abstand).

Es ist somit Alles fast wieder ausgeglichen. Ein Rauschgefühl war dieses Mal nicht vorhanden, nur vorübergehend etwas Müdigkeit.

Es zeigt sich auch hier die Störung der Fusion ganz unabhängig von der Leistungsfähigkeit der einzelnen Muskeln. Die Abnahme der Contractionsenergie entwickelt sich bei diesen ganz ungleichmässig, am stärksten an den Interni, so dass schliesslich der rechte Externus einen höheren Werth zeigt, als der Internus. An den wenigst betheiligten Muskeln ist auch die Störung am schnellsten wieder ausgeglichen.

In allen Fällen habe ich, sobald die Wirkung anfing deutlich zu werden, auch mittelst der sonst üblichen Methoden versucht, eine Veränderung in der Muskelthätigkeit nachzuweisen. Es gelang mir dies aber weder mit Hülfe eines vertikal brechenden Prismas noch mit einem Glasstäbchen nach Maddox, welche letztere Methode, wie ich früher gezeigt habe ${ }^{1}$ ), eine besonders empfindliche ist. Nach jeder Richtung, bis an die Grenzen des gemeinschaftlichen Blickfeldes zeigte sich bei den Seitenwendungen der binoculäre Sehakt ungestört. Die Schnelligkeitsmessung gestattet uns daher, Veränderungen nachzuweisen, welche den bisherigen Untersuchungsmethoden nicht zugänglich sind. Man könnte zwar sagen, dass die immer leicht controlirbare Fusionsfähigkeit auch in Mitleidenschaft gezogen war, doch werden wir unten sehen, dass dies durchaus nicht regelmässig der Fall ist, und dass unter Umständen keine andere Leistung als die Geschwindigkeit der Contraction sich herabgesetzt zeigt.

Nächst dem Alkohol habe ich die Wirkung verschiedener narkotischer Mittel in derselben Weise einer Prüung unterzogen.

B) Morphium.

Es ist eine alte Erfahrung am Krankenbette, dass dieselbe Morphiumgabe, so lange sie sich innerhalb gewisser Grenzen hält,

1) Sitzungsber. der ophthalmol. Gesellschaft. Heidelberg 1893 und Archiv für Augenheilkunde Bd. $29 \mathrm{H} .3$. 
auf verschiedene Personen sehr verschiedenartig einwirkt. Erst bei hohen Dosen kann man allgemein mit Sicherheit auf eine betäubende und lähmende Wirkung rechnen, während bei kleinen und mittleren (bis zu 0,01) nicht selten das Gegentheil erreicht wird, nämlich Erregung auf physischem und motorischem Gebiete in Form von geistiger Anregung, Unruhe, Bewegungsdrang, Schlaflosigkeit mit oder ohne gastrische Erscheinungen. Diese Wirkung wird besonders häufig bei Frauen beobachtet, nach einigen Autoren auch bei schwächlichen anämischen Personen, während bei Männern und kräftigen Individuen auch nach diesen Gaben schon eine narkotische Wirkung eintrete. Die Stufe der geistigen Entwicklung wird ebenfalls als maassgebend angesehen für die Art der Morphiumwirkung, insofern die hypnotische Wirkung um so deutlicher sein soll, je höher das Individuum in intellectueller Beziehung steht. So ist beobachtet, dass es bei Negern und Malayen nicht nur keinen Schlaf erzeugt, sondern heftige Erregung mit starken Muskelcontractionen und Krämpfen. Und selbst in Europa soll bei dem intelligenteren Individuum der grossen Stadt die hypnotische Wirkung deutlicher sein als bei der Landbevölkerung. Auch bei Kindern stellen sich leicht motorische Erregungszustände ein in Gestalt von klonischen Zuckungen einzelner Muskelgruppen, allgemeinen Convulsionen, Trismus und Opisthotonus.

Die meisten Erfahrungen über das Morphium bezw. das Opium, von dem es ja einen wesentlichen Bestandteil bildet, dürften im Oriente gemacht sein, bei der dort weit verbreiteten Sitte des Opiumgenusses. In kleinen Mengen per os genommen, gilt nun bei den mohamedanischen Völkern das Opium geradezu als ein Mittel zur Anregung der körperlichen Kraft und Erhöhung der Leistungsfähigkeit der Muskeln. Dieselbe Wirkung soll auch das Opiumrauchen haben, wenngleich in vermindertem Grade, und ebenso ist bekannt, dass es eine erregende Wirkung auf das Centralnervensystem ausübt, indem es die Einbildungskraft weckt, Hallucinationen hervorruft, psychische Hemmungen und Depressionen beseitigt, welchen Eigenschaften dieses Gift ja gerade seine Beliebtheit als Genussmittel verdankt.

Bei den Thierversuchen wird immer die grosse Widerstandsfähigkeit, zumal der Kaltblüter, gegen das Mittel hervorgehoben. Bei genügender Dosis sind aber die Erscheinungen analog denen beim Menschen. Witkowski konnte bei seinen Versuchen an ver- 
schiedenen Thieren ein Erregungsstadium nicht bemerken, sondern nur lähmende Wirkungen auf die Centren der bewussten Empfindung und willkürlichen Bewegung, schliesslich auf das Respirationscentrum. Bei Fröschen ist die Reihenfolge der Erscheinungen die, dass zunächst die freiwilligen Bewegungen langsamer und seltener werden, dann geht die Herrschaft über die Bewegungsfähigkeit allmälig verloren, und schliesslich auch die zur Bewabrung der gewohnten Stellung. Im Allgemeinen erfolgt die Wirkung in der Reihenfolge, dass zunächst die verschiedenen Centralorgane des grossen, dann des kleinen Hirns und schliesslich der medulla oblongata gelähmt werden. Die Reflexe dagegen werden nach einer vorübergehenden und nicht immer deutlichen Herabsetzung gesteigert, so dass es schliesslich zum Auftreten von Streckkrämpfen kommt. Die Wiederherstellung entwickelt sich in genau derselben Reihenfolge. Beim Warmblüter werden dagegen auch Aufregungszustände des Gehirns beobachtet, und sind Nothnagel-Rossbach der Ansicht, dass kleine Gaben dieselben Gehirntheile erregen, welche durch grössere gelähmt werden, äbnlich, wie wir dies bei anderen berauschenden und narkotischen Mitteln finden. Die erregende Wirkung, welche das Medicament zweifellos bei der Morphiumsucht ausübt, wird nicht von allen Autoren gleichmässig erklärt. Bei längerem Gebrauche des Morphins soll sich im Körper Oxydimorphin bilden, wie dasselbe auch ausserhalb des Organismus unter der Einwirkung von Oxydationsmitteln entsteht. Dieser Stoff wird als die Ursache der Abstinenzerscheinungen angesehen (Marmé), und sollen durch Einspritzung desselben in das Blut bei Hunden analoge Symptome hervorgerufen werden, wie die der Morphiumabstinenz, und ebenso wie diese durch Morphium $\mathrm{zu}$ beseitigen sein. $\mathrm{Ob}$ sich hierbei andere Stoffwechselproducte bilden, welche einen Einfluss auf das Oxydimorphin ausüben, ist nicht genügend aufgeklärt, und es bleibt also dahingestellt, ob die erregende Wirkung unmittelbar auf die nervösen Organe stattfindet, oder nur mittelbar durch Beseitigung eines Stoffes, welcher die Collapszustände hervorruft. Der uns am meisten interessirende Finfluss auf die Muskelleistung ist von $\mathrm{Rossi}^{1}$ ) untersucht mit Hülfe des Ergographen, und zwar am flex. digit. sublim. nach der Methode von Mosso. Er fand, dass Morphium in einer Gabe von 0,01-0,02 und Opium von 0,06 stark ermüdeten. Von einer erregenden

1) l. c. 
Wirkung ist, wenigstens in den mir zugänglichen Referaten, nichts bemerkt. Witkowski fand die motorischen Nerven bei Fröschen nicht direct durch Morphium beeinflusst, nur schliesslich in Folge der heftigen tetanischen Zuckungen erschöpft, dagegen konnten Gscheidlen und Albers eine theils erregende, theils lähmende Wirkung, je nach Grösse der Gabe, feststellen. Die peripheren sensiblen Nerven können schon mit Rücksicht auf die gesteigerte Reflexempfindlichkeit in ihrer Erregbarkeit nicht wesentlich beeinträchtigt sein. Die interessante Beobachtung von Rumpf, wonach die subcutane Anwendung von 0,01-0,015 Morphium nach 6-10 Minuten eine Herahsetzung des Raumsinnes am ganzen Körper hervorruft, dürfte wohl auch auf centralen Störungen beruhen.

Jedenfalls geht aus dem Gesagten hervor, dass eine sehr starke und verschiedenartige Beeinflussung der motorischen Sphäre durch das Morphium stattfindet, obschon die Reizbarkeit der willkürlichen Muskeln vollständig erhalten bleibt (Gscheidlen). Was speciell die Augenmuskeln betrifft, so kennen wir an diesen als häufigste Wirkung des Morpbiums die Pupillenverengerung, vorübergehend bei besonders erregbaren Individuen auch Accommodationskrampf. Bei chronischen Morphinisten sind während der Abstinenz Doppelsehen und Störungen der Accommodation beobachtet, welche, ebenso wie die übrigen Abstinenzerscheinungen, durch Morphium wieder zum Verschwinden gebracht werden. Die Wirkung wird bei vorübergehender Anwendung am gesunden Organismus in reinerer Form auftreten, als beim chronischen Gebrauche, denn der Symptomencomplex der Morphiophagie und die den Abstinenzerscheinungen zu Grunde liegenden Ursachen sind so complicirt, dass sie nur mit Vorsicht für das Studium der Morphiumwirkung verwerthet werden können.

Der Leichenbefund ergibt weder bei chronischen noch bei acuten Vergiftungen besondere örtliche Veränderungen des Centralnervensystems. Man findet nur, und auch nicht constant, eine allgemeine Hyperämie des Gehirns und seiner Häute.

Der Einfluss des Morphiums auf die physischen Vorgänge ist von Kraepelin ebenfalls in den Bereich seiner Untersuchungen gezogen worden. Er fand eine Anregung der intellectuellen Vorgänge, verbunden mit einer Lähmung des Willens, wie sie dem zweiten Stadium der Alkoholvergiftung entspricht. Das Mittel stellt 
sich hierdurch in Gegensatz zu vielen anderen Narcoticis, welchen jenes Stadium der Anregung fehlt. Dieselbe bezieht sich beim Morphium aber auch nur auf die intellectuellen Voröänge, wogegen die dem Alkohol eigenthümlichen motorischen Reizerscheinungen nicht beobachtet werden. „Es entwickelt sich kein Bewegungsdrang, sondern die Neigung zu behaglichem, ruhigem Hinträumen, wie sie der Erschwerung der centralen motorischen Akte entsprechen würde." Kraepelin findet eine befriedigende Uebereinstimmung zwischen seinen experimentellen Ergebnissen und unserer sonstigen Kenntniss der psychischen Morphiumwirkung. Dies mag in dem einen Punkte zutreffen, dass der Morphinist einen Verlust an moralischer Energie zeigt, welcher als Folge der wiederholten Willenslähmung anzusehen wäre. Im Uebrigen scheinen aber auch hier grosse individuelle Verschiedenheiten zu bestehen. Wenn die Erfahrungen der Opiumesser richtig sind, dass die körperliche Kraft und Leistungsfähigkeit gesteigert wird, so wäre auch ein gesteigerter Bewegungsdrang zu erwarten, da ein solcher mit einem erhöhten Kraftgefüble doch in der Regel verbunden ist. In der That wird auch von anderen Autoren Unruhe und gesteigerter Bewegungsdrang erwähnt, was ich aus persönlicher Erfahrung bestätigen kann.

Die Beobachtungen nun, welche sich am Bewegungsapparat des Auges mit Hülfe unserer obigen Methode ergeben, mögen durch die folgenden Versuchsprotokolle erläutert sein.

I.

Vor dem Versuche 1. Int. 28, 1. Ext. 21; r. Int. 27, r. Ext. 25. F.-N.-P. 5,5, F.-F.-P. $10^{\circ}$, etwas stark $\left(1 / \mathrm{a}-1 \mathrm{~cm}\right.$ Abstand), $8^{\circ}$ leicht. Pupille 4,5 .

$9 \mathrm{~h} 30^{\prime}$. $0,01 \mathrm{~g}$ Morph. muriat. per os. Bis $10 \mathrm{~h}$ keine andere Veränderung, als dass Prisma $10^{\circ}$ um diese Zeit vollständig überwunden wurde. Keine Schläfrigkeit, etwas Uebelkeit. Bis $11^{\text {h }}$ blieb alles gleich, nur entwickelte sich eine gewisse Erregung und Ideenflucht. Einschlafen erschwert.

\section{II.}

$9 \mathrm{~h} 45$ '. L. Int. 27, l. Ext. 19; r. Int. 25, r. Ext. 22. F.-N.-P. 5,0, F.-F.-P. $10^{\circ}$ leicht, vorübergehend $12^{\circ}$. Pupille 4,5 .

$10^{\mathrm{h}} 25 \%$. Morph. $0,01 \mathrm{~g}$ subcutan in linken Oberschenkel.

$10^{\mathrm{h}} 30^{\prime}$. Einzelne Stichproben normal. F.-N.-P. 5,5, F.-F.-P. w. o. Pupille 4,5. Beklemmungsgefühl," erschwerte Athmung.

$10^{\text {h }} 35^{\prime}$ bis $45^{\prime}$. I. Int. 25,6, l. Ext. 17,6; r. Int. 24. r. Ext. 23,3. Pupille nicht mehr ganz 4,5 aber grösser als 4,0 . F.-F.-P. $12^{\circ}$ wird leicht überwunden, vorïbergehend $14^{\circ}$. F.-N.-P. 5,5. 
Ueber den Einfluss von Giften auf den Bewegungsapparat der Augen. 353

$10^{\mathrm{h}} 55^{\prime}$ bis $11^{\mathrm{h}} 5^{\prime}$. L. Int. 24, l. Ext. 18; r. Int. 23,6, r. Ext. 23. F.-F.-P. $12^{\circ}$ leicht, $14^{0}$ etwas zu stark. Schwindelgefühl, Pupille 3,5 (kaum), Reaction direct und indirect prompt. F.-N.-P. 5,7.

$11^{\mathrm{h}} 15^{\prime}$ bis $25^{\prime}$. L. Int. 21,6 , 1. Ext. 19 ; r. Int. 23,3 , r. Ext. 22 . F.-N.P. 6,0 , F.-F.-P. $12^{\circ}$ leicht. Pupille 3,0 . Allgemeinbefinden sehr beeinträchtigt. Grosse Muskelunruhe, Zittern der Hande (namentlich beim Messen der Pupille sehr störend), etwas Uebelkeit und Schwindel.

$11^{\mathrm{h}} 30^{\prime}$ bis $40^{\prime}$. L. Int. 19,3 , I. Ext. 18,6 ; r. Int. 21, r. Ext. 21,6. Der Iinke Internus erweist sich hiernach schwächer als der rechte, und ergibt auch ein besonders darauf gerichteter Versuch, dass der linke Internus die Schiefheit nicht überwinden kann, wenn der Spalt auf den dem rechten Internus zukommenden Mittelwerth eingestellt ist, während sonst über das Gegentheil kein Zweifel möglich ist. F.-N.-P. 6,2, F.-F.-P. $12^{0}$ leicht, bei $14^{\circ}$ Abstand ron etwa $1 \mathrm{~cm}$. Pupille 3,0. Allgemeinbefinden jetzt wesentlich besser, Tremor hat nachgelassen, Trockenheit im Schlunde.

Schlaf danach sehr unruhig, mehrfach unterbrochen. Beim Aufstehen Uebelkeit, Abgeschlagenheit, Unruhe der Hände und Unsicherheit bei Bewegungen, Trockenheit im Schlunde.

$8^{\mathrm{h}}$ Vorm. L. Int. 28, 1. Ext. 21; r. Int. 28, r. Ext. 23 . F.-F.-P. $10^{\circ}$ (120 zu stark, bei $14^{0}$ ca. $7 \mathrm{~cm}$ Abstand). Pupille 3,5. F.-N.-P. 5,5.

Erst $2^{\text {h }}$ Nachm. ist die Pupille wieder 4,5. Die Accommodation wurỏe regelmässig festgestellt, aber während der ganzen Versuchsdauer keine Störung bemerkt.

III.

10h. L. Int. 27, 1. Ext. 19 ; r. Int. 25, r. Ext. 23. F.-N.-P. 5,4, F.-F.P. $10^{\circ}$ leicht, vorübergehend $12^{\circ}$. Pupille 4,5.

$10^{\mathrm{h}} 10^{\prime}$. Morph. mur. 0,01 $\mathrm{g}$ subcut. in rechten Obersehenkel.

Schon nach 4 Minuten Gefühl von Schwindel und Uebelkeit.

$10^{\mathrm{h}} 15^{\prime}$. Stichproben an 1. Fxt. und r. Int. normal. F.-N.-P. und F.-F.-P w. 0.

10 ${ }^{\text {h }}$ 20'. Stichproben an 1. Int. und r. Ext. normal. Schläfrigkeit, Druck in den Schläfen, sonst keine Allgemeinerscheinungen.

$10^{2} 25^{\prime}$ bis $30^{\prime}$. Alle vier Mnsireln normal. F.-N.-P. 5,4. Pupille 3,5-4,0. F.-F.-P. $14^{0}$ wird leicht äberwunden, bei $16^{\circ}$ nur $1-2 \mathrm{~cm}$ Zwischenraum vorübergehend ganz überwunden. Druck im Kopfe und Gefübl von Klopfen. Im Uebrigen sind die Erscheinungen nicht so unangenehm wie bei II.

10h 35'. Stichproben am 1 . Ext. und r. Int. normal.

$10^{\mathrm{h}} 45^{\prime}$ bis $55^{\prime}$. L. Int. 22,6 , 1. Ext. 17,3 ; r. Int. 20,3, r. Ext. 21,3 . Versuchsweise Einstellung auf die normalen Werthe entschieden zu stark. F.-F.-P. 14*, F.-N.-P. 5,6. Pupille 3,5.

$11^{\mathrm{h}} 5^{\prime}$ bis $15^{\prime}$. I. Int. 20,3, l. Ext. 17,6; r. Int. 20,3, r. Ext. 20,6. F.-N.-P. 5,4, F.-F.-P. $14^{0}$ wird sofort, aber nur für wenige Secunden überwunden. Tremor an den Händen.

Der Accommodationsnahepunkt zeigt sich jetzt um einige Centimeter näher gerückt, doch ist dies auch ohne Morphium zu erreichen, wenn ein Diaphragma mit einer der obigen Pupillenweite entsprechenden Oeffnung vor das Ange ge- 
setzt wird. Also offenbar eine nur scheinbare Vermehrung der Accommodationsfähigkeit, welche nur auf Verminderung der Zerstreuungskreise zurückzuführen ist. Die Erschlaffung des Accommodationsmuskels war jedenfalls sehr wohl mög. lich, wie sich daraus ergab, dass das Sehen für die Ferne nicht behindert war. Dje Nacht darauf sehr schlecht. Fast jede Stunde wach. Beim Aufstehen starker Schwindel, Uebelkeit und Muskeizittern. Nach kalter Abwaschnng besser. 8 b Vorm. L. Int. 27, 1. Ext. 23,3; r. Int. 26,3, r. Ext. 25,6. F.-N.-P. 5,4, F.-F.-P. $12^{\circ}$ leicht, bei $14^{\circ}$ nur $1 \mathrm{~cm} \mathrm{Z.-R.,} \mathrm{der} \mathrm{sich} \mathrm{allerdings} \mathrm{sehr} \mathrm{rasch} \mathrm{auf}$ ca. $6 \mathrm{~cm}$ vergrössert. Pupille 3,5 .

2b Nachm. L. Int. 27, 1. Ext. 21; r. Int. 26, r. Ext. 25. F.-N.-P. 5,2, F.-F.P. $12^{\circ}$ vorübergehend, bei $14^{\circ} 3 \mathrm{~cm}$ Z.-R., allmälig zunehmend, $10^{\circ}$ leicht, Pupille 3,5.

5h $30^{\prime}$. F.-F.-P. $10^{\circ}$, bei $12^{\circ} 2-3 \mathrm{~cm}$ Abstand, bei $14^{\circ} 10 \mathrm{~cm}$, rasch zanehmend. F.-N.-P. w. o. Pupille 3,5.

9 h $45^{\prime}$. F.-F.-P. wie 5 h $30^{\prime}$. F.-N.-P. 5.2. Pupille 3,5-4,0.

Vergleichen wir diese beiden Versuchsprotokolle, so finden sich deutliche Lähmungserscheinungen, beide Male nach etwa einer halben Stunide unverkennbar entwickelt. Die einzelnen Muskeln sind ungleich betheiligt und vorwiegend die Interni befallen. Dieses Verhalten der Innenwender des Auges gegenüber dem Morphium ist übrigens auch in der älteren Literatur schon erwähnt. Hier ist von besonderem Interesse eine Angabe von v. Gra efe ${ }^{1}$ ), welche bei der obigen, etwas summarischen Literaturübersicht nicht angeführt ist, weil sie im Zusammenhange mit unseren eigenen Versuchen näher besprochen werden sollte. Er sagt: „In einigen Fällen zeigte sich (nach hypodermatischen Morphiuminjectionen) ein Verschwommensehen entfernter Gegenstände, welches durch den Eintritt von Myopie bedingt war. Die Analyse der Erscheinungen ... ergab, dass die Myopie zum Theil eine wirkliche, auf Spasmus der Accommodation beruhende, zum Theil aber eine scheinbare war. Wurde nämlich ein Auge-geschlossen, so wich der Fernpunkt zurück, und es waren schwächere Concavgläser, als beim binoculären Sehakt erforderlich. Die Prismenversuche ergaben Insufficienz der Interni, die so wie jener Spasmus später durchaus verschwand; auf Grund dieser Insufficienz waren die relativen Accommodationsbreiten berangerückt. Bei mehreren Opiophagen habe ich exquisite muskulare Asthenopie, deren Symptome sich mit der Zeit eingefunden, beobachtet." Die Erscheinungen einer eigentlichen Insufficienz habe ich nun bei den obigen Versuchen, auch bei voller Entwicklung der Schwächezustände

1) Archiv f. Ophthalm. Bd. 8 H. 2 S. 342. 
des Bewegungsapparates niemals nachweisen können (Prismenversuch, Glasstab). Möglich, dass die Dosen hierfür zu gering waren, denn v. Graefe sagt ausdrücklich, dass starke Gaben erforderlich seien. Ebensowenig konnte ich, wie bereits erwähnt, eine Myopie finden. Diese wird von v. Graefe auch noch an einer anderen Stelle bebeschrieben ${ }^{1}$ ). Er bezeichnet dort den Spasmus der Accommodation als eine flüchtige und höchst unbeständige Erseheinung, welche nur bei sehr erregbaren Individuen und wahrscheinlich nur bei relativ hohen Dosen eintrete. Wenn überhaupt, so käme er am Ende des Erregungsstadiums. Die Accommodationsbreite verringere sich allmälig, um dann, wie mit einem Sprunge, zur Norm zurückzukehren, undr dauere das ganze Phänomen oft nur wenige Minuten. In den Lehrbüchern der Pharmakologie und Toxikologie ist dieser Angaben übrigens kaum gedacht. Nach Lewin ${ }^{2}$ ) soll der Accomodationskrampf unmittelbar nach der Injection oder nach ca. ${ }^{3 / 4}$ Stunden auftreten.

Die erwähnten Lähmungserscheinungen der äusseren Muskeln waren in unseren Versuchen so lange festzustellen, als diese fortgesetzt wurden, nämlich $1-1^{1 / 2}$ Stunden. Dazu bestand, als anderweitige motorische Störung, ein starkes Zittern der Hände und Unsicherheit der Bewegungen. Jene Symptome an den äusseren Augenmuskeln begannen in allen Fällen später als die Verengerung der Pupille, wenn man nicht die erste geringe Verminderung der Werthe im Versuch II schon als Lähmungserscheinungen auffassen will. Sie waren aber niemals von so langer Dauer wie die Pupillenenge, da diese in beiden Fällen noch in den Nachmittagsstunden des folgenden Tages nachzuweisen war, während die Leistungsfähigkeit der äusseren Muskeln sich stets am folgenden Morgen normal zeigte. Da man die Pupillenenge, nach der üblichen Annahme, ebenfalls durch centrale Vorgänge erkiärt, so ist man genöthigt, eine verschiedenartige Wirkung des Giftes auf anatomisch, wie physiologisch in engem Zusammenhang stehende Theile anzunehmen. Ein Erregungszustand an der einen Stelle findet sich gleichzeitig mit lähmender Einwirkung an der anderen. Noch mehr tritt diese Verschiedenheit der Giftwirkung hervor, wenn wir die eigenthümliche Beeinflussung der Fusionsfähigkeit betrachten. Es zeigte sich nämlich im ersten Ver-

1) Archiv f. Ophthalm. Bd. 9 H. 2 S. 66.

2) Nebenwirkungen der Arzneimittel. Berlin 1899. 
suche nach 10, im zweiten nach 15 Minuten eine Veränderung des Fusionsfernuunktes, insofern stärkere Abductionsprismen unter dem Einflusse des Morphiums überwunden werden konnten als vorher. Diese Thatsache war mir so auffällig, dass ich sie selbstverständlich auf das Genaueste controlirte, wobei ich sie aber immer wieder bestätigt fand. Ich darf hier gleich bemerken, dass dies zu Gunsten der Ansicht spricht, welche das Vorhandensein eines besonderen Divergenzcentrums vertritt, worauf wir indessen später noch eingehen wollen. Auffallend ist die lange Dauer dieser Wirkung im zweiten Falle, wo sie noch am folgenden Morgen angedeutet war, während im ersten Versuche um diese Zeit bereits wieder normale Verhältnisse vorlagen. $\mathrm{Ob}$ diesen letzteren ein Lähmungsstadium voranging, wurde nicht festgestellt, doch glich sich in dem anderen Versuche die Steigerung der Fusionsfähigkeit allmälig wieder aus ohne deutliches Lähmungsstadium. Im Uebrigen ist es in der Toxikologie etwas ganz Geläufiges, dass einzelne Nervencentren in verschiedenem Grade von demselben Mittel erregt werden, andere wieder gar keine Beeinflussung zeigen, oder zum Theil auch wieder gerade entgegengesetzte Wirkungen, indem der Uebergang von Erregung in Lähmung an der einen Stelle schneller erfolgt als an der anderen. Ich erinnere nur, um beim Opium und Morphium zu bleiben, an die Reizerscheinungen auf verschiedenen Gebieten (Erregung des Brechcentrums u. s. w.), bei bereits deutlicher Lähmung anderer Functionen, ferner an die oft lange anbaltende tetanische Muskelstarre der Strychninvergiftung, in Folge der Erregung des Rückenmarks, bei lähmender Wirkung auf das vasomotorische und Athmungscentrum u. s. w.

Die Steigerung der Fusionsfähigkeit hat in späteren Versuchen meine Aufmerksamkeit noch ganz besonders in Anspruch genommen. Jedenfalls ist dieselbe nicht etwa durch die Schwäche der Interni zu erklären, sondern steht hiermit in keinem unmittelbaren Zusammenhange. Auch habe ich versucht, festzustellen, ob sich vielleicht für die Convergenz, welche sich in den obigen Zahlen wenig beeinflusst zeigt, wenn auch nur vorübergehend, etwas Analoges findet. Der Zeitpunkt des Auftretens der Störung wurde zu dem Zwecke in späteren Versuchen durch Verkürzung der Zwischenräume möglichst genau beobachtet, wobei ich mich gleichzeitig von der Unabhängigkeit der einzelnen Symptome von einander noch mehr überzeugte. 
Ueber den Einfluss von Giften-auf den Bewegungsapparat der Augen. 357

IV.

9 h $40^{\prime}$ bis $50^{\prime}$. L. Int. 28, 1. Ext. 21; r. Int. 26, r. Ext. 25. F.-N.-P. 5,3, F.-F.-P. $10^{\circ}$. Pupille 4,5 .

9h 55'. 0,01 g Morph. hydrochl. in linken Oberschenkel.

Alle zwei Minuten F.-F.-P. und F.-N.-P. bestimmt, dazwischen Stichproben an den äusseren Muskeln, Verhalten von Pupille und Accommodation.

- $9 \mathrm{~h} \mathrm{58'.} \mathrm{Beginnende} \mathrm{Uebelkeit,} \mathrm{sonst} \mathrm{bisher} \mathrm{Alles} \mathrm{normal.}$

$10^{\mathrm{h}} 3^{\prime}$. F.-F.-P. $12^{\circ}$, wird vorübergehend ganz überwunden.

$10^{\mathrm{h}} 7^{\prime}$. Pupille $4^{\circ}$. Aeussere Muskeln normal. F.-F.-P. $12^{\circ}$ leicht, vorübergehend $14^{\circ}$. F.-N.-P. 5,5.

$10 \mathrm{~h} 10^{\prime}$. Es zeigt sich die erste Abnahme an den äussern Muskeln und zwar am linken Internus. Von jetzt ab je drei Einstellungen, wie früher.

L. Int. 24,3, die anderen Muskeln noch wie oben. Schwindelgefühl, mässige Uebelkeit, Pupillen 3,5.

$10^{\mathrm{h}} 15^{\prime}$ bis $25^{\prime}$. F.-F.-P. unverändert, F.-N.-P. 5,3. Starker Schwindel. Uebelkeit nimmt ab. L. Int. 24,3, l. Ext. 20; r. Int. 24,6, r. Ext. 24.

$10^{\mathrm{h}} 30^{\prime}$. F.-N.-P. unverändert, F.-F.-P. $12^{\circ}$ sehr leicht, $14^{0}$ vorübergehend, darauf $3-4 \mathrm{~cm} \mathrm{Z.-R.} 16^{\circ}$ wird im ersten Augenblick bis anf $2 \mathrm{~cm}$ Abstand überwunden.

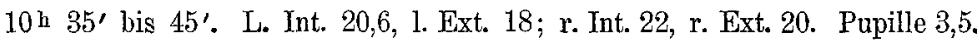
Beginnende Muskelunruhe an den Händen. " F.-F.-P. $14^{0}$ leicht, bei $16^{\circ} 4-5 \mathrm{~cm}$ Z.-R. Insufficienz der Interni weder mit Prisma noch Glasstab nachzuweisen. Sehschärfe für die Ferne normal.

$10 \mathrm{~h} \mathrm{55 \%}$. Starkes Muskelzittern an den Händen, beginnende hypnotische Wirkung. Beklemmung und Bedürfniss nach tiefen Athemzïgen. Schwankender Gang. Pupille 3,0-3,5. Sehschärfe für die Ferne normal.

$11^{\text {h }} 0^{\prime}$ bis 5'. L. Int. 18,3 , l. Ext. 16 ; r. Int. 20, r. Ext. 19,3. Subjectives Gefühl einer verminderten Contractionsenergie und Schwäche. Es fällt auf, dass die einzelnen Spaltbilder viel näher beisammenstehen (ebenfalls Zeichen verminderter Schnelligkeit s. l. c.). Hypnotische Wirkung nimmt zu. Mit Prisma oder Glasstab keine Insufficienz der Interni nachzuweisen. F.-N.-P. 5,5, F.-F.-P. $16^{\circ}$ wird vorübergehend ganz überwunden, $14^{\circ}$ leicht.

$11^{\mathrm{h}} 15^{\prime}$ bis $25^{\prime}$. Pupille 3,0-3,5. L. Int. 17, 1. Ext. 16; r. Int. 18,6, r. Ext. 19,3. F.-F.-P. wie oben, F.-N.-P. 5,6. Starkes Zittern, Trockenheit im Schlunde.

11 h $30^{\prime}$. Starkes Schlafbedürfniss. Pupille 2,5-3,0.

$11^{\mathrm{h}} 40^{\prime}$. F.-F.-P. noch unverändert. Zittern hat sehr nachgelassen.

Der Versuch wird hier beendigt. Schlaf danach schlecht. Beim Aufstehen Kopfschmerz, Mattigkeit. Nach einer Viertelstunde plötzlich Uebelkeit nnd Erbrechen. Danach leidliches Wohlbefinden.

7 h $45^{\prime}$ Vorm. L. Int. 28 , l. Fixt. 22; r. Int. 26, r. Ext. 25. F.-F.-P. bei $14^{\circ} 4-5 \mathrm{~cm}$ Abstand, $12^{\circ}$ wird leicht überwunden, auch bei mehrfacher Wiederholung und nicht nur vorübergehend. F.-N.-P. 5,3. Pupille 3,5. Muskelzittern noch angedeutet. 
$11^{\mathrm{h}}$ Vorm. F.-F.-P. $12^{\mathrm{o}}$ nur noch vorübergehend (5-10 Sec. lang), aber vollständig. Pupille 4-4,5. Leichte Uebelkeit noch vorhanden. Abgesehen von letzterer ist also Alles wieder zur Norm zurückgelehrt.

Wie man sieht, ist in diesem Versuche nicht genau nach dem bisherigen Schema vorgegangen, doch sind bezüglich der Schnelligkeitsmessung an den äusseren Muskeln die Pausen eingehalten, so dass eine Ermüdung vermieden wurde. Das erste, was sich bemerkbar machte als Morphiumwirkung, war eine leichte Uebelkeit, dann beginnt 8 Minuten nach der Injection die Verstärkung der Divergenzleistung, 4 Minuten später die Verengerung der Pupille unter fortgesetzter Zunabme der Fusionsfähigkeit (Abduction). Nach weiteren 3 Minuten zeigt sich die erste Abnahme an den äusseren Muskeln, welche beginnt am linken Internus. Dieses Bild bleibt unter $\mathrm{Zu}-$ nahme der subjectiven Beschwerden zunächst das gleiche, und treten deutliche Schwächezustände an den anderen äusseren Muskeln erst nach 25 Minuten auf, also 40 Minuten nach der Einspritzung, während die Vermehrung der Fusionsfähigkeit bereits ihren Höhepunkt erreicht hat. In Bezug auf den Fusionsnahepunkt zeigt sich auch bei diesem Versuche keine deutliche Veränderung, ebenso wenig ein Accommodationskrampf. Wenn auch in Folge von Verengerung der Pupille die Objecte etwas näher herangerückt werden können, ohne undeutlich zu werden, ist das Sehen in die Ferne doch immer ungestört. Die Schwäche der äusseren Muskeln ist durch eine andere Methode nicht nachweisbar, insbesondere keine Insufficienz der Interni in dem üblichen klinischen Sinne.

Es zeigt sich also eine vollständige Unabhängigkeit der Fusionsfähigkeit von der Energie der äusseren Muskeln. Der Gedanke lag ja nahe, dass die Ueberwindung von Abductionsprismen durch das Auftreten der Schwäche der Interni erleichtert sei, und um dies klar zu stellen, ist gerade der Zeitpunkt des Auftretens beider Erscheinungen sorgfältig beobachtet, mit dem Ergebnisse, dass die erstere sich von dem Verhalten der äusseren Muskeln ganz unabhängig erweist. Dass dies der Fall, eroibt auch der Befund am folgenden Morgen. Die Schwächezustände der äusseren Muskeln waren jetzt verschwunden, insbesondere beide Interni im Besitze ihrer gewohnten Energie, und doch die Veränderung des Fusionsfernpunktes noch angedeutet, um erst gegen Mittag vollständig zu verschwinden. 
Nach der üblichen pharmakologischen Ansicht hat das Morphium im Anfange eine erregende Wirkung auf bestimmte Hirncentren, woraus sich, wenigstens bei genügender Dosis, bald eine Lähmung entwickelt. Hier sehen wir, dass eine bestimmte Fähigkeit des binoculären Bewegungsapparates gesteigert wird, und dass diese Erregung sehr lange anhält, ohne dass (bei der angewandten Dosis) ihr ein Lähmungsstadium folgte, während ein solches bei anderweitigen Leistungen der betheiligten Muskeln deutlich zu erkennen ist. Es bleibt somit eine bestimmte Function nicht nur ungeschwächt, sondern sogar im Stadium der Erregung, während anderweitige Lähmungserscheinungen deutlich hervortreten. Diese Beobachtung hat an sich nichts Ueberraschendes, wie. schon oben dargethan, und wir brauchen uns gar nicht weit umzusehen, um Analogicen zu finden. Dieselben bieten sich bei den obigen Versuchen selbst dar in dem Verhalten des Brechcentrums. Die durch das Morphium hervorgerufene Uebelkeit muss auf eine Erregung dieses Centrums zurückgeführt werden, und ist bekannt, dass derselben bei höheren Dosen eine Lähmung folgt. Daher ja die Warnung, bei einer Morphiumvergiftung Emetica zu geben, da dieselben das Brechcentrum doch nicht mehr erregen und nur den Collaps steigern müssen. In unserem Versuche IV war nun offeubar die Dosis für dieses Centrum nicht hinreichend, um die Lähmung herbeizuführen, denn die Brechneigung dauerte nicht nur während des ganzen Versuches an, sondern war noch am folgenden Morgen bemerklich, und steigerte sich plötzlich in dem Maasse, dass ohne lange Nausea Erbrechen eintrat. Wir sehen remnach auch hier einen andauernden Erregungszustand, welcher fortbesteht, während die hypnotische und lähmende Wirkung an anderen Hirntheilen schon längst ihren Verlauf genommen und normalen Verbältnissen Platz gemacht hat.

Die Veränderungen, welche durch 0,01 g Morph. mur. (subcutan) an dem Bewegungsapparat meiner Augen hervorgerufen werden, sind also im Wesentlichen eine Verminderung der Contractionsenergie der Seitenwender und eine Veränderung des Fusionsfernpunktes in der Weise, dass die Fähigkeit zur Ueberwindung von Abductionsprismen gesteigert wird. Es muss auffallen: dass die Fusion im Sinne der Adduction so wenig beeinflusst ist. Bei einigen Versuchen ist der Nahepunkt etwas abgerückt, bei anderen so gut wie unverändert, eine Annäherung habe ich aber niemals gefunden. Möglich, dass die verhältnissmässig bedeutende Schwächung der Interni eine besondere Anstrengung derselben 
nicht mehr zuliess. Doch sind zur Klarstellung dieser Frage noch weitere Versuche erforderlich, welche ich später anzustellen gedenke.

Von der Veröffentlichung der übrigen, mir noch zur Verfügung stehenden Versuchsprotokolle kann ich absehen, da in ihnen kein wesentlich anderes Bild zu Tage tritt.

$$
\text { C) Chloralbydrat. }
$$

Als Nebenerscheinungen der Chloralwirkung sind sowohl bei medicinalen wie toxischen Dosen mehrfach Störungen an den Augenmuskeln beobachtet. So erwähnt Mondeville ${ }^{1}$ ) einen Patienten, der wegen Zahnschmerzen 3 Dosen à 30 Gran Chloral genommen hatte, und darauf in einen unwiderstehlichen Schlaf verfiel, der bis zum nächsten Tage dauerte. Als er erwachte, bestand eine lebhafte Conjunctivalreizung und Doppelsehen, welches 3 Tage lang anhielt. Welche Muskeln speciell in ihrer Thätigkeit gestört waren, ist nicht festgestellt, wenigstens im Referat nicht erwähnt. Eine häufige Folge der Chloralwirkung scheinen solche Störungen der äusseren Muskeln indessen nicht zu sein. Bei Vergiftungen lässt sich in der Regel nur das Verhalten der Pupillen prüfen, und beobachtet man hier meistens Myosis, von welcher Schiff behauptet, dass eine reflectorische Erweiterung auf sensible Reize nicht mehr stattfinde. Nach hohen Dosen, oder lange fortgesetztem Gebrauche ist aber auch Mydriasis beobachtet. Dass auf Störungen der Augenbewegungen beim medicinalen Gebrauche des Chlorals geachtet sei, ist mir nicht bekannt, und dürften solche mit den üblichen Hilfsmitteln auch kaum nachzuweisen sein.

Bekanntlich wird das Medikament meistens verabfolgt, um Schlaf und Beruhigung motorischer Erregung herbeizuführen, und zwar ist das Zweite nicht unmittelbar als die Folge des Ersten anzusehen, sondern es scheint auch eine besondere Beeinflussung der motorischen Sphäre zu den Eigenthümlichkeiten des Mittels zu gehören. Dieselbe ist indessen nicht selten der beabsichtigten entgegengesetzt, obschon man eine excitirende Wirkung hier nicht so häufig findet, wie beim Morphium. Auch kann man nicht sagen, dass dem Stadium der Lähmung stets ein solches der Frregung vorhergehe; ausnahmsweise wird aber doch statt Schlaf Schlaflosigkeit erzeugt, und zwar

1) Americ. journ. of the medic. scienc. oct. 1872. Ref. in Ophthal. Jahresberichte 1872 S. 458. 
Ueber den Einfluss von Giften auf den Bewegungsapparat der Augen. 361

nicht etwa nur nach kleinen Dosen, sondern auch nach stärkeren (bis zu $3 \mathrm{~g}$ ) sind Erregungszustände beobachtet. Bei längerem Gebrauche ist es sogar recht häufig, dass das Mittel versagt, und wegen der Unruhe und Aufregung, welche es hervorruft, ausgesetzt werden muss. Nach Mittheilung der Neurologen treten bei Neurasthenie und Hysterie oft solche Zustände ein, die sich mitunter bis zu Delirien mit Hallucinationen steigern. Dieselben können unmittelbar nach Verabfolgung des Mittels beginnen in Form von Schreck- und Angstzuständen, ganz entsprechend dem Bilde der Alkoholdelirien, also mit hoher motorischer Erregung. Dieser Zustand kann in 5-10 Minuten vorübergehen, oder auch lange anhalten und schliesslich in Collaps und Tod endigen. Bei Epileptikern ist durch Chloralhydrat ein Häufigerwerden der Anfälle beobachtet, desgleichen bei Tobsüchtigen eine Steigerung der Erregung. Anderseits treten auch centrale Lähmungszustände auf, eingeleitet von Kopfschmerzen und Schwindelgefühl, desgleichen Gefühlsstörungen mit lähmungsartigem Charakter. Nach längerem Gebrauche finden sich Schwäche der Gliedmaassen, unsicherer, schwankender Gang, Ataxie, unter Umständen Krämpfe in symmetrischen Muskeln und Paramyoclonus. Aehnliches kommt vor beim chronischen Chloralismus ${ }^{1}$ ).

Die den obigen analogen Versuche Kraepelin's mit diesem Mittel führten den Autor zu der Annahme, dass dasselbe im Gegensatze zu anderen Narkoticis nur lähmende Wirkungen habe. Besonders findet er interessant den Gegensatz zur Paraldehyd wirkung, insofern die durch beide Mittel erzeugte Narkose äusserlich ähnlich sei, während die bei dem letzteren nachweisbare motorische Erregbarkeitssteigerung bei dem ersteren sich nicht finde. Auch andere Forscher constatirten Herabsetzung der Sensibilität und Motilität (D e Sarlo \& Bernardini). Kraepelin findet, wenn er die Wirkung von Alcohol, Paraldehyd und Chloral vergleicht, dass das letztere die motorischen Funktionen von vornherein, oder doch sehr bald und schon in kleinen Gaben lähme, der Alkohol erst spät nach anfänglicher Erregung, oder bei höherer Dosis, das Paraldehyd gar nicht oder nur in sehr grossen Mengen. Nach den (1. c.) beigefügten Curven zeigt das Chloralhydrat sofort nach Einnahme von $1 \mathrm{~g}$ eine Lähmung der motorischen Erregbarkeit, welche zwar weniger intensiv ist, als die der sensorischen und intellectuellen Vorgänge, aber doch

1) Siehe Lewin l. c., wo auch die Literatur angegeben ist. 
gleichmässig ansteigt, so dass sie nach einer Wirkungsdauer von etwa ${ }^{3 / 4}$ Stunden ihr Maximum erreicht, um dann allmählich wieder abzunehmen. Damit stimmen überein die Angaben von Rossi ${ }^{1}$, welcher auf $2 \mathrm{~g}$ Chloral am Ergographen eine erhebliche lähmende Wirkung feststellte, die nach Ablauf einer Stunde am stärksten war.

Nach diesen experimentellen Untersuchungen ist also die Einwirkung auf die Muskulatur im Allgemeinen eine lähmende und die Leistungsfähigkeit herabsetzende, indem nicht nur die Auslösung von Bewegungen wahrscheinlich verlangsamt (K ra e p eli n), sondern auch die grobe Kraft vermindert wird (Rossi). Als besondere Einwirkung auf die Augenbewegungen ist bereits erwähnt das Doppelsehen, welches aber in seiner klinischen Erscheinungsweise nicht näher geschildert ist (Referat). Die lähmende Wirkung des Mittels kann ich aus meinen Versuchen für die Augenmuskeln bestätigen, und zwar zeigt sich dieselbe schon nach verbältnissmässig kleinen Dosen in sehr ausgesprochenem Maasse, namentlich im Vergleiclie zur hypnotischen Wirkung.

I.

Vor dem Versuche 1. Int. 27, 1. Ext. 20; r. Int. 25, Ext. 23. 9 h $30^{\prime} 1 \mathrm{~g}$ Chloralhydrat. $10^{\mathrm{h}} 30^{\prime}$ heginnt. sich erst eine schwache hypnotische Wirkung bemerklich zu machen. Die alsdann vorgenommene Schnelligkeitsmessung ergibt 1. Int. 22, 1. Ext. 15,3; r. Int. 21,6, r. Ext. 20.

$11 \mathrm{~h}$. Hypnotische Wirkung jetzt deutlicher. L. Int. 20,6, 1. Fixt. 15; r. Int. 20,3, r. Ext. 19,6. Fusionsnahepunkt und -Fernpunkt zeigten sich bei jeder Untersuchung, trotz der deutlichen Schwäche der Muskeln, normal. Accommodation und Pupille gleichfalls.

Am folgenden Morgen hatten die Muskeln wieder die normalen Werthe. In den späteren Versuchen wurde das Eintreten der hypnotischen Wirkung nicht mehr abgewartet, sondern von Anfang an in regelmässigen Pausen das Verhalten aller in Betracht kommenden Functionen geprüft.

II.

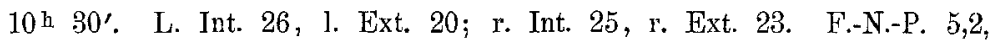
F.-F.-P. $10^{\circ}$. Pupille 4,5 .

10h $40^{\prime}$. $1 \mathrm{~g}$ Chloralhydrat.

Während der ersten zehn Minuten wurden alie zwei Minuten Stichproben an einzelnen Muskeln vorgenommen. Da sich in dieser Zeit gar keine Veränderungen zeigten, wurden dieselben von da ab nur alle fünf Minuten wiederholt, bis die ersten Veränderungen auftraten. Alsdann Fortsetzung wie gewöhnlich, dazwischen auch alle fünf Minuten die Fusion und die Pupille untersucht. Die erste Veränderung zeigte sich $11^{\text {b }} 30^{\prime}$ und zwar an beiden Interni.

1) l. $\mathrm{c}$. 
Ueber den Einfluss von Giften auf den Bewegungsapparat der Augen. 363

$11^{\text {h }} 30$ \% L. Int. 22,6; r. Int. 21. Die Externi normal. F.-N.-P. 5,5, F.-F.-P. wie oben. Hypnotische Wirkung kaum vorhanden.

$11^{\text {h }} 45^{\prime}$ bis $55^{\prime}$. L. Int. 21,3 ; r. Int. 20,6. An den Externi noch immer keine Veränderung. F.-N.-P. 5,3, F.-F.-P. wie oben. Papille 5,5-6,0.

$12^{\mathrm{h}} 5^{\prime}$ bis $15^{\prime}$. L. Int. 22 , 1. Ext. $19 ;$ r. Int. 20, r. Ext. 21. Hypnotische Wirkung immer noch schwach. F.-N.-P. 5,8, F.-F.-P. unverändert. Pupille $4,5-5,0$. Versuch beendigt.

Schlaf darauf fest, keine Nachwehen an folgenden Morgen.

8 h $45^{\prime}$. L. Int. 27, 1. Ext. 22; r. Int. 26, r. Fxt. 24 . F.-N.-P. 5,3, F.-F.P. $10^{\circ}$. Pupille 4,0 .

In beiden Versuchen fällt zunächst auf das späte Eintreten einer Wirkung, nämlich jedes Mal erst nach Ablauf von beinahe einer Stunde, obschon die Dosis für ein von jedem Erregungszustande freies Nervensystem doch keine so geringe war. Das erste Mal war die Störung insofern erheblicher, als auch die Externi sich betheiligten, während dieselben im zweiten Versuche vollkommen leistungsfähig blieben, oder wenigstens nur eine Herabsetzung bemerken liessen, die auch als physiologische Schwankung vorkommt. Der Fusionsnahepunkt war zeitweise etwas abgerückt, aber nur um wenige Millimeter, so dass man hieraus eine Insufficienz der Interni, die in gewissem Sinne ja vorhanden war, wohl nicht hätte diagnosticiren können. 'Abweichend von der Regel ist die, wenn auch nur kurzdauernde, aber doch sehr deutliche Erweiterung der Pupille.

Es wurden ausserdem noch Versuche mit stärkeren Dosen angestellt, von welchen das folgende Protokoll ein Beispiel gibt.

\section{III.}

9 h $20^{\prime}$ bis $30^{\prime}$. L. Int. 27, l. Ext. 20; r. Int. 25, r. Ext. 23. Pupille 4,5-5,0. F.-F.-P. $10^{\circ}$ (leicht), bei $12^{\circ} \mathrm{1} / 2 \mathrm{~cm}$ Abstand. F.-N.P. 5,2.

$9 \mathrm{~h} 40^{\prime}$. 2 g Chloralhydrat.

9 b $50^{\prime}$ bis $55^{\prime}$. Aeussere Muskeln sämmtlich normal. Pupille 4,5. F.-N.-P. 5,5, F.-F.-P. $10^{0}$ nur vorübergehend, alsdann $1 / 2-1 \mathrm{~cm}$ Abstand, bei $12^{0} 4-5 \mathrm{~cm}$ Abstand.

$10^{\mathrm{h}} 0^{\prime}$ bis $10^{\prime}$. Externi normal, aber beginnende Abnahme an den Interni, nämlich links 22,6, rechts 21,3. F.-N.-P. 6,0. Mit Glasstab oder Prisma ist eine Gleichgewichtsstörung oder Insufficienz der Jnterni nicht nachweisbar, indem die beiden Bilder genau dasselbe Verhältuiss zeigen, wie in normalem Zustande. F.-F.-P. $8^{\circ}$; bei $10^{0} 2 \mathrm{~cm}$ Zwischenraum. Pupille 4,5. Hypnotische Wirkung fängt an sich bemerkbar zu machen.

$10^{\mathrm{h}} 20^{\prime}$ bis $30^{\prime}$. Externi normal. Int. links 21,3, rechts 20,3 . F.-N.-P. 6,3, F.-F.-P. wie oben. Schläfrigkeit deutlich, aber noch leicht zu überwinden. Pupille unverändert. 
$10^{\text {In }} 40^{\prime}$ bis $50^{\prime}$. Jetzt auch die Externi geschwächt. L. Int. 19,6, 1. Ext. 17,6; r. Int. 20, r. Ext. 21, F.-F.P. wie oben, F.-N.-P. 6,6. Pupille 4,5.

$11 \mathrm{k} 15^{\prime}$ bis $25^{\prime}$. L. Int. 18,3 , l. Ext. 20 ; r. Int. 19,6, r. Ext. 21,6 . F.-F.-P. $8^{0}$ wie oben. F.-N.-P. 6,0. Pupille 4,5. Hypnotische Wirkung nicht merklich gesteigert.

Schlaf danach fest. Beim Erwachen am folgenden Morgen noch entschiedenes Schlafbedürfniss.

8 3 30' Vorm. L. Int. 27, I. |Ext. 20; r. Int. 25, r. Ext. 24. Pupille 3,5-4,0. F.-N.-P. 5,4, F.-F.-P. $10^{0}$, bei $12^{\circ} 1 \mathrm{~cm}$ Zwischenraum.

Der grösseren Dosis entsprechend sehen wir hier die Wirkung schon nach 20 Minuten eintreten und zwar wiederum zuerst an den Interni, welche auch im weiteren Verlaufe am meisten geschwächt werden, so dass schliesslich das Verhältniss zu den Externi sich umkehrt. Denn obschon auch bei diesen eine Abschwächung sich allmälig bemerkbar machte, zeigten sie vorübergehend eine grössere Contractionsenergie, als die Interni. Die Abschwächung der Externi ist keine sehr auffällige und steht in keinem unmittelbaren Zusammenhange mit der sich schon vorher geltend machenden verminderten Fähigkeit, Abductionsprismen zu überwinden. Es ist letzteres bei diesem Versuche sogar das erste Zeichen einer Einwirkung, welches auftritt $\mathrm{zu}$ einem Zeitpunkte, wo alle übrigen Funktionen noch unverändert sind. Bereits nach 10-15 Minuten erweist sich dasjenige Prisma zu stark, welches vor dem Versuche noch mit Leichtigkeit überwunden wurde. Nach 20-25 Minuten hat diese Abschwächung der Fusionsfähigkeit ihren Höhepunkt erreicht, wenigstens trat während der Versuchsdauer keine Veränderung mehr ein. Diese Abschwächung der Fusionsfähigkeit war jedes Mal sehr deutlich, wenn mit grösseren Dosen (von $2 \mathrm{~g}$ an) operirt wurde, zeigte sich aber nicht immer zuerst bei der Abduction, sondern in anderen Fällen, und vielleicht noch stärker in Bezug auf den Nahepunkt. Es ist selbstverständlich, dass diese Eigenthümlichkeit des Chlorals meine Aufmerksamkeit, gleich bei ihrem Auftreten, ganz besonders auf die Leistungsfähigkeit der äusseren Muskeln lenkte, da ich naturgemäss in einer Schwäche dieser die Ursache für die Einschränkung der accommodativen Bewegungen vermuthete. Es gelang mir aber nicht, einen Zusammenhang zwischen beiden Erscheinungen wahrzunehmen, vielmehr komte ich mich mit Sicherheit davon überzeugen, dass die Energie der Seitenbewegung noch gänzlich ungeschwächt war zu einer Zeit, wo die Fusionsfähigkeit schon 
eine deutliche Verminderung erkennen liess. Auch diese Beobachtung ist also zu denjenigen zu rechnen, welche auf verschiedene Centren für beide Vorgänge hinweisen. Man könnte bei Versuch III im Zweifel sein, wie sich die Sache in Bezug auf die Interni verhält. Das Abrücken des Nahepunktes trat hier zu gleicher Zeit auf mit der Herabsetzung der Interni-Werthe. Trotzdem sehen wir nicht eine eigentliche Insufficienz sich ausbilden, da eine Gleichgewichtsstörung nicht nachweisbar ist. Dass eine Schwäche der Interni sich nur durch ein Abrücken des Convergenznahepunktes zu erkennen gäbe ohne Schwankungen der Gleichgewichtslage, entspricht nicht unseren sonstigen Erfahrungen über diesen Zustand. Im Gegentheil wissen wir, dass selbst bei ausoesprochener Insufficienz der Interni durch eine besondere Innervationsanstrengung der Convergenznahepunkt sich fast unverändert zeigen kann, so dass durch den von v. Graefe angegebenen Prismenversuch erst eine grössere Sicherheit der Diagnose erzielt wurde. Die Verminderung der Contractionsgeschwindigkeit, wie sie sich in unseren Versuchen ergab, bedeutet keine solche Abschwächung der Muskelkraft, dass hierdurch die Externi ein wirkliches Uebergewicht bekämen. Vielmehr ist die Abschwächung eine so geringe, dass sie sich durch anderweitige Veränderungen der Leistungsfähigkeit gar nicht zu erkennen gibt. Man wird also auch hier zu der Annahme gedrängt, dass das Hinausrücken des Fusionsnahepunltes ebenfalls als eine besondere centrale Wirkung anzusehen ist, zu deren Frklärung die geringe Schwäche der Interni, welche sich in den obigen Zahlen ausdrùckt, nicht genügt. Diese Ansicht gewinnt um so mehr an Wahrscheinlichkeit, als das Hinausrücken des Nahepunktes sich schon sehr entschieden zu einem Zeitpunkte bemerklich machen kann, wo die Contractionsenergie noch vollkommen in normalen Grenzen bleibt. Hierfür ein Beispiel.

\section{IV.}

9и 50'. L. Int. 29, 1. Ext. 21; r. Int. 27, r. Ext. 25. F.-N.-P. 4,8, F.-F.-P. $10^{\circ}$ leicht, bei $12^{\circ} 1 / 2-1$ cm Zwischenraum. Pupille $4,0-4,5$.

$10^{\mathrm{h}} 15^{\prime}$. 2,5 g Chloralhydrat.

10h 20'. Stichproben an r. Int. und Ext. normal. F.-N.-P. und F.-F.-P. wie oben.

$10^{\text {h }} 25^{\prime}$. F.-N.-P. 5,2. Sonst alles unverändert.

$10^{\mathrm{h}} 30^{\prime}$. F.-N.-P. 5,5, F.-F.-P. wie oben. Stichproben 1. Int. 27, r. Int. 26.

$10 \mathrm{~h} 35^{\prime}$. F.-N.-P. 6,0. Dabei sehr schnelle Ermüdung, so dass er nach jeder Einstellung weiter abrückt. Beginnende Schläfrigkeit. 
$10^{\mathrm{h}} 40^{\prime}$ bis $50^{\prime}$. L. Int. 23,6 , 1. Ext. 20,6; r. Int. 23,3 , r. Ext. 23 . Mit Glasstab and Prisma keine Gleicligewichtsstörung. F.-F.-P: bei $10^{\circ}$ keine vollständige Deckung mehr (ca $1 \mathrm{~cm}$ Abstand), bei $12^{0} 4-5 \mathrm{~cm} \mathrm{Zwischenraum,} \mathrm{rasch}$ zunehmend auf etwa $10 \mathrm{~cm}$. F.-N.-P. 6,3, bei drei Einstellungen starkes Müdigkeitsgefühl. Pupille unverändert.

$11^{\text {h }} 0^{\prime}$ bis $10^{\prime}$. L. Int. 20,3, l. Ext. 19 ; r. Int. 20, r. Ext. 21. F.-F.-P. $8^{0}$ wird überwunden, bei $10^{\circ}$ Schwankungen von $2-5 \mathrm{~cm}$, bei $12^{\circ} 5-10 \mathrm{~cm}$. F.-N.-P. 6,3. Glasstab und Verticalprisma ergehen keine Gleichgewichtsstörung.

$11^{\mathbf{h}} 20^{\prime}$ bis $30^{\prime}$. Keine Aenderung. Man erhält fast dieselben Zablen. Versuch beendigt.

Während der Nacht fester Schlaf. Keine Nachwehen beim Erwachen.

8 h Vorm. L. Int. 30, 1. Ext. 22 ; r. Int. 27, r. Fxt. 27. F.-F.-P. 89, bei $10^{\circ} 1 / 2-1 \mathrm{~cm}$. F.-N.-P. 5,3. Schnelle Ermüdung.

2h. F.-N.-P. 4,8. F.-F.-P. $10^{\circ}$ leicht, vorübergehend $12^{\circ}$.

Das Abrücken des Nahepunktes zeigt sich hier als erste Wirkung nach Einnahme des Mittels und nimmt während der nächsten 10 Minuten noch weiter zu, während nun erst eine Abnahme an den Interni bemerkbar wird, die sich rasch steigert. Alsdann kommt der Fusionsfernpunkt an die Reihe, und diesem folgen schliesslich die Externi. Am folgenden Morgen ist die Fusion noch in jedem Sinne geschwächt, während die Muskeln selbst ihre volle Leistungsfähigkeit zeigen. Erst um 2 Uhr ist jede Wirkung verschwunden.

Das Gefühl der Schläfrigkeit trat auch hier viel später ein, als die Beeinflussung der Muskelthätigkeit. Bei der fortgesetzten Anspannung der Aufmerksamkeit kann die hypnotische Wirkung naturgemäss nicht in der Weise zur Geltung kommen, wie dies bei rubigem Verhalten zu erwarten wäre. Dieselbe kann daher überhaupt nicht als Maassstab für die Beeinflussung der Nervencentren angesehen werden, und ist jedenfalls nicht einer so scharfen Controle zugänglich, wie wir sie für die Innervation der Muskulatur auszuüben in der Lage sind.

\section{D) Paraldehyd.}

Bei chronischem Missbrauche dieses Mittels, welcher trotz des schlechten Geschmackes zuweilen vorkommt, sind Zustände, ähnlich dem Alkoholismus, beobachtet, und betheiligt sich auch die Muskulatur in analoger Weise (Schwäche, Tremor, schwankender Gang). Bei vorübergehender Anwendung gilt das Paraldehyd aber als eines der harmlosesten Narkotica, bei welchem unangenehme Nebenwirkungen kaum vorkommen. Jedenfalls ist nicht bekannt, dass 
Ueber den Einfluss von Giften auf den Bewregungsapparat der Augen. 367

bestimmte Centren oder Abschnitte des Nervensystems in besonderem Maasse einer nachtheiligen Wirkung ausgesetzt wären. Kraepelin findet eine gewisse Aehnlichkeit von Paraldeybd und Alkohol, insofern auch bei dem ersteren eine centrale motorische Erregbarkeitssteigerung sich geltend mache. In der Curve, welche (l. c.) die Wirkung von $2 \mathrm{~g}$ rlarstellt, erreicht diese Erregung ihr Maximum nach etwa 20 Minuten und ist nach 40 Minuten abgelaufen, um einer geringen Verminderung Platz zu machen. Dass dieses in dem klinischen Bilde der Paraldehydwirkung nicht hervortrete, führt Kraepelin auf die sehr starke Schläfrigkeit zurück, welche den Zugang Bewegung auslösender Reize in viel höherem Maasse abschneide, als beim Alkohol. Wir befänden uns somit gewissermaassen sofort im zweiten Stadium eines sehr intensiven Rausches, in welchem weder von aussen, noch aus unserem Gedankengange eine Anregung zur Auslösung von Willensbewegungen zur Entwickelung gelangen könne. Durch Aufbietung grosser Anstrengung, sei dies aber doch zu erzwingen und die Umsetzung äusserer Anregung in Bewegung sei alsdann eher erleichtert als erschwert. Insofern bestehe, wie schon oben bemerkt, ein scharfer Gegensatz zwisehen Paraldehyd und Chloral.

In Uebereinstimmung hiermit konnte ich feststellen, dass auch bezüglich der Augenmuskeln dieser Gegensatz sich findet, indem der bei dem letzteren Mittel so deutliche lähmende Einfluss durch das erstere kaum zu erzielen ist. Frst bei Anwendung der Maximaldosis macht er sich bemerklich, und alsdann auch nur in geringem Maasse, während, wie wir sahen, schon relativ kleine Dosen Chloral, welche noch keine erhebliche hypnotische Wirkung hervorrufen, sehr deutlich die Schnelligkeit der Contraction beeinflussen. Hierzu einige Versuchsprotokolle, bei welchen wir uns, da sie fast negativ sind, kurz fassen können.

I.

9 h $45^{\prime}$. L. Int. 27, 1. Ext. 20; r. Int. 26, r. Ext. 24. F.-N.-P. 5,1. F.-F.-P. $10^{\circ}$. Pupille 4,5 .

9h. 55'. 3,0 g Paraldehyd.

$10^{\mathrm{h}} 5^{\prime}$. Stichprobe am 1 . Int. línd $r$. Ext. unverändert, die übrigen Werthe gleichfalls.

$10^{\mathrm{h}} 30^{\prime}$. F.-N.-P. 5,3. Sonst alles wie oben. Schläfrigkeit.

$10^{\mathrm{h}} 45^{\prime}$. Alles normal. Starke Schläfrigkeit.

11 h. Pupille 4,0. F.-N.-P. 5,2. Im Uebrigen keine Aenderung. 
II.

9b. 4ّ̌'. L. Int. 27, 1. Ext. 22 ; r. Int. 27, r. Ext. 24. F.-N.-P. 5,4. F.-F.-P. $10^{\circ}$ leicht, $12^{\circ}$ vorübergehend. Pupille 4,5 .

9 h 55'. 5 g Paraldehyd.

$10^{\mathrm{h}} 5^{\prime}$. Stichproben an 1. Int. und $\mathrm{x}$. Ext. normal. F.-N.-P. und F.-F.-P. desgleichen. Pupille wie oben.

$10 \mathrm{~h} 25^{\prime}$ bis $35^{\prime}$. Dasselbe.

10 h $45^{\prime}$ bis 55'. L. Int. 21, 1. Ext. 21; r. Int. 24, r. Ext. 23. Die übrigen Werthe normal. Schlafbedürfniss.

$11^{\text {h }} 5^{\prime}$ bis $15^{\prime}$. L. Int. 23,6 , 1. Ext. 20 ; r. Int. 23, r. Ext. 23 . Sonst normal.

Also selbst bei dieser grossen Dosis fand sich erst nach Ablauf einer Stunde eine Herabsetzung der Contractionsenergie an den Interni, besonders deutlich ausgesprochen links, während sie am rechten geringer war. Bis zur Beendigung des Versuches war dieselbe noch nicht ausgeglichen. Eine Einwirkung auf die. Fusionscentren war gar nicht zu bemerken. Die übrigen Protokolle zeigen dasselbe Bild.

\section{E) Sulfonal.}

Bei diesem Hypnotikum findet man eine starke Beeinflussung der motorischen Sphäre, sobald wegen zu grosser Dosis oder besonderer Empfindlichkeit des Individuums Vergiftungserscheinungen zu der Schlaf machenden Wirkung hinzutreten. Die Angriffspunkte für das Sulfonal sind die Hirnrinde und die motorischen Centren des Rückenmarkes (Lewin). In welchem Maasse und in welcher Zeit es die Muskelkraft beeinflusst, scheint bisher nicht näher studirt zu sein. Wir wissen, dass die hypnotische Wirkung sehr häufig erst spät eintritt, so dass man immer mehrere Stunden vor dem beabsichtigten Schlafe dasselbe verabfolgen muss. Ja, die Wirkung ist so unsicher, dass mitunter während der nächsten Nacht überbaupt nicht, sondern erst am folgenden Tage sich Schlaf einstellt. In anderen Fällen wird gar keine Beruhigung erzielt, sondern im Gegentheil Erregung. Bei schweren Vergiftungen sind lähmungsartige Zustände an den Gliedmaassen und Ataxie beobachtet, welchen Symptomen zuweilen Delirien und Muskelunruhe vorangingen. In leichteren Fällen zeigte sich nur Mattigkeit und Schwindel mit ausgesprochenen Störungen des Gleichgewichtes. Dazu kann sich an Armen und Beinen eine Ataxie entwickeln, welche an die der Tabiker erinnert. Auch können sich nur an einzelnen Muskelgruppen Störungen zeigen, wie Zittern und klonische Zuckungen. Jene Läh- 
mungszustände, welche Lew in einer Aufhebung der motorischen Rindenfunction zuschreibt, können einen solchen Grad erreichen, dass das Gehen, selbst mit Unterstützung, unmöglich wird. Solche Erscheinungen finden sich sowohl nach einmaligen Gaben, wie nach länger fortgesetztem Gebrauche. Bei Morphinisten sollen Bewegungsstörungen durch die Einwirkung des Medicamentes ganz besonders leicht auftreten ${ }^{1}$ ). Auch wenn die Schlaf machende Wirkung vorüber, bleibt mitunter lange Zeit eine erhebliche Beeinträchtigung der Muskelfunctionen, von blosser Mattigkeit der Glieder bis zur vollständigen Gebrauchsunfähigkeit, so dass selbst Nahrungsaufnahme nicht mehr ohne fremde Hilfe möglich ist. Solche Zustände können wochenlang andauern. Ferner sind beobachtet mehrtägige Ptosis, halbseitige Gesichtslähmung, Schwerfälligkeit der Sprache und Zungenbewegung, Lähmung der Sphincteren von Blase und Mastdarm u. s. w. (s. Lewin 1. c.).

Als anatomischen Befund beschreibt $\mathrm{Helwe} \mathrm{g}^{2}$ ) bei einer Frau, welche drei Monate lang jeden Abend $1 \mathrm{~g}$ Sulfonal gebraucht hatte, im Rückenmarke, und zwar besonders im untersten Theile, eine Degeneration und Verminderung aller Nervenzellen der Vorder- und Hinterhörner, wie bei akuter Myelitis.

Eine nachtheilige Wirkung auf die Muskelthätigkeit konnte ich nun durch meine Versuche vollauf bestätigen. Da ich bei persönlichem Gebrauche das Sulfonal bisher nur als ein wenig wirksames und unzuverlässiges Hypnoticum kennen gelernt hatte, so war ich gerarlezu überrascht durch die Ergebnisse der Schnelligkeitsmessung. Dieselben zeigten in vielen Versuchen eine so deutliche Herabsetzung der Leistungsfähigkeit, dass ich anfangs an technische Versuchsfehler glaubte, bis ich mich durch fortgesetzte Beobachtungen überzeugte, dass hier thatsächlich eine Sulfonalwirkung vorlag. Besonders auffallend ist die Schnelligkeit, womit dieselbe in einzelnen Versuchen auftrat.

Wir sind gewohnt, das Sulfonal als ein sehr langsam, aber auch cumulativ wirkendes Mittel anzusehen, theils wegen seiner geringen Löslichkeit, theils wegen der Bestäridigkeit des Sulfonalmolecüls. Die Aufnahme erfolgt aber jedenfalls schneller, als die Ausscheidung. Fs ist eine Ansammlung des Mittels im Körper erforderlich, und

1) Jastrowitz, Verhandl. d. Ver. f. innere Medicin Bd. 9. Berlin 1890.

2) Hospital Tidende 1892 Bd. 10. 
erst, wenn dieselbe ein gewisses Maass erreicht hat, sehen wir die Schlaf machende Wirkung eintreten. Wegen dieses Verhaltens erfreut sich das Medicament schon längst des Rufes einer grossen Unsicherheit und Unzuverlässigkeit, und hat sich derselbe auch in unseren Versuchen bewahrheitet. Ich habe mich bemüht, den Einfluss des Mittels auf die Leistungen der Augenmuskeln in längeren Sitzungen und mit kleinen Pausen zu studiren, um auch vorübergehende Einwirkungen zu erkennen, habe dieselben aber trotzdem zuweilen gänzlich vermisst, während sie in anderen Fällen sehr deutlich waren, verhältnissmässig früh eintraten und lange genug anhielten, um mehrfach constatirt zu werden. Damit die Resorption sich möglichst gleichmässig gestaltete und von dem jeweiligen Mageninhalte thunlichst unabhängig bliebe, wurde das Medicament in gelöstem Zustande mit dem erforderlichen Quantum Wasser genommen. Nichtsdestoweniger zeigte sich auch unter diesen Umständen die Wirkung sehr unbeständig.

I.

9 h $10^{\prime}$ bis $20^{\prime}$. L. Int. 26, l. Ext. 19 ; r. Int. 25, r. Ext. 22. F.-N.-P. 5,2, F.-F.-P. $10^{\circ}$, bei $12^{\circ} 1-2 \mathrm{~cm}$ Zwischenraum.

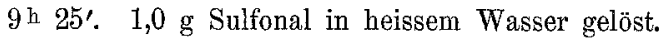

$9 \mathrm{~h} 35^{\prime}$ bis $40^{\prime}$. Rechtswendung (Stichproben) normal. F.-F.-P. und F.-N.-P. wie oben.

$9 \mathrm{~h} 45^{\prime}$. Beide Interni normal.

$9 \mathrm{~h} 50^{\prime}$ bis 55'. L. Int. und Ext. normal. F.-N.-P. 5,3, F.-F.-P. wie oben. $10^{\mathrm{h}} 5^{\prime}$ bis $15^{\prime}$. Ebenso.

$10^{\mathrm{h}} 25^{\prime}$ bis $35^{\prime}$. Alle Prüfungen normal.

$10^{\mathrm{h}} 45^{\prime}$ bis $55^{\prime}$. Beginnende Abnahme an den Interni (trotz grösster Anstrengung). L. Int. 22,6, r. Int. 22. Externi normal. Die Einstellung für die Interni stimmt fast für den wach derselben Richtung drehenden (sonst immer schwächeren) Externus. F.-N.-P. 5,3, F.- F.-P. wie oben. Nit Glasstab und Prisma keine Gleichgewichtsstörung nachzuweisen.

$11^{\mathrm{h}} 15^{\prime}$. Es ist alles wieder normal. Dasselbe bei einer $11^{\mathrm{h}} 25^{\prime}$ vorgenommenen Prüfung. Eine hypnotische Wirkung nicht deutlich vorhanden.

II.

7h 15 ' Abends. L. Int. 27, 1. Ext. 21; r. Int. 26, r. Ext. 25. F.-N.-P. 5,1, F.-F.-P. $10^{\circ}$, bei $12^{1 / 2}-1 \mathrm{~cm}$ Abstand.

$7^{\mathrm{h}} 30^{\prime}$. $1,0 \mathrm{~g}$ Sulfonal, in sehr heissem Wasser bis auf die letzten Spuren gelöst.

$9 \mathbf{h} 0^{\prime}$ bis $10^{\prime}$. Interni scheinen geschwächt. Es gelingt auch bei äusserster Kraftanstrengung nicht, die früheren Werthe zu erreichen. Das Durchschnittsergebniss ist links 25,0 , rechts 23,6. Externi normal. F.-N.-P. und F.-F.-P. unverändert. 
$10^{\text {h }} 20^{\prime}$ bis $30^{\prime}$. L. Int. 23 , 1. Ext. 21 ; r. Int. 23,3 , r. Ext. 24,3. F.-N.-P. 5,1, F.-F.-P. wie oben. Hypnotische Wirkung sehr mässig.

Schlaf danach fest; Aufwachen etwas schwierig.

$7^{\text {h }} 50^{\prime}$ bis $8^{\text {h }}$ Vorm. L. Int. 27, l. Ext. 21; r. Int. 24, r. Ext. 27. F.-N.-P. 5,2, F.-F.-P. $8^{\circ}$, bei $10^{\circ} 1 / 2-1 \mathrm{~cm}$, bei $12^{\circ} 4-5 \mathrm{~cm}$ Zwischenraum.

Diese Zahlen machen durchans noch nicht den normalen Eindruck, da ich um diese Tageszeit (s. u.) meistens viel höhere Werthe fand. Nur der rechte Externus scheint sich seiner vollen Leistungsfähigkeit zu erfreuen, fällt aber auch sehr auf durch sein Verhältniss zu den anderen Seitenwendern. Dieses Verhältniss ist für gewöhnlich ein so festes, dass ich gerade die Störung desselben für eines der sichersten Zeichen einer vorhandenen Abnormität halte.

Die Pupille zeigte sich, nebenbei bemerkt, immer unverändert.

III.

7h Abends. L. Int. 99, 1. Ext. 21; r. Int. 28, r. Ext. 26. F,-N.-P. 4,9, F.-F.-P. $10^{\circ}$, bei $12^{\circ} 2 \mathrm{~cm}$ Zwischenraum.

$7 \mathrm{~h} 20^{\prime} .1 \mathrm{~g}$ Sulfonal, fast vollständig in heissem Wasser gelöst.

7h 55' bis $8 \mathbf{h} 5$ '. Beginnende Abnahme am l. Int. (24). Sonst alles normal. (Die Einstellung wird wiederhoit vorgenommen, und gelingt es, trotz grösster Anstregung, nicht, sich dem früheren Werthe zu nähern).

8h $30^{\prime}$ bis $40^{\prime}$. L. Int. 24, l. Ext. 21; r. Int. 23, r. Ext. 26. Also auch der rechte Internus geschwächt. F.-N.-P. 4,9, F.-F.-P. $8^{\circ}$, bei $10^{\circ} 2 \mathrm{~cm}$, bei $12^{\circ}$ $10 \mathrm{~cm}$ Zwischenraum.

Mit Glasstab oder Prisma keine Gleichgewichtsstörung nachweisbar.

9 h $0^{\prime}$ bis $10^{\prime}$. L. Int. 23,3, 1. Ext. 21; r. Int. 24, r. Ext. 25,6. F.-N.-P. 5,1, F.-F.-P. unverändert.

9 h $40^{\prime}$ bis $50^{\prime}$. L. Int. 23,6, l. Ext. 20; r. Int. 24,3, r. Ext. 24,6. F.-N.-P. こ̌,2, F.-F.P. unverändert.

Mit Prisma oder Glasstab kein Befund.

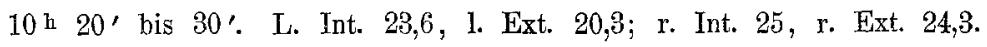
F.-N.-P. 5,1, F.-F.-P. derselbe.

Eine hypnotische Wirkung war bis jetzt überhaupt nicht zu bemerken. Schlaf danach ununterbrochen. Erwachen von selbst $6^{1 / 2}$ Uhr.

Eine Wirkung des Sulfonals auf die Muskelenergie scheint mir nach diesen (und anderen) Versuchen unverkennbar. Es sind hauptsächlich die Interni, welche befallen werden, während, wenigstens bei der angewandten Dosis, die Externi sich ungeschwächt zeigen; der Versuch, die Schwäche in anderer Weise festzustellen, bleibt ohne Ergebniss, insbesondere zeigt sich die Lage des Nahepunktes unverändert. Vorübergehend war die Abductionsfähigkeit vermindert, trotz vollkommener Leistungsfähigkeit der Externi. Dieser Befund kann offenbar wieder nur durch centrale Vorgänge erklärt werden, im Uebrigen ist er inconstant, sowie die Sulfonalwirkung auf die 
Muskeln überhaupt, sowohl in Bezug auf die Zeit des Eintrittes, wie den Grad der Schälligung, also dasselbe Verbalten, wie wir es hinsichtlich der hypnotischen Wirkung schon längst kennen.

\section{F) Trional.}

Dieses dem vorhergehenden chemisch nahe stehende Hypnoticum zeigt auch ein ähnliches Verhalten in seinen Nebenwirkungen, besonders auch hinsichtlich derjenigen auf die Motilität. Dieselben können wiederum theils lähmend, theils erregend sein. Abgesehen von Müdigkeit und Schwächegefühl ist allgemeine Parese mit Erlöschen der Reflexe und Anästhesie beobachtet, unsicherer Gang, Muskelzittern an Extremitäten und Zunge, Schwindelgefühl. Eine Herabsetzung der motorischen Kraft in solchen Zuständen ist wohl zweifellos, es wäre nur festzustellen, ob diese zu den regelmässigen Trionalwirkungen gehört, auch ohne dass schwere Vergiftungserscheinungen auftreten. Anderseits kommen auch maniakalische Zustände vor mit grosser Erregung auf psychischem und motorischem Gebiete, ferner Krämpfe in mehr oder weniger grosser Ausbreitung bis zu allgemeinen epileptoiden Anfällen. Diese Zustände sind aber meist nur bei sehr hohen Gaben beobachtet, und es fragt sich, ob auch bei dem üblichen medicinalen Gebrauche eine Wirkung auf die Muskelthätigkeit festzustellen ist.

Die Schwerlöslichkeit und langsame Aufnahme in den Organismus hat das Trional bekanntlich mit Sulfonal gemein, und musste hierauf bei den Versuchen Rücksicht genommen werden. Es wurde immer in Lösungen von heissem Wasser genommen, und die Beobachtung Stunden lang fortgesetzt.

I.

$10^{\text {h }} 15^{\prime}$ bis $25^{\prime}$. L. Int. 29 , 1. Ext. 23 ; r. Int. 28 , r. Ext. 26 . F.-N.-P. 5,1, F.-F.-P. $10^{\circ}$ leicht, bei $12^{\circ} 1-2 \mathrm{~cm} \mathrm{Zwischenraum.}$

$10 \mathrm{~h} 30^{\prime} .1 \mathrm{~g}$ Trional, fast ganz in heissem Wasser gelöst. Alle zehn Minuten Stichproben an einzelnen Muskeln und Bestimmung der Fusion.

$11^{\mathrm{h}} 15^{\prime}$ bis 25'. Erste Abnahme. L. Int. 25,3, 1. Ext. 21; r. Int. 24, r. Ext. 25,3. F.-F.-P. $8^{\circ}, 10^{\circ}$ konnte schon vor zehn Minuten nur noch vorübergehend überwunden werden, jetzt entschieden zu stark (1-2 cm Zwischenraum), bei $12^{\circ}$ ca. $5 \mathrm{~cm}$ Abstand, rasch zunehmend. F.-N.-P. 5,6. Mit Prisma oder Glasstab keine Gleichgewichtsstörung nachweisbar.

$11^{\text {h }} 35^{\prime}$ bis $45^{\prime}$. L. Int. 25,3 , I. Ext. 21,3; r. Int. 24, r. Ext. 25,6 . F.-F.-P. $8^{\circ}$, bei $10^{\circ} 2-3 \mathrm{~cm}$ Zwischenraum. 
$11^{\text {h }} 55^{\prime}$ bis $12^{\text {h }} 5$ '. L. Int. 23,6, l. Ext. 21; r. Int. 22,3, r. Ext. 25,6. F.-N.-P. 5,5, F.-F.-P. $8^{0}$, bei $10^{0} 2-3 \mathrm{~cm}$, bei $12^{\circ} 8-10 \mathrm{~cm}$ Zwischenraum. Hypnotische Wirkung nicht merklich.

Fs zeigen sich also am meisten wiederum die Interni geschwächt, während das Convergenzcentrum trotzden recht kräftig functionirt. Dagegen hat die Divergenzfähigkeit entschieden nachgelassen, bei kaum angedeuteter Beeinflussung der Externi.

II.

8h Abends. L. Int. 28, 1. Ext. 22; r. Int. 27, r. Ext. 25. F.-N.-P. 5,3, F.-F.-P. $10^{\circ}$, bei $12^{\circ}$ ca. $1 \mathrm{~cm}$ Zwischenraum, bei $14^{\circ} 4-5 \mathrm{~cm}$.

$8 \mathrm{~h} 30^{\prime} .1 \mathrm{~g}$ Trional, fast vollständig in heissem Wasser gelöst.

$10^{\mathrm{h}} 0^{\prime}$ bis $10^{\prime}$. L. Int. 23 , 1. Ext. 21 ; r. Int. 21,3, r. Ext. 25. F.-N.-P 5,2, F.F.P. $10^{\circ}$ nur vorübergehend, bei $12^{\circ} 4-5 \mathrm{~cm}$ Zwischenraum, $8^{\circ}$ wird leicht überwunden. Die Abschwächung der Interni ist unzweifelhaft; es gelingt selbst bei äusserster, fast schmerzhafter Kraftanstrengung durchaus nicht, sich den früheren Werthen zu nähern. Nit Glasstab oder Prisma kein Befund.

$11^{\mathrm{h}} 10^{\prime}$ bis $20^{\prime}$. L. Int. 23,3 , 1. Ext. 21; r. Int. 21,6, r. Ext. 25. F.-N.-P. 5,4, F.-F.-P. unverändert.

Eine hypnotische Wirkung war bis jetzt kaum zu bemerken. Schlaf in der folgenden Nacht fest, Erwachen ohne Nachwehen.

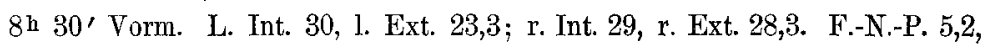
F.-F.-P. $8^{\circ}$, bei $10^{0} 1 / 2-1 \mathrm{~cm}$ Zwischenraum, bei $12^{\circ} \mathrm{ca} .5 \mathrm{~cm}$.

Das Ergebniss ist also, dass trotz ungeschwächter Energie der Externi wiederum die Divergenzfähigkeit vermindert war, während umgekehrt die Convergenz unverändert ist, trotz deutlicher Schwäche der Interni.

III.

8 h Abends. L. Int. 27, l. Ext. 21; r. Int. 26, r. Ext. 25. F.-N.-P. 4,8, F.-F.-P. $10^{\circ}$, vorübergehend $12^{\circ}$.

$8 \mathrm{~h} \mathrm{15}$. $1 \mathrm{~g}$ Trional in heissem Wasser gelöst.

9 h $15^{\prime}$ bis $25^{\prime}$. L. Int. 22, 1. Ext. 21; r. Int. 20,6, r. Ext. 22 (trotz äusserster Kraftanstrengung). F.-N.-P. 5,2, F.-F.-P. $8^{\circ}$, vorübergehend $10^{\circ}$, sonst Zwischenraum von ca. $1 \mathrm{~cm}$, bei $12^{\circ} 5-6 \mathrm{~cm}$, schnell zunehmend bis mindestens $10 \mathrm{~cm}$. Glasstab und Prisma negativ.

10h $15^{\prime}$ bis $25^{\prime}$. L. Int. 20,6, 1. Ext. 20; r. Int. 21,6, r. Ext. 20,6. F.-N.-P. 4,9 , F.-F.-P. $10^{\circ}$, bei $12^{0} 3-4 \mathrm{~cm} \mathrm{Zwischenraum.}$

$11^{\mathrm{h}} 15^{\prime}$ bis $25^{\prime}$. L. Int. 21,6, l. Ext. 21; r. Int. 22,3, r. Ext. 21. F.-N.-P. 5,0, F.-F.-P. wie vorher.

Hauptsächlich sind demnach die Interni geschwächt, doch blieb auch der rechte Externus in diesem Versuche nicht ganz frei. Ganz unverkennbar war aber wiederum die Schwäche des Divergenz- 
centrums. Eine Täuschung oder die Einwirkung anderer zufälliger Einflüsse kann hier nicht vorliegen, da ich in zahlreichen Controlversuchen eine Abnahme der Divergenzfähigkeit niemals gefunden habe. Der zu Anfang festgestellte Werth bleibt in der Norm während des ganzen Abends unverändert, und schliesst auch anderseits die regelmässige Wiederkehr derselben Erscheinungen jeden $\mathrm{Zweifel}$ in Bezug auf den ursächlichen Zusammenhang aus. Im Wesentlichen ist dies nämlich dasselbe Bild, welches ich auch in anderen Versuchen fand, die ich nicht näher anzuführen brauche. Die Aehnlichkeit mit der Wirkung des Sulfonals ist unverkennbar. Wir sehen deutlich eine Abschwächung der Muskelenergie, und zwar eigentlich nur an den inneren geraden Muskeln und schon bei einer Dosis, welche kaum eine Neigung zum Schlafe hervorruft. Auch hier kommen hauptsächlich wieder centrale Wirkungen in Frage, wie die Unabhängigkeit der im Interesse der Fusion stattfindenden Leistungen von der absoluten Muskelkraft beweist.

G) Cocain.

Die Nebenwirkungen dieses Mittels sind sehr zablreich, und nach jeder Art des Gebrauches beobachtet, sowohl nach Einspritzungen unter die Haut, wie nach Anwendung an den verschiedensten Schleimhäuten und Körperhöhlen, ja sogar schon nach Einträufelungen in das Auge. Die örtlichen Wirkungen interessiren uns hier weniger, sondern nur die in Folge der Resorption hervorgerufenen. Dieselben sind sehr mannigfaltig und wechselnd bei versebiedenen Personen und auch nicht immer der angewandten Dosis entsprechend. Einen besonderen Rang beanspruchen die in Bezug auf die motorischen Functionen beobachteten Erscheinungen, und nehmen gerade diese im Krankheitsbilde der Cocainvergiftung einen hervorragenden Platz ein. Bekannt sind die sogenannten Cocainkrämpfe, welche sowohl bei ganz gesunden Personen, als auch namentlich bei solchen auftreten, welche zu Krampfanfällen neigen. Dieselben sind in allen Graden beobachtet, von leichten klonischen Zuckungen einzelner Muskeln bis zu heftigen choreaartigen und schüttelnden Bewegungen des ganzen Körpers. Auch allgemeine, längere Zeit andauernde Muskelstarre ist beschrieben, welche mit klonischen Zuckungen und automatischen Bewegungen wechseln kann. Nicht selten ist allgemeines Muskelzittern, welches sich mitunter wieder zu heftigen klonischen oder tonischen Krämpfen aller oder einzelner Körpertheile 
steigert. Schon nach Einträufelung in das Auge sind solche Zustände beschrieben ${ }^{1}$ ). Seltener ist eine lähmende Wirkung. Dieselbe kann sich zeigen in Form von Müdigkeit, Schwere der Gliedmaassen, Coordinationsstörungen, unsicherem Gang, oder auch auf einzelne Muskeln oder Muskelgruppen beschränkt bleiben. So sah man Lähmung des musc. frontal. nach Einträufelung in das Auge, nach Injection in das Zahnfleisch Lähmung der Gliedmaassen auf der injicirten Seite $\mathrm{u}$. s. w.

Am Auge ist bekannt die durch Reizung des Sympathicus hervorgerufene Erweiterung der Lidspalte und die der Pupille. Letztere findet man nicht nur nach örtlicher Anwendung, sondern auch nach Resorption des Mittels von entfernten Körperstellen, und wird sie auch in diesem Falle als Folge einer Sympathicusreizung angesehen. Einige Beobachter haben auch Pupillenenge gefunden, entweder für sich allein, oder im Anschlusse an Pupillenerweiterung. Auf den muse. tensor chorioid. soll das Medicament erregend wirken können und tetanische Krämpfe desselben hierdurch hervorrufen. Häufiger ist eine vorübergehende Abschwächung der Accomodation. In Bezug auf die äusseren Muskeln ist von besonderem Interesse die Angabe von Stell $\mathrm{wag}^{2}$ ), dass dieselben durch das Mittel entspannt würden. Hierdurch sei der Mangel an Glaskörperdruck hervorgerufen, welcher sich bei Entbindung des Cataract unter Cocain oft so unangenehm bemerkbar macht. Diese Herabsetzung des Augendruckes ist indessen auch keine constante Eigenschaft des Mittels, indem von anderen Autoren Drucksteigerungen bis zum acuten Glaukomanfalle beobachtet wurden ${ }^{3}$ ).

Beim chronischen Cocainismus kommt Doppelsehen vor, und finden sich im Uebrigen bei diesem Zustande analoge Erscheinungen von Seiten der Nerven und Muskeln, wie bei der acuten Vergiftung. Harmloserer Art ist der in Südamerika weit verbreitete habituelle Genuss der Cocablätter. Schon bei der Eroberung Peru's dureh die Spanier wurde bekanntlich diese Sitte dort angetroffen in Gestalt eines förmlichen Cocacultus bei den Incas. Auf grösseren Märschen waren die Blätter den Eingeborenen unentbehrlich, und wurde den-

1) Baaker, New Orleans med. Journ. 1894 p. 529.

2) Neue Abhandl. aus dem Gebiete der Augenheilkunde 1886 S. 272.

3) Centralblatt f. prakt. Augenheilkunde 1885 und Javal, Bullet. de l'academie de médecine 1886. 2. Sér. t. 15. 
selben nachgerühmt, dass sie das Nahrungsbedürfniss verminderten, die Ermüdung beseitigten und die Widerstandsfähigkeit gegen Strapazen erhöhten. Einzelne Pharmakologen ${ }^{1}$ ) wollen dieselbe Wirkung beobachtet haben bei innerlicher Darreichung von 0,05-0,1 Cocain. Die neueren Methoden der Muskelphysiologie haben diese Erfahrungen bestätigt. Durch Untersuchung mit dem Mosso'schen Ergographen fand Benedicenti ${ }^{2}$ ) eine sehr günstige Wirkung des Cocain auf die Muskelleistung, insofern dasselbe die Muskelenergie nachweislich erhöhte, während andere ebenfalls erregende Mittel, wie Kaffee, Thee, Maté u. s. w. die Ermüdung länger hinausschoben, ohne die Hubhöhen zu steigern.

Die Literatur über die Cocainwirkungen ist eine sehr umfangreiche und durch Vorstehendes bei Weitem nicht ersehöpft. Ich habe auch nur einen summarischen Ueberblick über die verschiedenen hier in Betracht kommenden Wirkungen geben wollen, ohne auf dieselben im Einzelnen näher einzugehen, um so mehr, weil das Ergebniss meiner eigenen Versuche über die Beeinflussung der Augenmuskeln so gut wie negativ war. Mit Rücksicht auf die vielfachen Berichte von theils erregender, theils lähmender Wirkung auf die Muskelthätigkeit hatte ich von dem Cocain eher eine Einwirkung erwartet, als von manchem anderen Mittel, doch fand ich diese Erwartung nicht bestätigt.

Mit Dosen von 0,01 hatte ich begonnen und dieselben in Wochen langen Zwischenräumen gesteigert bis zur Maximaldosis 0,05. Weiter wollte ich nicht gehen, da die Wirkung des Mittels, wenn auch nicht auf die Muskeln, so doch anderweitig sich sehr deutlich bemerkbar machte. Es bleibt also dahingestellt, ob nicht mit noch grösseren Gaben ein positives Ergebniss wäre erzielt worden, doch sind solche Versuche von zweifelhaftem Werthe, da bei den zu erwartenden schwereren Vergiftungserscheinungen eine sachgemässe Beobachtung an unserem Apparate vielleicht nicht mehr möglich gewesen wäre, uud namentlich die Beeinflussung der verschiedenen in Betracht kommenden Functionen, deren gegenseitiges Verhalten mich besonders interessirte, schwerlich noch hätte studirt werden können. Es hat keinen Zweck, eine grössere Anzahl von Versuehsprotokollen hier anzuführen, und dürfte ein Beispiel gentigen.

1) Rabow-Bourget, Arzneimittellehre 1897.

2) Molechott's Untersuchungen $\mathrm{Bd} .16 \mathrm{H} .1 \mathrm{u} .2$. 


\section{Versuch.}

9 h $45^{\prime}$ bis 55'. L. Int. 27, I. Ext. 21; r. Int. 25, r. Ext. 24. F.-N.-P. 5,2, Pupille 4,5, F.-F.-P. $10^{\circ}$, vorühergehend $12^{\circ}$, bei $14^{\circ} 4-5 \mathrm{~cm}$ Zwischenraum.

$10 \mathrm{~h} 5^{\prime} .0,05 \mathrm{~g}$ Cocain hydrochl. in linken Oberschenkel.

$10^{\mathrm{h}} 15^{\prime}$ bis $20^{\prime}$. Stichproben (Rechtsdrehung) normal. Pupille 5,5-6,0, beiderseits gleich, rund und nicht excentrisch. Alles Uebrige unverändert. Gesteigertes Kraftgefühl, sowohl körperlich wie geistig, vorübergehend, aber starker Schwindel; Puls 84. Patellarreflex sehr lebhaft, schon bei leichtem Anschnellen eines Fingers auszulösen.

$10^{\mathrm{h}} 30^{\prime}$ bis $35^{\prime}$. Alle äusseren Muskeln normal. F.-N.-P. 5,1, F.-F.-P. wie oben. Pupille 5,5. Die Wirkung ist sowohl an der Pupille, wie durch das Gefühl gesteigerten Wohlbefindens sehr deutlich. Puls 76 . Schwindel vorüber. Kein Muskelzittern. Eine unangenehme Wirlsung jetzt überhaupt nicht zu bemerken.

$10^{\text {h }} 45^{\prime}$ bis $50^{\prime}$. Puls 64 ; äussere Muskeln und auch sonst Alles unverändert.

$11^{\mathrm{h}} 0^{\prime}$ bis $5^{\prime}$. Papille 6,0, beiderseits gleichmässig rund. Sonst keine Aenderung.

$11^{\mathrm{h}} 15^{\prime}$ bis $25^{\prime}$. Pupille 5,0. Im Uebrigen alles wie bisher.

Der Bewegungsapparat zeigte sich also in Bezug auf alle untersuchten Functionen unverändert. Hinsichtlich der Pupillenerweiterung füge ich hinzu, dass ich dieselbe durch $0,02 \mathrm{~g}$ noch nicht erreichen konnte. Das erste Mal wurde sie beobachtet nach $0,03 \mathrm{~g}$, und zwar ebenfalls schon nach 10 Minuten. Hier war sie aber nicht von so langer Dauer wie oben, sondern 40 Minuten nach ihrem Auftreten wieder verschwunden. Auf eine Injection von 0,04 war die Zeit des Eintretens der Erweiterung gleichfalls dieselbe, und blieb sie hier fast eine Stunde lang mit kleinen Schwankungen bestehen. Die Lichtreaction, sowohl direct, wie indirect, war stets eine prompte.

\section{H) Inhalationsgifte.}

Von diesen habe ich nur Aether und Chloroform, als die für die Praxis bedeutsamsten, untersucht. In Betreff der beiden Mittel ist schon vor langer Zeit eine Verschiedenheit der Wirkung auf die Augenbewegungen behauptet worden, insofern bei dem Chloroform Coordinationsstörungen an den Augenmuskeln beobachtet sind, welche bei der Aethernarkose fehlen sollen. Warner hat meines Wissens zuerst auf solche dissociirten Augenbewegungen in der Chloroformnarkose aufmerksam gemacht ${ }^{1}$ ), während er sie bei dem Aether nicht fand. Es würde dies dafür sprechen, dass durch die Chloroform-

1) Siehe Ophthalmol. Jahresber. 1877. 
wirkung die in Betracht kommenden Theile des Centralnervensystems stärker in Mitleidenschaft gezogen werden, als durch den Aether. Dass die Aethernarkose überhaupt eine weniger tief greifende sei, würde sich aus diesem Umstande allein nicht folgern lassen (Knies). Wir wissen, dass durch bestimmte Gifte einzelne Theile des Centralnervensystems in böherem Maasse beeinflusst werden, als andere. Wenn also bei einem Mittel die bei einem anderen wahrnehmbare Wirkung auf bestimmte Organe fehlt, so kann es darum nicht ohne Weiteres als das harmlosere angesehen werden, denn das Nichteintreten einer bestimmten Wirkung schliesst nicht aus, dass vielleicht andere und viel wichtigere Centren dafür in um so höherem Maasse benachtheiligt werden.

Im Allgemeinen werden schädliche Einwirkungen auf die Muskeln beim Aether nicht besonders häufig beobachtet. Sie zeigen sich vorkommenden Falles meist als Erregungszustände, gesteigerte Reflexe, klonische Zuckungen bis $\mathrm{zu}$ allgemeinen Krämpfen. Auch tonische Spasmen, tetanusartige Zustände und Opisthotonus können auftreten. Die Pupillen verhalten sich wechselnd, sind mitunter verengt, mit späterer Erweiterung, meistens aber von Anfang an erweitert. Als Nachwirkungen, sowie beim chronischen Gebrauche treten die Lähmungen mehr in den Vordergrund, von blosser Schwäche und Zittern bis zu apoplektischen Zuständen. Mitunter sind aber auch hier Erregungen und Krämpfe beobachtet.

Interessant sind für uns wiederum die einschlägigen Versuche von Kraepelin. Sie hatten das Ergebniss, dass der Aether bei leichter Narkose die Bewegungsauslösung erleichterte, und zwar zu einer Zeit, wo die sensorischen und intellectuellen Functionen sich schon deutlich verlangsamt zeigten. Dieses Stadium erreichte nach etwa 10 Minuten seinen Höhepunkt, um sich durch die frühzeitige Unterbrechung der Einathmung sehr schnell wieder auszugleichen. Es entsprach diese Wirkung einer Aetherinhalation von 3 Minuten Dauer. Bei tieferer Narkose, hervorgerufen durch eine Inhalation von 5 Minuten, war die Wirkung auf die motorischen Functionen eine viel schwächere, aber doch immer noch angedeutet. Sie dauerte etwa 15 Minuten, um alsdann Lähmungserscheinungen Platz zu machen. Aehnlich verhielt sich das Chloroform. Auch hier zeigten sich bei leichter Narkose im Anfange Reizsymptome auf motorischem Gebiete, doch fehlte dieses Stadium bei tieferer Narkose gänzlich und wurde durch deutliche Lähmungserscheinungen ersetzt. Für 
Ueber den Einfluss von Giften auf den Bewegungsapparat der Augen. 379

beide Gifte liegen auch Versuche von Mommsen vor am motorischen Froschnerven, in welchen eine anfängliche Steigerung und späteres Sinken der Erregbarkeit nachgewiesen wurle. Nebenbei bemerkt, fand Kraepelin beim Amylnitrit, mit welchem ich nicht experimentirt habe, nur das erste (Reiz-)Stadium sehr ausgesprochen, während das letztere, wenigstens nach den Gaben, welche experimentell angewendet werden konnten, überhaupt nicht zur Entwickelung kam.

Im Uebrigen sind die durch das Chloroform hervorgerufenen gröberen Störungen auf motorischem Gebiete durch die chirurgische Anwendung desselben zur Genüge bekannt. Wir beobachten tonische und klonische Krämpfe verschiedener Körpergegenden, Trismus und Opisthotonus, sowohl in der Narkose, wie als Nachwirkungen. Dem anfänglichen Stadium der Excitation folgt das der allgemeinen Muskelerschlaffung und das Erlöschen der Refiexe. Die Reihenfolge der Wirkungen ist ähnlich wie beim Alkohol und Aether. Wir sehen zuerst das Grosshirn, dann das Kleinhirn, das Rückenmark, schliesslich die medulla oblongata und zuletzt die peripheren Nerven von der Lähmung befallen. Jedenfalls können letztere noch functionsfähig sein, wenn die Nervencentren schon vollständig ausser Thätigkeit gesetzt sind. Nach den Untersuchungen von Bernstein sind die Erregungszustände des sogenannten Excitationsstadiums weniger als Reizerscheinungen, als vielmehr als Folge einer Lähmung centraler bewegungshemmender Apparate aufzufassen. NothnagelRossbach nehmen auch eine gesteigerte Erregung reflexvermittelnder Apparate an. Die Einwirkung des Chloroforms auf die Nervensubstanz ist eine directe, und nicht etwa nur durch Veränderungen in der Blutzufuhr bedingt, da man auch bei blutleer gemachten Fröschen, wie bei solchen, deren Blut durch Kochsalzlösung ersetzt ist, eine Chloroformwirkung eintreten sieht. Ebenso scheint die Muskelsubstanz selbst verändert zu werden. Wenn man in eine klare Myosinlösung Chloroformdämpfe leitet, so trübt dieselbe sich nach etwa $3 / 4$ Stunden (Ranke). Eine ähnliche, wenn auch schwächere Wirkung hat der Aether. Hieraus wird die Muskelstarre erklärt, die sich bei Fröschen nach Injection von Chloroform in die Muskelgefässe entwickelt und auch nach blossen Einathmungen von Chloroform beobachtet werden kann. Auch $\mathrm{Fürth}$ hat beim liünstlichen

1) Arch. f. experim. Pathol. u. Pharmakol. Bd. 37 H. 6. 
Durchblutungsversuche constatirt, dass die Eiweisskörper des Muskelplasma's rurch Chloroform zur Gerinnung gebracht werden. Fettige Entartung des Herzens und zum Theil auch der willkürlichen Muskeln wird häufig beschrieben. Weniger scheinen die glatten Muskeln beeinflusst zu werden. Lewin sieht diesen Befund überhaupt nicht als Zeichen einer fettigen Entartung, sondern einer fettigen Einlagerung an, welche die Folge eines jeden Anästhetikums sei, dem eine mehr oder weniger grosse Fähigkeit zur Lösung von Fett zukomme. Dies liesse sich beweisen durch vergleichende Untersuchungen über den Fettgehalt von Blut und Lymphe vor und nach protahirten Narkosen.

Hinsichtlich der Augenmuskeln sind die Veränderungen der Pupillen bekannt und oft genug geschildert. An den äusseren Muskeln kennt man die bereits erwähnten Coordinationsstörungen, doch sind auch hiermit unsere Erfabrungen über die Beeinflussung der Augenbewegungen durch das Chloroform erschöpft, ebenso in Bezug auf den Aether. Meine Versuche machte ich in der Weise, dass ich das Narkotikum unmittelbar einathmete, indem ich die Nase dicht an die Flasche hielt und so weit hineinsteckte, dass sie den Rand des Gefässes überall berührte, ohme natürlich luftdicht abzuschliessen. In dieser Weise konnte ich den Aether minutenlang inhaliren, ohne eine besondere Wirkung auf das Sensorium zu bemerken, während beim Chloroform allerdings sehr rasch eine solche eintrat. 'Die Versuche mit dem Aether machten anfangs insofern Schwierigkeiten, als dieselben nicht unmittelbar am Rotationsapparate ausgeführt wurden, weil ich wegen der Nähe der Lampe Bedenken trug. Die Inhalationen wurden daher in einem dunkelen Nebenraume gemacht, und erst wenn ich eine deutliche Allgemeinwirkung verspürte, begab ich mich möglichst schnell an den Apparat, um die Messung auszuführen. Diese Versuche blieben bezüglich der Schnelligkeitsmessung immer gänzlich negativ, und zwar, wie ich später fand, aus dem Grunde, weil die Wirkung eine sehr kurzdauernde ist, wie sich übrigens aus der ebenfalls sehr flüchtigen Wirkung auf das Sensorium schon vermuthen liess. Bei anderweitiger Versuchsanordnung gelang es, ganz zweifellose Einwirkungen des Aethers auf die verschiedenen Functionen zu beobachten. Hierbei wurde in der Weise verfahren, dass die Inhalationen am Apparate selbst stattfanden mit möglichster Vorsicht in Bezug auf das Licht. Vorher war, um eine rasche Bestimmung zu erzielen, an der Gradeintheilung der normale Werth 
Ueber den Einfluss von Giften auf den Bewegungsapparat der Augen. 381

für den zu untersuchenden Muskel eingestellt, und wurde nun unmittelbar nach der Inhalation durch sehnell vorgenommene Seitenwendungen ermittelt, ob derselbe noch stimmte, oder welche Aenderung erforderlich war. Zuweilen hielt die Wirkung so lange an, dass es gelang, noch einen zweiten Muskel zu untersuchen. Ebenso wurde die Fusion unmittelbar nach der Inhalation in besonderen Versuchen geprüft. Ich nahm dabei die Inhalation auf einem Stuhle sitzend vor und hatte das Prüfungsobject in einer Eutfernung von $5 \mathrm{~m}$ vor mir, während eine Sammlung von Prismen zur Hand lag, so dass ich dieselben sofort nach beendigter Einathmung vor das Auge bringen konnte. Auch hatte ich zur Bestimmung des Fusionsnahepunktes alles in Bereitschaft, um ohne Aufentbalt die Beobachtung ausführen zu können. Auf diese Weise liess sich eine dentliche Beeinträchtigung der Fusionsfähigkeit nachweisen, z. B.:

I.

Vor dem Versuche Muskelthätigkeit in jeder Hinsicht normal. L. Int. 27, 1. Ext. 21; r. Int. 26, r. Ext. 24. F.-N.-P. 5,1, F.-F.-P. $10^{\circ}$.

$9 \mathbf{h} 50^{\prime}$. Beginn der Aetherinhalation. Dauer 5 Minuten.

$9 \mathrm{~h}$ 55'. F.-F.-P. $8^{\circ}$, bei $10^{\circ} \mathrm{ca} .3 \mathrm{~cm}$ Zwischenraum. Diese Bestimmung nahm etwa 1 Minute in Anspruch, danach Fortsetzung der Inhalation noch 3 Minuten lang. $8^{\circ}$ erwies sich jetzt ebenfalls zu stark und liess sich nur noch vorübergehend überwinden. F.-N.-P. 6,2. Mit Glasstab oder Prisma keine Insufficienz nachweisbar. Unmittelbar nach Beendigung der Inhalation leichtes Schwindelgefühl, welches aber schon nach wenigen Minuten vorüber. Stichproben an den äusseren Muskeln erwiesen sich normal, trotzdem (ohne neue Inhalation) um $10^{\text {h }} 7^{\prime}$ F.-N.P. 5,8, $10^{\text {h }} 8^{\prime}$ F.-F.-P. $8^{\circ}, 10^{\mathrm{h}} 15^{\prime}$ F.-N.-P. 5,3, F.-F.-P. $10^{\circ}$ nur noch wenig zu stark (ca. $1 / 2 \mathrm{~cm}$ Zwischenraum), vorübergehende Deckung. Von 10 zu 10 Minuten wird weiter untersucht. $11^{\mathrm{h}}$ F.-N.-P. 5,2, $11 \mathrm{~h} 30^{\prime}$ F.-F.-P. $10^{0}$ wird jetzt wieder leicht überwunden.

Während die gröberen Störungen also sehr bald schwanden, blieb eine geringe Abschwächung noch längere Zeit bestehen. Dieselbe war so unbedeutend, dass man sie unter anderen Umständen kaum als abnorm hätte ansehen können, in diesem Falle dürfte dies aber doch geboten sein mit Rücksicht auf die vorher festgestellte Leistung und die allmälige Wiederkehr derselben. Das Sensorium war bei diesen wie auch den späteren Versuchen wenig angegriffen, und habe ich die Inbalationen bis zu einer wirklichen Betäubung nicht fortgesetzt.

Hier ein Beispiel für die Beeinträchtigung der Contractionsschnelligkeit. Dieselbe wurde in der oben angegebenen Weise un- 
mittelbar nach Unterbrechung der Inhalation geprüft. Die Wirkung war von viel kürzerer Dauer, als die auf die Fusion.

II.

$10 \mathrm{~h} 20^{\prime}$ bis $25^{\prime}$. L. Int. 29, l. Ext. 20; r. Int. 26, r. Ext. 25. F.-N.P. 5,2, F.-F.-P. $10^{\circ}$ leicht, vorübergehend $12^{\circ}$. Pupille 4,5 .

$10^{\mathrm{h}} 30^{\circ}$. Beginn der Inhalation 3 Minuten lang.

$10 \mathrm{~b} 33^{\prime}$. L. Int. 24, r. Ext. 24, r. Int. 22, 1. Ext. 25 (in dieser Reihenfolge sind die Bestimmungen gemacht). Die Einstellungen dauerten etwa 3 Minuten, danach 5 Minuten lang erneute Inhalation: 1. Int. 25, r. Int. 21.

Wiederholung der Inhalation 5 Minuten lang und sofortige Prüfung der Externi: links 19, rechts 25 ; also nicht wesentlich verändert. Die ohne erneute A etheranwendung alsdann vorgenommene Prüfung der Interni ergab links 24, rechts 22.

Prüfung der Fusion. Einathmung 4 Minuten lang: F.-N.-P. 6,2, F.F.-P. $8^{0}$, bei $10^{\circ} \mathrm{ca} .3 \mathrm{~cm}$, bei $12^{\circ} \mathrm{ca} .10 \mathrm{~cm}$ Zwischenranm. Nach diesen Prüfungen ist auch Pr. $8^{\circ}$ schon zu stark.

5 Minuten Pause. Pr. $10^{\circ}$ wird wieder leicht überwunden, vorübergehend auch $12^{\circ}$. F.-N.P. $5,1$.

Erneute Inhalation 5 Minuten lang. L. Int. 21, r. Int. 20. Nach 5 Minuten ergeben sich wieder die normalen Werthe.

Jedes Mal hatte sich ein leichtes Schwindelgefühl von kurzer Dauer eingestellt. Man gewinnt zuweilen den Eindruck, dass die Muskeln dem Willen nicht mehr gehorchen, indem mitunter gar nicht beabsichtigte Bewegungen gemacht werden oder die beabsichtigten in fehlerhafter Richtung (Ataxie).

Auch hier ist die Wirkung auf die Fusion als eine centrale und von der Muskelenergie nicht unmittelbar abhängige anzusehen. Die übrigen Versuchsprotokolle zeigen analoge Ergebnisse und soll nur noch über einen Versuch mit innerlicher Anwendung von Aether berichtet werden.

Wir wissen, dass der Aether bei innerlichem Gebrauche einen dem Alkoholrausche ähnlichen Zustand hervorruft, und bat er schon lange Zeit, bevor er in den Arzneischatz eingeführt wurde, zu diesem Zwecke gedient. Sogar zu fortgesetztem Genusse ist er als Ersatzmittel des Alkohols in Gebrauch, namentlich in Irland, jetzt auch in Lithanen und einzelnen Gegenden von Ostpreussen. Die Rauschwirkung ist bald erreicht, doch ist dieselbe, ebenso wie ihre etwaigen anatomischen Folgen bei der glücklicher Weise geringen Verbreitung des Lasters bisher noch wenig studirt. Ich habe einen Versuch 
gemacht mit $10 \mathrm{ccm}$ auf ein Mal eingenommen, und die Wirkung auf die Augenmuskeln in der bisherigen Weise beobachtet.

\section{III.}

$10^{\mathrm{h}} 0^{\prime}$ bis $10^{\prime}$. L. Int. 28 , 1. Ext. 21 ; r. Int. 26 , r. Ext. 25. F.-F.-P. $10^{\circ}$, F.-N.-P. 4,8. Pupille 4,0-4,5.

$10 \mathrm{~h} 20^{\prime} .10 \mathrm{ccm}$ Aether per 0s, ohne Beimischung.

$10 \mathrm{~h} 30^{\prime}$. Stichproben an den äusseren Muskeln (etwa alle 3 Minuten) bisher normal. F.-N.-P. 5,3, F.-F.-P. wie oben.

10h $40^{\prime}$. Stichproben immer noch normal. F.-N.-P. 5,8, F.-F.-P. wie oben.

10 h $45^{\circ}$. F.-N.-P. 5,8. Sonst alles normal. Fortwährend höchst widerwärtige Ructus.

$10^{\mathrm{h}} 55^{\prime}$. F.-N.-P. 5,3. $11^{\mathrm{h}}, 11^{\mathrm{h}} 5^{\prime}$ und $11^{\mathrm{h}} 10^{\prime}$ desgleichen.

Eine andere Veränderung hat sich nicht ergeben. Im Vergleiche. zu der vor dem Tersuche festgestellten Entfernung war also dell Nahepunkt für längere Zeit abgerückt. Ich zweifele nicht daran: dass bei grösseren Quantitäten sich noch andere Störungen an den' Augenmuskeln hätten finden lassen, doch waren diese Versuche wegen des unangenehmen Geschmackes und des häufigen Aufstossens mir so widerlich, dass ich mich zu einer Fortsetzung nicht entschliessen konnte. Auch ist die Dosirung zu ungenau, da sich der Aether bei der Wärme des Magens natürlich sofort verflüchtigt, und sich gar nicht controliren lässt, wie viel durch das Aufstossen wieder verloren geht. Eine Rauschwirkung oder sonstige Folgen auf das Allgemeinbefinden habe ich von dem obigen Quantum nicht bemerkt.

Gehen wir nunmehr über zu den mit Chloroform gemachten Versuchen, so fand sich hier stets eine viel schneller eintretende Wirkung, die aber fast eben so rasch wieder vorüber war. Es war mir überhaupt nicht möglich, die Inhalationen minutenlang fortzusetzen, wie beim Aether, sondern es trat schon nach wenigen Zügen ein Gefühl von starkem Schwindel, Herzklopfen und Beklemmung ein, mit erheblicher Beeinflussung des Sensoriums. Nach Unterbrechung der Inhalation waren diese Allgemeinerscheinungen schnell wieder beseitigt, und liess sich nunmehr eine kurz dauernde Wirkung auf die verschiedenen Functionen der Augenmuskeln feststellen. Dieselbe war indessen so fluchtig, dass für die Untersuchung fast jeder einzelnen ein neuer Versuch gemacht werden musste, so dass verschiedene Reihen von einzelnen Feststellungen mit jedes Mal erneuten Inhalationen entstanden. Zwischen den Versuchen stellten sich sehr raseh die normalen Werthe wieder ein. Auch hier mussten 
alle Beobachtungen gleich am Apparate und unter solchen Verhältnissen angestellt werden, dass eine unmittelbare Ausführung des Versuches möglich war. Folgendes Protokoll möge als Beispiel dienen.

Versuch.

$9 \mathrm{~h} 30^{\prime}$. L. Int. 27, I. Ext. 20; r. Int. 25, r. Ext. 23. F.-N.-P. 5,3, F.-F.-P. 10\%. Pupille 4,5.

9h 45'. Beginn der Einathmung. Nach 6-7 Zügen starker Schwindel, Beklemmungsgefühl. Die sofort angestellte Prüfung der Rechtsdrehung ergibt 1. Int. 22, r. Ext. 20. Nach etwa $1 / 2$ Minute sind Schwindel und Beklemmungsgefuhl wieder verschwunden, fast ebenso schnell auch die Einwirkung auf die Muskeln, so dass bei einem sofort angestellten zweiten Versuche die Werthe wieder normal sind, nämlich l. Int. 27, r. Ext. 23.

Für die Prüfung der Linksdrehung war somit gar keine Zeit, und wurde für diese der Versuch wiederholt.

Sechs Athemzüge. Alsdann 1. Ext. 17, r. Int. 20. Bei den sich unmittelbar anschliessenden Prüfungen steigende Werthe, gleichzeitig mit dem Schwinden der Allgemeinwirkung, nämlich für 1. Ext. 20 (normal), für r. Int. 22, darauf 25. Also sehr prompte Wiederberstellung. In diesen Versuchen wurden, ähnlich wie vom Aether erwähnt, bei noch ungeschwächter Wirkung des Chloroforms zuweilen gar nicht beabsichtigte Bewegungen, oder auch beabsichtigte in unregelmässiger Weise gemacht, auch statt einer Contraction schnell zwei hinter einander ausgeführt.

Die übrigen Functionen wurden in derselben Weise, also jedes Mal nach 6-7 Zügen Chloroform untersucht. Für den F.-F.-P. fand sich danach Pr. 10\%, welches vorher leicht überwunden wurde, zu stark, indem ein Abstand von ca. $3 \mathrm{~cm}$ blieb. Prisma $8^{\circ}$ wurde vollständig überwunden. Als F.-N.-P. ergab sich in vier schnell hinter einander gemachten Einstellungen $6,5,7,0,6,5,6,5$. Drei Minuten nach der letzten 5,5.

Pupille und Accommodation zeigten sich bei derselben Versuchsmethode unverändert.

Abgesehen hiervon wurden die einzelnen Muskeln für sich allein geprüft bei gleicher Anwendungsweise des Chloroforms. Zum Beispiel wurde für den linken Internus der Spalt anf den vor dem Versuche gefundenen Werth $27^{\circ}$ eingestellt. Dies erwies sich nach der Einathmung entschieden zu stark, erst bei $22^{\circ}$ erfolgte Geradstellung. Nach kurzer Pause war dies schon zu wenig, bis nach 2 Minuten $27^{\circ}$ wieder erreicht waren. Für den rechten Internus fand sich in derselben Weise: Unmittelbar nach der Einathmung 18, nach 1 Minute 20, nach 3 Minuten 22, nach 5 Minuten 24, nach 10 Minuten 25-26. Für linken Externus: unmittelbar nach der Einathmung 16, nach 1 Minute 18, nach 3 Minuten 20.

Für den Nahepunkt fand sich in einem anderen Versuche als Mittel von je drei Einstellungen: unmittelbar nach der Einathmung 6,7, nach 2 Minuten 6,0, nach 4 Minuten 6,0, nach 6 Minuten 5,5. Untersuchte man nach solchen Inhalationen das Muskelgleichgewicht mit Glasstab oder Prisma, so war etwas Abweichendes nicht festzustellen. 
Wir sehen somit eine erheblicbe lähmende Wirkung des Giftes auf die äusseren Augenmuskeln, welche in allen angestellten Versuchen, die ich nicht näher ausführen will, sehr deutlich hervortrat. Eine Untersuchung ist natürlich nur in den Anfangsstadien möglich, so lange das Bewusstsein frei ist, was bei mir, wie gesagt, schon nach 6-7 Einathmungen seine Grenze erreicht. Bei der heftigen Wirkung, welche das Chloroform auf das Nervensystem äussert, kann diese schnelle Lähmung auf motorischem Gebiete nicht überraschen, und zwar finden wir sowohl die Fusion, wie die associirten Bewegungen abgeschwächt. Ein Stadium, wo nur die eine von beiden Leistungen wäre geschädigt gewesen, habe ich nicht finden können, da sie sich bei allen Versuchen sämmtlich vermindert zeigten. Freilich war die Wirkung so flüchtig, dass sehr bald wieder die eine oder andere Function sich normal fand, es konnte aber keine von ihnen der Einwirkung von 6-7 Einathmungen Widerstand leisten.

Die oben wiedergegebenen Protokolle beziehen sich, wie ersichtlich, auf eine ganze Reihe von einzelnen Versuchen, und dürften dieselben zur Erläuterung des Gesagten genügen.

\section{J) Erregende Mittel.}

Es gibt bekanntlich verschiedene Stoffe, denen man die Eigenschaft zuschreibt, das Müdigkeitsgefühl zu 'beseitigen und die Leistungsfähigkeit der Musculatur zu erhöhen. Für manche derselben liegen genauere Versuche vor, in denen die Muskelleistungen vor und nach Einwirkung des Mittels verglichen sind. Dass sich die Cocablätter in dieser Beziehung eines alten Rufes erfreuen, ist bereits oben erwähnt, und kann bezüglich dieser Drogue auf das Gesagte verwiesen werden. Ausserdem habe ich das Coffeïn und den, namentlich in neuerer Zeit viel gerühmten Zucker darauf hin untersucht, ob sie einen merklichen Einfluss auf die Contractionsenergie der Augenmuskeln haben.

Ueber beide Stoffe hat vor einigen Jahren U. Moss o genauere Versuche mit Hülfe des von seinem Bruder Angelo erfundenen Ergographen angestellt. Auf die älteren Versuche mit Thee und Kaffee werden wir gleich zurückkommen. Die Beobachtungen Mosso's über die Kolanuss ${ }^{1}$ ) haben ergeben, dass $5 \mathrm{~g}$ gepulverter Kola, auf einmal genommen, die Leistungsfähigkeit der Muskeln für 
einen Zeitraum von 2-7 Stunden erhöhen, und zwar in dem Maasse, dass das Vierfache der gewöhnlichen Arbeitsleistung erreicht wird. Das Maximum stellt sich nach Verlauf einer Stunde ein. Dieser Gabe von Kolanuss entsprechen 0,12 g Coffeïn, und liess sich anch durch dieses dieselbe Wirkung erzielen. Indessen erwies sich das Coffeïn nicht als das einzig wirksame Princip der Kolanuss, sondern auch nach Extraction desselben blieben immer noch Stoffe zurück, welche, wenn auch in geringerem Maasse, die Leistungsfähigkeit erhöhten. Das Kolaroth hatte in reinem Zustande keinen Einfluss auf die Muskeln, wohl aber noch das vom Kolaroth und Coffeïn befreite Pulver. Wurde dieser Rückstand mit heissem Wasser ausgezogen, so war der Rest ganz wirkungslos, und Mosso schliesst hieraus, dass der noch wirksame Bestandtheil die in das heisse Wasser übergegangene Stärke sein müsse. Jedenfalls kommt für die Wirkung in erster Linie das Coffein in Betracht und habe ich mit diesem meine Versuche angestellt.

Die gleichfalls mit dem Ergographen angestellten Experimente von Benedicenti sind schon oben (beim Cocaïn) erwähnt. Hier sei noch nachgetragen, dass derselbe die Wirkung des Kaffees viel energischer fand als die des Thees, indem die erstere eine Stunde anhalten konnte, währeud die von Thee meist nach ${ }^{1 / 2}$ Stunde vorüber war. Beide Mittel steigerten aber nicht die Leistung an sich (Gegensatz zu Mosso), sondern wirkten nur der Ermüdung entgegen. Die Befunde schwankten bei verschiedenen Menschen in weiten Grenzen. Demgegenüber hatte Rossi bei Versuchen mit Coffeïn überhaupt nur einen geringen Erfolg. Einen besonderen Einfluss auf die Eiweisskörper der Muskelsubstanz fand $\mathrm{F}$ ü $\mathrm{rth}$ (l. c.), indem er feststellte, dass beim künstlichen Durchblutungsversuche auch durch Coffeïn der lebende Muskel zur Gerinnung gebracht wird.

Diesen Arbeiten gingen voraus die Versuche, welche Kraepelin über die Einwirkung von Thee angestellt hat. Er fand unter dem Einflusse desselben eine am Dynamometer nachweisbare Erhöhung der muskulären Leistungsfähigkeit, und zwar eine solche, die nicht wie beim Alkohol rasch wieder verschwindet, sondern längere Zeit anhält. Die einzelnen Reihen zeigen, ebenso wie die Normalreihen, ein Fortschreiten der Anfangsleistung, was $\mathrm{Kr}$ a e pelin auf den Einfluss der Uebung zurückführt. Die maximale Leistung wurde aber beim Theeversuch stets innerhalb der ersten 20 Minuten erreicht, während in den Normalreihen die höchsten Zahlen erst später 
auftraten. Im Uebrigen waren die Werthe für den Thee auch schon von Anfang an höher, als dem Durchschnitte der normalen entsprach. Eine Abnahme stellte sich erst nach Ablauf von 30-40 Minuten ein, uñd auch dann war diese so gering, dass die letzten Zahlen der Theereihen immer noch relativ hohe blieben. Selhst nach $\mathrm{Ab}-$ lauf einer Stunde war die Steigerung zuweilen noch nachweisbar. Aehnliche Erfahrungen ergaben die Dynamometerversuche de Sarlo's und Bernardini's mit Kaffee.

Im Gegensatze zu seinen dynamometrischen Messungen fand Kraepelin, dass die Auslösung von Bewegungen durch den Thee keine Beschleunigung erfährt. Etwas Aehnliches ergab sich, aber im umgekehrten Sinne, auch für den Alkohol, insofern die Beschleunigung der motorischen Vorgänge bei diesem weit länger dauerte, als die Steigerung der Dynamometerwerthe, die erstere also gleichfalls von der letrteren sich unabbängig erwies. Eine Steigerung der muskulären Kraftleistung ist daher nicht immer mit einer Beschleunigung der motorischen Vorgänge verbunden, ebenso wie die letztere vorhanden sein kann, ohne Zunahme der Kraft. Das der Alkoholwirkung eigenthümliche subjective Gefühl beschleunigter Reaction fand Kraepelin beim Thee nicht. Er bält es für wahrscheinlich, dass die Ursachen für die Erhöhung der muskulären Kraftleistung für den Thee weniger auf centralem, wie auf peripherem Gebiete zu suchen sind, und glaubt, dass chemische Veränderungen in den Muskeln hauptsächlich die Erregbarkeitssteigerung durch das Coffein bewirken. Kobert ${ }^{1}$ ) hat bereits den Nachweis erbracht, dass die Leistungsfähigkeit des Froschmuskels selbst durch das Gift erhöht wird. Kraepelin sucht seine Ansicht zu stützen durch verschiedene Erwägungen, welche sich aus seinen Versuchen ergeben, auf die wir indessen hier nicht näher eingehen können. Die tägliche Erfahrung über die Theewirkung bestätigt die Angaben von Kraepelin, indem eine wirkliche motorische Erregung, wie wir sie vom Alkohol kennen, sich durch den Theegenuss niemals entwickelt, auch niemals eine entsprechende Steigerung des Kraftgefühls.

Bei Vergiftungen mit Coffeïn sind übrigens gröbere Einwirkungen auf die Muskelthätigkeit wohl bekannt, und zwar sowobl lähmungsartige Zustände, als auch klonische Krämpfe, Zittern, Steifigkeit und Starre der Muskeln.

1) Arch. f. experim. Pathol. u. Pharmakol. Bd. 15. 
Schliessen wir hieran das Wesentliche, was über die Einwirkung des Zuckers auf die Muskelleistung bekannt ist, so ist zunächst zu erwähnen die Arbeit von U. Mosso und Paoletti ${ }^{1}$ ). Albertoni hatte bereits früher beobachtet, dass durch Zucker die Herzthätigkeit verstärkt wird, und Mosso hatte eine ebensolche Einwirkung für das Amylum festgestellt, wie er ja auch die anregenden Eigenschaften der Kolanuss zum Theil auf den Stärkegehalt zurückführt. In Gemeinschaft mit Pa oletti studirte er nun den Einfluss des Zuckers auf die Ermüdungscurven am Ergographen, und fand, dass $100 \mathrm{~g}$ Zucker in $50 \mathrm{~g}$ Wasser gelöst, keinen Einfuss hatten, wohl aber, wenn man zur Lösung eine grössere Wassermenge nahm. Gaben von 30-60 g übten ebenfalls eine verstärkende Wirkung, und zwar unabhängig von der Menge des Lösungsmittels. Der Höhepunkt der Wirkung trat ein $1 / 2$ Stunde nach Einnahme des Zuckers. Etwas später erschien die Arbeit von $\mathrm{Harley}^{2}$ ) über denselben Gegenstand. Er fand, dass Zugabe von Zucker zu einer kleinen Mahlzeit die Muskelkraft bedeutend erhöhe, ferner, dass eine Zuckergabe in den frühen Abendstunden das sonst am Abend eintretende periodische Fallen der Muskelkraft verbinderte und die Widerstandsfähigkeit gegen Ermüdung erhöhte. Er bediente sich zu seinen Versuchen ebenfalls des Ergographen und der Methode von Mosso. Dieser Einfluss des Zuckers ist von Stokvis ${ }^{3}$ ) bestritten, von Mosso und Harley vertheidigt, von Schumburg u. A. wieder bestätigt worden. Letzterer hält den Zucker nicht nur für eine Muskelnahrungs- sondern auch Erfrischungsmittel, indem er das Ermüdungsgefühl beseitige. Kaffee, Thee und auch der Alkohol wirken nach seiner Ansicht nur dadurch, dass sie die Nahrungsaufnahme anregen, da sie auf den völlig erschöpften Muskel, welchem keine Nahrungsstoffe aus dem Blute mehr zugingen, keinen Einfluss hätten. Dies steht nicht im Einklange mit den von anderer Seite (Bugoslavskj u. A.) gemachten Beobachtungen, wonach eine neue Nahrungsaufnahme zur Anregung auch des völlig erschöpften Muskels nicht erforderlich ist, indem auch Reizung der Sinnesorgane und psychische Reize dies bewirken können. Im Uébrigen fand $S \operatorname{chumburg}$ den Zucker nur beim ermüdeten Muskel wirksam. Jedenfalls herrschen auf diesem

1) Atti della R. academei dei Lincei CCXC (2). 1893.

2) Journ. of Physiolog. vol. 16. H. 1 u. 2. 1894.

3) Brit. med. Journ. Nr. 23. 1895. 
Ueber den Einfluss von Giften auf den Bewegungsapparat der Augen. 389

Gebiete noch vielfache Widersprüche, namentlich auch in Bezug auf die praktischen Versuche am marschirenden Soldaten (Leiterstorfer, Leistikow), woraus wohl zu schliessen ist, dass theils individuelle Verschiedenheiten, theils Fehlerquellen eine Rolle spielen.

An den Augenmuskeln ist es mir niemals gelungen, irgend einen erregenden Einfluss auf die Muskelthätigkeit wahrzunehmen, auch nicht bei genauer Befolgung der von Anderen gegebenen Vorsehriften. Ob eine schnelle Wiederherstellung der Muskelkraft nach Ermüdung oder eine Verzögerung der letzteren durch die betreffenden Stoffe stattfindet, habe ich allerdings nicht untersucht, kann also nur sagen, dass ich eine Erhöhung der ungeschwächten Muskelkraft nach der angegebenen Methode nicht feststellen konnte, wie sie von $\mathrm{Benedicenti}$ für die Coca, von Mosso für das Coffein u. s. w. gefunden wurde. Auch der Kampher, welchem Rossi eine sehr energische Wirkung auf die Muskelkraft zuschreibt, zeigte sich bei mir ohne Einfluss.

Um dies zu erklären, wären verschiedene Möglichkeiten in Betracht zu ziehen. Es liesse sich annehmen, dass auf Grund einer individuellen Figenthümlichkeit die versuchten Mittel auf meine Muskeln nicht einwirken. Dies am Ergographen zu prüfen, hatte ich keine Gelegenheit, doch ist die Annahme sehr unwabrscheinlich, da irgend eines von den versuchten Mitteln wohl die erregende Wirkung hätte zeigen müssen. War es mir doch nicht einmal möglich, eine erregende Wirkung des Alkohols auf die Muskelthätigkeit zu finden, welche doch von verschiedenen Autoren auf anderem Wege und an anderen Muskeln zweifellos erwiesen scheint.

Ferner wäre es denkbar, dass die erregende Wirkung sich nicht an allen Muskeln in gleichem Maasse zeigte und dass sie gerade an den Augenmuskeln am wenigsten hervorträte. Um dies festzustellen, wären vergleichende Untersuchungen mit den mir nicht zur Verfügung stehenden Apparaten erforderlich gewesen. Eine gewisse Wahrscheinlichkeit hat diese Annahme immerhin, wenn wir in Betracht ziehen, dass an den viel umfangreicheren, zu höheren Leistungen befähigten und mit reichlicherer Blutzufuhr versehenen Extremitätenmuskeln die Stoffwechselvorgänge jedenfalls viel lebhafter sind, als an den Augenmuskeln mit ihren bescheidenen Verhältnissen. Aus diesem Grunde müssen diejenigen Mittel, wèlche auf die Muskeln selbst wirken, je nach diesen Verhältnissen einen sehr verschiedenartigen Einfluss ausüben, während es für solche, deren Angriffspunkte 
mehr die centralen Innervationsvorgänge sind, auf die Beschaffenbeit der Muskeln selbst weniger ankommt. Die von uns untersuchten lähmenden Mittel mit ihren zum Theil sehr erheblichen Einwirkungen auf das Centralnervensystem gehören nun offenbar zu der letzteren Gruppe, während bei der Mehrzahl der verschiedenen Stärkungsmittel eine Beeinflussung des Centralnervensystems viel weniger hervortritt.

Schliesslich wäre zu erwägen, ob unsere Methode der Schnelligkeitsmessung vielleicht nicht fein genug ist, um die wahrscheinlich nur geringen Schwankungen durch erregende Mittel hervortreten zu lassen. Diese Annahme hat keine hesondere Wahrscheinlichkeit, da die Schwankungen im entgegengesetzten Sinne, wie wir sahen, sehr deutlich sind, schon nach kurzer Zeit hervortreten und sich in ihrem Ablaufe bequem verfolgen lassen. Ja man kann mit Hülfe des Apparates, wie ich zum Schlusse noch anführen will, Steigerungen der Muskelthätigkeit thatsächlich beobachten, wenn man die regelmässigen Tagesschwankungen verfolgt. Die Muskelenergie erweist sich nämlich nicht als die gleiche, je nach der Tageszeit, zu welcher die Untersuchung vorgenommen wird, und da das Hervortreten solcher, ihrer Natur nach sehr subtilen Unterschiede in der Muskelthätigkeit eine grosse Feinheit des Instrumentes voraussetzt, so dürfte die Zuverlässigkeit der Methode damit schon zur Genüge bewiesen sein.

Ich habe vielfach Beobachtungen gemacht äber diese Tagesschwankungen, wobei ich anfangs nur von der Absicht geleitet wurde, festzustellen, ob noch irgend welche Folgen der am Abend vorher gemachten Experimente sich in Bezug auf die Muskelleistung am nächsten Morgen nachweisen liessen. Hierbei fand ich indessen, unerwarteter Weise, oft höhere Werthe, als dem am Abend gefundenen Durchschnitte (s. o.) entsprach. In der Folge habe ich dieses Verhalten systematisch weiter untersucht, natürlich ohne dass irgend welche schwächenden Einflüsse vorausgegangen wären, und kann behaupten, dass diese höheren Morgenwerthe bei mir die Regel sind. Bis Nachmittags um 2 Uhr hatte sich die Steigerung wieder ausgeglichen, so dass die um diese Zeit gefundenen Werthe mit den abendlichen übereinstimmten. In der beigefügten Tabelle sind die Zahlen (ohne die Zehntel) von 20 Morgenbestimmungen aufgefürt, und sehen wir aus denselben, dass nicht nur der Durchschnitt im Allgemeinen höher liegt, sondern dass auch einzelne Werthe, nament- 
Ueber den Einfluss von Giften auf den Bewegungsapparat der Augen. 39]

\begin{tabular}{l|c|c|c}
\hline \multicolumn{2}{c|}{ Links } & \multicolumn{2}{c}{ Rec hts } \\
\cline { 3 - 4 } Internus & Externus & Internus & Externus \\
\hline & & 27 & 26 \\
30 & 24 & 28 & 27 \\
32 & 22 & 27 & 26 \\
28 & 23 & 30 & 27 \\
31 & 24 & 25 & 23 \\
26 & 22 & 30 & 27 \\
30 & 22 & 24 & 23 \\
27 & 20 & 26 & 23 \\
27 & 19 & 27 & 25 \\
30 & 24 & 28 & 26 \\
30 & 22 & 27 & 25 \\
29 & 22 & 28 & 28 \\
31 & 24 & 28 & 27 \\
31 & 21 & 27 & 26 \\
29 & 21 & 28 & 26 \\
29 & 22 & 29 & 28 \\
32 & 26 & 26 & 26 \\
29 & 21 & 27 & 26 \\
30 & 22 & 25 & 23 \\
27 & 21 & 28 & 27 \\
30 & 23 & 27,2 & 25,9 \\
\hline 29,4 & 22,2 & &
\end{tabular}

lich am linken Internus, den Abenddurchschnitt weit überragen. Dreissig und darüber habe ich Abends nie erreichen können. Dass diese morgendliche Steigerung die unmittelbare Folge einer durch den Schlaf geschaffenen Erholung sei, wage ich nicht zu behaupten, denn selbst nach recht schlechten Nächten und ungenügendem Schlafe fand ich zuweilen auffallend hohe Werthe. Es entspricht dies übrigens der Erfahrung, dass eine ungenügende Nachtruhe durehaus nicht immer unmittelbar erschlaffend wirkt, sondern im Gegentheil anfangs eine gewisse Erregung hervorruft, wäbrend das Ruhebedürfniss sich erst nach einiger Zeit einstellt.

Die Ansichten der Autoren über den Einfluss des Schlafes auf die Muskelenergie lauten nicht übereinstimmend. Dass Tagesschwankungen vorhanden sind, ist bei regelmässigen, darauf gerichteten Untersuchungen mehrfach festgestellt. Solche fand z. B. Harley (1. c.) in dem Sinne, dass die Muskelkraft Nachmittags grösser sei als Vormittags. Bugoslavskj $j^{1}$ ) bestätigt diese Angabe, indem er nach der von Mosso angegebenen Methode fand, dass die kleinste Arbeit auf die Morgenstunden falle, und dass unmittelbar nach dem Erwachen die Ermüdbarkeit am grössten sei. Die

1) Inaugg.-Dissert. Petersburg. 
maximale Arbeitsleistung falle zwischen 1 und 2 Uhr Nachmittags. Das Ergebniss sei das gleiche, ob die Contraction der Muskeln durch den faradischen Strom oder freiwillig herbeigeführt werde, und hieraus sei zu schliessen, dass die Wirkung des Schlafes nicht auf einer Verminderung der Willensimpulse, sondern auf einem schwächenden Einflusse auf die Peripherie (Muskeln und Nerven) beruhe. Uebereinstimmend mit dieser Beobachtung fand der genannte Autor, dass langdauerndes Wachen keinen Einfluss auf die Ermüdungscurve habe. Im Gegensatze hierzu behauptet Mosso, der eigentliche Begründer dieser Seite der Muskelphysiologie, dass Nachtwachen die Muskelkraft verminderten und die Ermüdbarkeit erhöhten, der Einfluss des Schlafes müsste demnach ein anregender sein, und würden meine Versuche zu Gunsten der letzteren Angabe sprechen. Es bleibt aber der Unterschied der Methode hervorzuheben, sowohl hier wie bei den oben ausgeführten Vergleichen zwischen den mit dem Ergographen und den von mir gemachten Beobachtungen. Aus der Schnelligkeit der Contraction lassen sich nicht unmittelbar Schlüsse ziehen auf die Hubhöhen oder auf die Widerstandsfähigkeit gegen Ermüdung, eben so wenig umgekehrt. Wie wir schon bei Erörterung der Versuche Kraepelin's über den Alkohol und Thee feststellten, kann der Ablauf centraler Auslösungsvorgänge beschleunigt sein, ohne dass die Muskelkraft selbst gesteigert ist, und wird ersteres nicht nur für eine Reihe hintereinander ausgeführter, sondern auch für den Ablauf der einzelnen Bewegungen von Bedeutung sein.

\section{Ergebois e.}

Ziehen wir die Schlussfolgerungen aus dieser Arbeit, so ergibt dieselbe zunächst, dass die von mir angegebene Methode der Schnelligkeitsmessung der Augenbewegungen sich zu praktischen Untersuchungen vollkommen verwerthen lässt. Voraussetzung hierfür ist eine gewisse Uebung und eine längere Beobachtung des zu Untersuchenden, behufs Feststellung der für ihn gültigen Durchsehnittswerthe. Hierin liegt allerdings auch ein Hinderniss für die allgemeine Anwendung zu diagnostischen Zwecken in der Sprechstunde, doch erseheint die Möglichkeit nicht ausgeschlossen, falls bei Beginn einer Erkrankung, welche Bewegungsstörungen herbeiführt, die Werthe einmal festgestellt sind, aus deren fernerem Verhalten Schlüsse auf die weitere Entwicklung des Leidens zu ziehen. Bei 
physiologischen Versuchen ist die Methode aber jedenfalls im Stande, feinere Störungen in den Leistungen der Muskeln aufzudecken, als wir bisher mit Hülfe der anderen diagnostischen Mittel feststellen konnten. Dass Arzneimittel von ausgesprochen narkotischer Wirkung die Leistungsfähigkeit auf motorischem Gebiete beeinflussen würden, war von vorne herein nicht anders zu erwarten. Es war aber nicht bekannt, in wie weit dies auf dem von uns studirten Gebiete sich nachweisen lässt, und in welcher Form und bis zu welehem Grade die Störung sich entwickelt. Durch Beobachtung des besonderen Verhaltens der einzelnen in Betracht kommenden Functionen dürfte es gelungen sein, einen Beitrag zu der Lehre von den Augenbewegungen zu liefern, welcher insofern nicht ohne Interesse ist, als er ein Licht wirft auf die Abhängigkeit bezw. Unabhängigkeit der einzelnen Leistungen des Bewegungsapparates von einander.

- Wir unterscheiden bekanntlich bei den seitlichen Bewegungen der Augen zwei verschiedene Formen, nämlich die gleichzeitige Wendung beider Blicklinien nach rechts oder links, i. e. die associirten Bewegungen, und die accommodativen Bewegungen, hervorgerufen durch gleichzeitige Convergenz oder Divergenz der Blicklinien. Für beide Bewegungen müssen wir verschiedene Centren und wohl auch verschiedene Leitungsbahnen annehmen. Eine Meinungsverschiedenheit besteht insofern, als nach der Ansicht der meisten Autoren sowohl die Convergenz wie die Divergenz eine Leistung der Interni ist, abhängig von ihrem mehr oder weniger starken Contractionszustande, während nach der Auffassung Anderer auch die Divergenz ein activer Vorgang und für denselben ein besonderes Divergenzcentrum anzunehmen ist, welches ebenso auf die Fxterni wirkt, wie das Convergenzcentrum auf die Interni. Die erstere Ansicht wird z. B. von Graefe ${ }^{1}$ ) vertreten, welcher sagt, dass die Interni vor den übrigen Muskeln insofern eine besondere Stellung einnehmen, als sie einem zweifachen Bewegungsprincipe zu dienen berufen sind, einmal der associirten Seitenbewegung, ein anderes Mal der accommodativen Convergenzstellung. Letztere werde dadurch ausgeführt, dass beicie inneren Augenmuskeln mit gleichmässig wachsenden, resp. abnehmenden Spannungsgraden zu einer Cooperation zusammentreten. Von einer Betheiligung der Externi ist hier keine Rede, und müssten wir uns deren Wirkung demnach

1) Graefe-Saemisch, 2, Aufl. 1. Lief. S. 15 . 
so zu denken baben, dass sie obne active Innervation nur durch ihre elastische Spannung bei Ahnahme der Innervation der Interni die Divergenzbewegung zu Stande bringen. An einer späteren Stelle (S. 391) wird diese Auffassung noch näher erörtert und damit begründet, dass der Nachlass der durch die Convergenzbewegung her * vorgerufenen Zerrung der Externi genüge, um die Augen ihrem physikalischen Ruhezustande wieder zuzuführen, als welcher die Parallelstellung anzusehen sei. Dass dies thatsächlich hierfür ausreiche, sei bewiesen durch die Fälle von Abducenslähmung, bei welchen, das Fehlen der secundären Contractur eines Internus vorausgesetzt, das Auge mit dem Nachlasse der Internusinnervation in die Ruhestellung zurückzukehren vermöge. Eine Zusammenziehung der Externi brauche daher nur erst einzutreten, wenn das Auge aus der mittleren Stellung sich seitlich bewegt, und da eine solche gemeinsame Bewegung beider Augen niemals physiologisches Postulat sei, so liege kein Grund vor, ein Centrum anzunehmen für die conjugirte Zusammenwirkung beider recti externi, wie ein solches für die Interni bei den accommodativen Convergenzbewegungen gefordert wird.

Dass eine active Divergenzstellung für gewöhnlich nicht vorkommt, ist ja zweifellos richtig, aber eben so zweifellos ist, dass sie vorkommen kann, z. B. beim Vorlegen von Abductionsprismen. Wenn nun aus dem Umstande, dass eine Convergenzbewegung ausführbar, zu schliessen ist, dass es hierfür ein gemeinschaftliches Centrum gibt, so sollte man meinen, dass diese Schlussfolgerung auch für die Externi gelten muss. Der Unterschied, dass die eine Bewegung beim gewöhulichen Gebrauche der Augen ausgeführt wird, die andere nur unter besonderen Verhältnissen, kann doch als ein durchschlagender kaum bezeichnet werden. Wir wissen, namentlich aus den Versuchen von Hering, dass die Innervationsimpulse auf beide Augen sich immer gleichmässig vertheilen, selbst wenn das eine bei der ausgeführten Bewegung still steht, und ist eine solche gleichmässige Innervation ohne gemeinschaftliche Centralstelle nicht denkbar. Da nun die Divergenz als ein activer, nicht nur auf Erschlaffung der Interni beruhender Vorgang auftreten kann, so müssen wir folgerichtig auch für diesen eine solche Centralstelle annehmen.

Abgesehen hiervon, gibt es, wie ich glaube, doch einen Fall, wo eine Divergenzinnervation auch für die normale physiologische Bewegung der Augen angenommen werden muss. Es ist, wie wir sahen, zuzugeben, dass das Streben nach dem physikalischen Ruhezustande 
genügt, um die Augen aus einer Convergenzstellung allmälig in eine mittlere Lage hinüberzuführen. Anders aber, wenn diese Bewegung schnell und mit einer gewissen Energie ausgeführt werden soll. Wenn man einen nahe gelegenen Punkt fixirt und nunmehr rasch auf einen entfernten einstellt, so spricht das subjective Gefühl jedenfalls dagegen, dass dies lediglich durch eine Muskelerschlaffung zu Stande kommen sollte. Man hat im Gegentheil die Empfindung, dass es sich hier um eine vollkommen active und sogar anstrengende Muskelleistung handelt, so dass sich bei wiederholter kräftiger Ausführung der Bewegung jene Empfindung sogar bis zu einem gewissen Schmerzgefühle steigern kann, welches sich bei mir sehr deutlich in der Gegend der Externi localisirt.

Das Vorhandensein einer besonderen Divergenz-, ebenso wie Convergenzinnervation ist denn auch schon seit Jahren, hauptsächlich von französischen Autoren, behauptet. Gehen doch Einzelne so weit, das concomitirende Schielen aus einer ungenügenden Function der einen oder anderen dieser Innervationen zu erklären. Ebenso werden klinische Beispiele für das Vorkommen einer reinen Divergenz-, sowie Convergenzlähmung angeführt. Für die erstere ist besonders Parinaud eingetreten, und werden von Straub ${ }^{1}$ ), Uhthoff ${ }^{2}$ ) u. A. Fälle beschrieben, welche das bei Lähmung des hypothetischen Divergenzcentrums zu erwartende Symptomenbild zeigen. Das Vorhandensein eines besonderen Convergenzcentrums, sowie das Vorkommen einer isolirten Lähmung desselben wird weniger bestritten und eine solche u. A. auch von Graefe angenommen. Er glaubt, dass bei der sogenannten Insufficienz der Interni zu unterscheiden ist zwischen den Fällen, wo eine Schwäche der Innervation und soleben, wo eine wirkliche Schwäche der Muskeln vorliegt. Parinaud fand die Convergenzlähmung stets mit Lähmung der Accommodation und mit Fehlen der Pupillarreaction auf Convergenzanstrengungen verbunden. Schweigger ${ }^{3}$ ), welcher schon 1881 das Krankheitsbild beschrieben hat, erwähnt diese Complicationen nicht, wogegen Andere das von Parinaud geschilderte Symptomenbild gleichfalls fanden, Andere wiederum mehrfache Abweichungen feststellten. Eine solche Lähmung ist beobachtet bei den verschiedensten Affectionen des Central-

1) Centralbl. f. prakt. Augenheilkunde 1897 S. 8.

2) Berl. klin. Wochenschr. 1893 S. 370.

3) Klinische Untersuchungen über das Schielen. 
nervensystems, wie multiple Sklerose, Erkrankungen der Brücke der Vierbügel u. s. w., aber auch als selbstständiges Symptom.

Diese Beobachtungen bilden also eine Parallele zu den Lähmungen der associirten Bewegungen auf beiden Augen, welche am häufigsten in Bezug auf die seitlichen Bewegungen, aber auch hinsichtlich der Höhenablenkungen beobachtet sind, sowohl für sich allein, wie mit Störung der accommodativen Excursionen. So beschreibt v. Schroeder $\mathbf{r}^{1}$ ) einen Fall von Lähmung der associirten Bewegung nach unten, nebst Spasmus der Bewegung nach oben, sowie einen solchen von Lähmung der associirten Bewegung nach oben und unten mit gleichzeitiger Lähmung der Divergenz. Weitere Beispiele finden sich bei Graefe (l. c. S. 60 ff.). Darunter auch solche von Lähmung der associirten Thätigkeit der Interni bei Fortbestehen ihrer accommodativen.

Dass für die Augenbewegungen gemeinschaftliche Centren vorhanden sind, von denen eine gleichmässige Innervation ausgeht, ist bei der grossen Uebereinstimmung, mit welcher dieselben ausgeführt werden, gar nicht anders denkbar. Wir wissen, dass von jeder Ausgangsstellung die Erhebung und Senkung der Blicklinien vollkommen gleichmässig erfolgt, dass wir es gar nicht fertig bringen, dieses gesetzmässige Zusammenwirken durch den Einfluss des Willens zu verïndern, dass selbst unter der deckenden Hand oder bei Erblindung eines Auges, ja beim absolut blind Geborenen (Donders) und ebenso im Schlafe die beiderseitige Stellung immer die gleiche ist. Selbst in dem Falle, wo nur ein Auge sich bewegt und das andere stillsteht, nämlich dann, wenn ein fixirtes Object sich auf der Blicklinie des einen Auges bewegt, findet, wie besonders Hering bewiesen hat, auch eine beiderseitige Innervation statt, und wird der Stillstand des einen Auges nur dadurch herbeigeführt, dass die Innervationsimpulse zur Convergenz und zur Seitenwendung sich gegenseitig aufheben. Wenn hierüber Meinungsverschiedenheiten kaum vorhanden sind, so ist eben nur für die Frage noch keine Uebereinstimmung erzielt, ob auch die Divergenz durch active Innervation vor sich geht. Den oben angeführten klinischen Beobachtungen von Divergenzlähmung wird von anderer Seite die Möglichleit entgegengehalten, dass es sich um Convergenzkrampf könne gehanłelt haben. Nichtsdestoweniger lässt sich die Wahrscheinlichkeit einer

1) Petersb. med. Wochenschr. 1893 S. 208. 
gleichmässigen Divergenzinnervation meines Erachtens nicht in Abrede stellen, und dürfte die Annahme eines Divergenzcentrums nicht zu umgehen sein. Sobald die Nothwendigkeit zur Ausführung einer Divergenzbewegung sich einstellt, geht dieselbe auch ohne Schwierigkeit vor sich und müssten demnach die erforderlichen Einrichtungen dazu vorhanden sein.

Die Existenz solcher Centren würde aber vollends unzweifelhaft sein, wenn der Beweis zu erbringen wäre, dass die von ihnen abhängigen Functionen sich selbstständig verändern können, und dass sie dem erregenden bezw. lähmenden Einflusse verschiedener Mittel zugänglich sind. Finden wir z. B., dass die Fähigkeit zur Divergenz vermindert werden kann, ohne dass die Fähigkeit zur Convergenz oder überhaupt die Energie der Interni sich steigert bezw. die der Externi abnimmt, so ist wohl keine andere Erklärung denkbar, als dass eine die Divergenz auslösende Innervation für sich allein geschwächt ist. Wenn umgekehrt die Fähigkeit zur Divergenz gesteigert wird, so kann man doch auch nicht bei den Interni eine vermehrte Neigung zur Erschlaffung annehmen, sondern nur die Erregung eines Divergenzcentrums, namentlich wenn hinsichtlich der Convergenz selbst sich gar keine Veränderungen zeigen. Handelte es sich nur um den passiven Vorgang der Erschlaffung, so wäre zu erwarten, dass derselbe sich auch in anderweitigen Veränderungen der Leistungsfähigkeit der Interni zu erkennen gäbe, während bei zwei unabhängig von einander wirkenden Centren die höhere Leistungsfähigkeit des einen nicht ohne Weiteres eine Abschwächung des anderen bedingt. Für die Klarstellung dieser Verhältnisse waren wir bisher auf zufällige klinische Beobachtungen angewiesen, welche, wie wir oben sahen, nicht immer ein deutliches Bild geben. Unsere Methode gibt uns dagegen die Möglichkeit einer experimentellen Erforschung der Frage, indem sie gestattet, die einzelnen Leistungen zu trennen und Schwankungen derselben nach Zeit und Art ihres Auftretens zu studiren.

Von einer gegenseitigen Unabhängigkeit der verschiedenen Functionen des Bewegungsapparates der Augen finden sich in den obigen Versuchen mehrfache Beispiele. Die Convergenz- und Divergenzfähigkeit können sich ganz verschieden verhalten und sind ausserdem bis zu einem gewissen Grade unabhängig von der Leistungsfähigkeit der einzelnen Muskeln. Letztere können z. B. in ihrer Energie ganz unverändert sein, und trotzdem die Fusionsfähigkeit ganz erheblich 
erschwert. Einige Beispiele dieser Art sollen hier noeh kurz besprochen werden.

Alk ohol. Bei Nr. III zeigt sich die Divergenzfähigkeit deutlich vermindert, im Gegensatze zu der sehr geringen Beeinflussung der Externi, bei gleichzeitiger Schwächung der Interni. Erstere bleibt auch noch in demselben Grade gestört, zu einer Zeit, wo alles Uebrige wieder die normalen Werthe zeigt. Bei Nr. IV wurde in kürzeren Zwischenräumen untersucht, um die Entwicklung der einzelnen Störungen zu beobachten. Hierbei zeigte sich, dass das allererste Symptom einer Einwirkung die Verminderung der Divergenzfähigkeit war. Dieselbe trat schon nach 10 Minuten auf, zu einer Zeit, wo alle übrigen Functionen noch ihre normalen Werthe zeigten. Erst nach weiteren 10 Minuten fand sich die Muskelleistung beeinträchtigt; jetzt begann auch der Nahepunkt abzurücken, unter fortwäbrender Abnahme der Divergenzfähigkeit. Auch bei dem allmäligen Ausgleiche blieb die Fusionsfähigkeit auffallend lange beeinträchtigt. Ebenso ist in Versuch $V$ die Fusion schon ganz erheblich geschwächt, während Stichproben an den einzelnen Muskeln immer noch normale Werthe geben. Fs dauert fast 15 Minuten länger, bis die erste $A b-$ nahme der Contractionsenergie der einzelnen Muskeln sich zeigt und zwar zunächst nur an den inneren, welche überhaupt auch in den anderen Versuchen fast immer am meisten beeinträchtigt sind. Bei dem Ausgleiche ist es wieder die Divergenz, welche die meiste Zeit braucht, um die Störung zu überwinden. Diese Einwirkung auf die Fusionsfähigkeit fällt um so mehr in's Gewicht, wenn wir berücksichtigen, dass die Abschwächung der Muskeln an sich eine sehr geringe ist, indem sich dieselbe nur mit Hülfe der Schnelligkeitsmessung überhaupt nachweisen lässt, während sonst bei Prüfung mit den üblichen diagnostischen Mitteln die associirten Bewegungen keine Unregelmässigkeiten zeigen. 'Es kann nicht befremden, dass der Ablauf der Erscheinungen nicht jedes Mal in genau derselben Weise sich vollzieht. Verschiedenheiten sind unvermeidlich, sowohl durch das genossene Quantum selbst, wie auch den Zustand des Magens, die nicht immer gleiche Widerstandsfähigkeit der betheiligten Nervencentren u. s. w. Die Divergenzfähigkeit ist aber in allen Versuchen zuerst und am meisten benachtheiligt, und ich muss daher annehmen, dass die diese Leistung vermittelnden Centralorgane, wenigstens bei mir, in hervorragendem Maasse durch den Alkohol geschädigt werden, während andererseits die Energie der Seitenwendung am meisten bei 
den Interni leidet. Dass es sich hier nur um centrale Wirkungen handeln kann, beweist eben die Unabhängigkeit der Fusion von der sonstigen Muskelthätigkeit.

Morphium. Ein ganz anderes Verhalten zeigt dieses Medicament. Hier fincien wir als erstes Symptom eine ganz auffallende Steigerung der Divergenzfähigkeit, wie ich sie niemals wieder bei irgend einem anderen Mittel constatiren konnte. Selbst die kleinste Dosis, mit welcher ich per os Versuche gemacht habe $(0,01 \mathrm{~g})$ und welche, wohl wegen der langsamen Resorption, alles Uebrige unverändert liess, zeigte eine geringe Erleichterung der Fusionsfähigkeit, welche mir damals so auffällig war, dass ich sie Beobachtungsfehlern zuzuschreiben geneigt war, bis die stärkere Wirkung der subcutanen Einspritzungen mich darüber belehrte, dass durchaus keine Täuschung vorlag. Diesen Erfolg einer subcutanen Einspritzung erläutert z. B. Versuch II. 10 Minuten nach der Einspritzung steigt die Divergenzfähigkeit zugleich mit einer beginnenden Myose zu einem Werthe, den ich in der Norm niemals erreichen kann, wäbrend die Geschwindigkeitsmessung nur geringe Schwankungen aufweist. Bei keinem Versuche trat jemals eine schwächende Wirkung des Morphiums auf die Fähigkeit zur Ueberwindung von Abductionsprismen hervor, während eine solche in Bezug auf die übrigen Functionen sebr deutlich war. Es kann dies natürlich nur Geltung haben für die angewandten Gaben, und zweifele ich nicht daran, dass bei stärkeren Dosen das Morphium die in Frage kommenden Hirntheile seinem lähmenden Einflusse ebenso gut unterwerfen würde, wie die übrigen. Convergenz, sowie die Energie der Seitenbewegung sind aber immer deutlich geschwächt, die Pupillen verengt, die Wirkung auf das Allgemeinbefinden macht sich in höchst unangenehmer Weise bemerklich, nur die Divergenzfähigkeit ergibt fortwährend auffallend hohe Werthe. Auch im Versuch III ist diese Steigerung der Divergenzfähigkeit neben Pupillenenge das erste Symptom, dieselbe wird vorübergehend sogar bis zu $16^{\circ}$ erhöht, während ich in der Norm nie mehr als $12^{\circ}$ (ausnahmsweise) erreiche. Selbst am nächsten Morgen war die Ueberwindung von Abductionsprismen noch erleichtert. Am längsten dauerte in allen Fällen die Wirkung auf die Pupille, welche stets, auch am folgenden Tage, noch längere Zeit nachweisbar war. Bei den in kürzeren Zwischenpausen angestellten Proben des Versuches IV konnte die erste Entwicklung der Divergenzveränderung 8 Minuten nach der Injection festgestellt werden, kurz 
darauf der Beginn der Pupillenenge, alsdann weitere Steigerung der Divergenzfähigkeit, unter deutlicher Abschwächung der Contractionsenergie. Der Fusionsnahepunkt zeigt sich in diesem wie in den früheren Versuchen kaum verändert. Wir sehen also unter dem Finflusse des Morphiums eine ausgesprochene Mischung von erregenden und lähmenden Wirkungen, welche im Uebrigen unseren Erfahrungen über dieses Mittel vollständig entspricht. Das Gebiet, auf dem die einzelnen Erscheinungen sich abspielen, ist ein ziemlich weitläufiges, indem nicht nur der Oculomotoriuskern, sondern auch Theile der Hirnrinde als Bewegungscentren für die Augen anzusehen sind. Namentlich ist dies für die Einstellungsbewegungen nachgewiesen (siehe unten), und da, wie die Einwirkung auf die Psyche beweist, auch andere Theile der Hirnrinde durch Morphium in Erregung versetzt werden können, so liegt dis gesteigerte Fusionsfähigkeit unserem Verständnisse nicht so fern.

Chloralhydrat. Hier wieder ein ganz anderes Bild, nämlich eine Wirkung auf die Fusion überhaupt nicht nachweisbar, bei Dosen $(1 \mathrm{~g})$, welche eine erhebliche Minderung der Contractionsenergie, und zwar besonders an den Interni, herbeiführen. Höchstens dass der Fusionsnahepunkt vorübergehend etwas abrückt, der Fernpunkt bleibt gänzlich unverändert. Bei stärkeren Gaben leisten aber auch die Fusionscentren der Chloralwirkung keinen Widerstand mehr, sondern zeigen sich deutlich geschwächt, und zwar sowohl in Bezug auf Convergenz wie Divergenz. Die Unabhängigkeit der associirten und accommodativen Muskelleistungen von einander tritt nicht bei allen Versuchen gleich deutlich hervor, ist aber z. B. bei Versuch III bezüglich des Divergenzcentrums unverkennbar, indem eine Schwächung der Externi sich erst eine Stunde später zeigt.

Paraldehyd. Der gesammte Bewegungsapparat des Auges wird von diesem Mittel kaum beeinflusst, trotz dentlicher Hypnose. Aber gerade diese negative Beobachtung beweist den specifischen Einfluss einzelner Mittel auf bestimmte Hirntheile und ihre Wirkungslosigkeit auf andere.

Sulfonal und Trional zeigen beide im Wesentlichen dieselbe Wirkung, nämlich eine deutliche Abschwächung der Energie der Innenwendung, welche aber nicht so erheblich war, dass sie sich durch andere Untersuchungsmethoden hätte erkennen lassen. Die Divergenzfähigkeit wurde beschränkt ohne wesentliche Beeinflussung der associirten Aussenwendung. 
Cocain hatte nur einen Einfluss auf die Pupille, liess aber den Bewegungsapparat, trotz Anwendung der Maximaldosis, unverändert.

Die Inhalationsoifte A ether und Chlor of orm zeigen, auch wenn sie nicht bis zur Betäubung angewendet werden, eine schnell vorübergehende, aber sehr deutliche Wirkung auf den Bewegungsapparat, bestebend in Abschwächung der Fusion, und zwar sowohl für Convergenz wie Divergenz. Sowohl die Innen- wie Aussenwendung sind erheblich verlangsamt. Dazu treten vollständig ataktische Bewegungen auf. Am stärksten ist die Wirkung beim Chloroform und zeigt sich hier schon nach wenigen Athenzügen, während für den Aether immer eine mehrere Minuten lang dauernde Einathmung erforderlich war. Die Wirkung ging so rasch vorüber, dass schon bei schneller Wiederholung der Einstellungen die Werthe stetig wuchsen und auch bald wieder die Norm erreicht hatten. In Folge dessen konnten die einzelnen Functionen auch nur für sich gepruft werden unmittelbar nach der Inhalation.

Als wichtigstes Ergebniss aller positiv ausgefallenen Beobachtungen findet sich also eine vollständige Unabhängigkeit der associirten und der accommodativen Bewegungen, welche sich darin äussert, dass die dieselben vermittelnden Bewegungsapparate in sehr verschiedenem Maasse der Einwirkung von Giften zugänglich sind. Dass diese Wirkungen theilweise nur centrale sein können, dürfte keinem Zweifel unterliegen, da bei einer Abschwächung der peripheren Apparate allein die Folgen immer dieselben sein müssten. Es wäre ja allerdings denkbar, dass die Feststellung der Fusionsfähigkeit kein so feines Reagens ist für die Energie der Muskeln, wie die Schnelligkeitsmessung, und könnte somit die erstere sich ganz normal zeigen, während die letztere vermindert ist. Wir haben aber auch den umgekehrten Fall, dass die letztere unvermindert war, während die erstere eine Abschwächung erkennen liess. Es erinnert dies an die mangelhafte Fusion, welche als selbstständiges (corticales) Symptom beschrieben ist, z. B. als Ersatz eines Anfalles von Flimmerskotom (Knies).

Abgesehen von den physiologiseben und klinischen Gründen macht schon die vielgestaltige anatomische Gliederung des Oculomotoriuskernes das Vorhandensein solcher besonderen Centren für die einzelnen Functionen des Bewegungsapparates in hohem Maasse wahrscheinlich. Die Literatur über diesen Gegenstand ist bekanntlich eine recht grosse und ebenso die Meinungsverschiedenheiten, die dabei zu 
Tage getreten sind. Jedenfalls sind wir weit entfernt, den einzelnen anatomisch nicht einmal allgemein anerkannten Abschnitten des Oculomotoriuskernes ihre physiologische Aufgabe anweisen zu können. Als Convergenzcentrum wird von einigen Forschern der sogenannte centrale Kern angesehen (Knies, Stuelp), Andere suchen dasselbe an anderen Stellen. Dazu kommt die Betheiligung der Hirnrinde. Der Oculomotoriuskern ist ja nur gleichsam eine Zwisehenstation für die Umschaltung und Leitung des Reizes, welcher ihm von verschiedenen Stellen der Rinde zugehen kann. Dies gilt sowohl für die willkürlichen Bewegungen, wie für die reflectorischen, welche hauptsächlich von der Seh- und Hörsphäre ausgelöst werden. Von besonderem Interesse für das Verständniss dieser reflectorischen Bewegungen sind die Versuche von Munk und Schaefer, nach welchen Reizung der Sehsphäre einer Seite associirte Bewegungen nach der anderen Seite, von gewissen Stellen aus auch Convergenzbewegungen auslöst. Obregia hat diese Beobachtungen bestätigt und dahin ergänzt, dass diese Bewegungen um so ausgiebiger sind, je weiter entfernt die Reizstelle von der Maculagegend der Sehsphäre liegt. Es entspricht dies den natürlichen Vorgängen bei der Einstellung der Augen auf einen im Gesichtsfelde auftauchenden Gegenstand. Je weiter derselbe nach der Peripherie liegt, um so ausgiebiger muss die Einstellungsbewegung sein, und um so geringer, je näher er an der Macula sich befindet. Liegt er in der Blicklinie, trifft also die Stelle des deutlichsten Sehens selbst, so ist überhaupt eine Einstellungsbewegung nicht mehr nöthig. Da wir uns anscheinend in jeder Sehsphäre ein optisches Projectionsfeld für die entgegengesetzte Gesichtsfeldhälfte denken müssen, in welchem die Centralstellen für die einzelnen Lichtreize sich ebenso um die Maculàstelle gruppiren, wie die entsprechenden Punkte auf der Netzhaut, so ist das Ergebniss jener Versuche verständlich, indem jede Erregung einer solchen Centralstelle reflectorisch eine entsprechende Augenbewegung auslösen muss. Denn auch beim natürlichen Gebrauche der Augen erfolgen solche Einstellungsbewegungen unwillkürlich und bedürfen eines bewussten Widerstandes zu ihrer Unterdrückung ${ }^{1}$ ).

In unseren Versuchen erfolgte die Innervation des nucleären Centrums auch zum Theil reflectorisch von der Sehsphäre ans, zum

1) Diese Verhältnisse sind eingehend geschildert bei $\mathrm{Kn}$ ies, Die Beziehungen des Sehorganes und seiner Erkrankungen zu den übrigen Krankheiten des Körpers und seiner Organe. Wiesbaden 1893. 
Theil aber auf anderem Wege, insoweit die Bewegungen keine reflectorischen, sondern bewusste und gewollte waren. Solche Bewegungen sind ja auch nach Zerstörung der Sehsphäre noch möglich und erfolgen somit durch eine directe Innervation der Muskelkerne von anderen Centren aus, welche nach der verbreitetsten Annahme in der von Ferrier näher beschriebenen Stelle des Stirnhirnes zu suchen sind. $\mathrm{Zu}$ den reflectorischen Bewegungen, welche durch Vermittlung der Sehsphäre zu Stande kommen, gehören diejenigen, welche die Fusion bewerkstelligen, da von der Sehsphäre aus die motorischen Impulse für diejenigen Bewegungen ihren Ausgang nehmen, welche erforderlich sind, um störende Doppelbilder zu beseitigen und die Lichtreize auf correspondirende Stellen der beiden Netzhäute zu bringen. Die besondere Einwirkung einzelner Mittel (Alkobol) auf die Hirnrinde würde daun auch erklären, dảss die Fusion durch dieselben nachhaltiger beeinflusst wird, als die gröberen Muskelleistungen. Es kommen für die verschiedenen Functionen räumlich weit getrennte Hirntheile in Betracht, und dass ein Medicament auf einzelne Theile des Centralorganes intensiver wirkt als auf andere, ist eine ganz alltägliche Erfahrung. Was die Betheiligung der Kerne betrifft, so ist der des Abducens offenbar widerstandsfähiger als der des Oculomotorius, indem wir überall eine weit stärker und auch viel früher auftretende Wirkung an den r. interni fanden. Eine Ausnahme macht vielleicht der Alkohol, von dem auch die Externi leblafter beeinflusst wurden, was übrigens in den Abducenslähmungen des chronischen Alkoholismus (siehe oben) eine Bestätigung finden könnte, wenn es sich hier picht, zum Theil wenigstens, un neuritische Veränderungen handelte. Inwieweit die Muskeln selbst betheiligt sind, bleibe dahingestellt, doch deuten die obigen Erscheinungen vorwiegend auf centrale Einflüsse.

In Anbetracht, dass es sich hier fast durchgehends um Schlaf erzeugende Mittel handelt, wird man erinnert an die Ansicht von Mauthner, dass der Oculomotoriuskern auch beim natürichen Schlafe in hervorragendem Maasse beeinflusst sei. Eines der ersten Zeichen, durch welche eine beginnende Schläfrigkeit sich ankündigt, ist bekanntlich das Herabsinken des oberen Augenlides, welches Mauthner als den Ausdruck einer beginnenden Oculomotoriuslähmung auffasst. Von anderer Seite ist aber schon längst dagegen geltend gemacht, dass die im Schlafe auftretende Pupillenenge mehr für eine Lähmung des Sympathicus spricht, welche ja auch die Ptosis 
erklären würde. Eigentümliche Störungen im Gebiete der Augenmuskeln unter dem Kinflusse des Schlafes schildert v. Helmholtz ${ }^{1}$, aus welchen er schliesst, dass die Verbindung, welche zwischen den Bewegungen beider Augen besteht, nicht durch einen anatomischen Mechanismus erzwungen sein kann. Er fand nämlich, dass uncoordinirte Bewegungen auftreten, sobald die Augendrehungen in Folge eintretender Schläfrigkeit dem Einflusse des Willens nicht mehr gehorchen. Was er bei sich selbst in dieser Hinsicht feststellte, beschreibt er folgendermaassen: „Ich beobachtete ... regelmässig, dass, wenn ich Abends beim Lesen schläfrig werde oder nach einem langen Diner aus Rücksicht auf die Gesellschaft meine Augen offen zu halten strebe, ich Doppelbilder der vor mir liegenden Objecte sehe, welche bald nur zu grosse Divergenz, bald verschiedene Höhe, bald abnorme Raddrehungen der Augen anzeigen. Sowie ich durch dergleichen ungewöhnliche Doppelbilder aufmerksam gemacht, mich ermuntere, gehen die Doppelbilder meist schnell wieder zusammen und wenn ich sie dann willkürlich aus einander zu treiben suche, kommen nur die gewöhnlichen, neben einander stehenden Doppelbilder zu Stande, die von zu grosser oder zu geringer Convergenz für das Object herrühren." Es dürfte schwer zu entscheiden sein, ob es sich hier um beginnende Lähmungen oder um Krämpfe handelte, wie sie unter dem Einflusse des Schlafes ja auch an anderen Muskeln auftreten (Gähnen). Jch selbst bemerke, wenn ich gegen Schläfrigkeit ankämpfe, immer gleichnamige Doppelbilder, also eine Convergenzstellung, doch ist es nicht leicht, aus solchen Beobachtungen irgend welche sicheren Schlüsse zu ziehen auf die Art der Störung, welche vorliegt. Der Grund liegt in der Natur der Sache. Im Zustande der Schläfrigkeit, welcher solche Doppelbilder auftreten lässt, wird eine zuverlässige Beobachtung kaum möglich sein. Sowie man aber aufmerksam wird und die Erscheinungen zu analysiren sucht, so ist eine gewisse Ermunterung und Ueberwindung der Schläfrigkeit die Folge und die Doppelbilder kommen nothwendiger Weise zum Verschwinden, wie es Helmholtz schildert.

1) Physiol. Opt. 2. Aufl. S. 633 . 